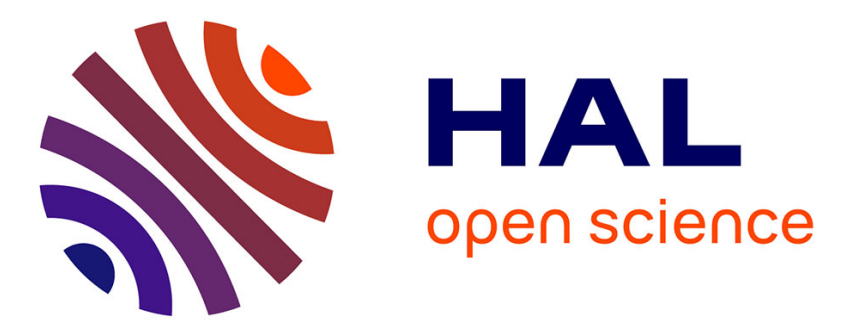

\title{
L'enseignement de la linguistique et de la philologie en France au XIXe siècle d'après les affiches de cours des facultés de lettres (1845-1897)
}

Gabriel Bergounioux

\section{- To cite this version:}

Gabriel Bergounioux. L'enseignement de la linguistique et de la philologie en France au XIXe siècle d'après les affiches de cours des facultés de lettres (1845-1897). Archives et documents de la société d'histoire et d'épistémologie des sciences du langage, 1990, 2 (1), pp.1-105. 10.3406/hel.1990.3356 . hal-01824156

\section{HAL Id: hal-01824156 \\ https://hal-univ-orleans.archives-ouvertes.fr/hal-01824156}

Submitted on 26 Jun 2018

HAL is a multi-disciplinary open access archive for the deposit and dissemination of scientific research documents, whether they are published or not. The documents may come from teaching and research institutions in France or abroad, or from public or private research centers.
L'archive ouverte pluridisciplinaire HAL, est destinée au dépôt et à la diffusion de documents scientifiques de niveau recherche, publiés ou non, émanant des établissements d'enseignement et de recherche français ou étrangers, des laboratoires publics ou privés.

\section{(1) (1) $\$$}

Distributed under a Creative Commons Attribution - NonCommercial - NoDerivatives| 4.0 


\section{L'enseignement de la linguistique et de la philologie en France au} XIXe siècle d'après les affiches de cours des facultés de lettres (1845-1897)

\section{Gabriel Bergounioux}

\section{Citer ce document / Cite this document :}

Bergounioux Gabriel. L'enseignement de la linguistique et de la philologie en France au XIXe siècle d'après les affiches de cours des facultés de lettres (1845-1897). In: Archives et documents de la Société d'histoire et d'épistémologie des sciences du langage, Seconde série, $n^{\circ} 2,1990$. pp. 1-105;

doi : https://doi.org/10.3406/hel.1990.3356

https://www.persee.fr/doc/hel_0247-8897_1990_num_2_1_3356

Fichier pdf généré le 09/05/2018 


\section{Gabriel BERGOUNIOUX}

\section{L'ENSEIGNEMENT DE LA LINGUISTIQUE ET DE LA PHILOLOGIE EN FRANCE AU XIXe SIECLE}

d'après les affiches de cours des facultés de lettres

$$
\text { (1845-1897) }
$$

- Juin 1990 - 


\section{SOMMAIRE}

INTRODUCTION. 5

Enseignants et enseignements $\quad 7$

Présentation du travail 11

Tableau des réponses $\quad 13$

Notations 15

Bibliographie 16

Extrait de Dauzat : La défense de la langue française $\quad 18$

UNIVERSITE DE PARIS $\quad 19$

Enseignements de littérature française

et de grammaire comparée :

Tableau $\quad 20$

Notes $\quad 21$

Enseignements de latin et de grec :

Tableau $\quad 26$

$\begin{array}{ll}\text { Notes } & 27\end{array}$

Enseignements de sanscrit et langues vivantes :

Tableau $\quad 32$

Notes 33

UNIVERSITES DE PROVINCE

AIX-EN-PROVENCE
Tableau

$\begin{array}{ll}\text { Notes } & 39\end{array}$

BESANCON

Tableau $\quad 44$

Notes $\quad 45$

BORDEAUX
Tableau

$\begin{array}{ll}\text { Tableau } & 46 \\ \text { Notes } & 47\end{array}$

CAEN

Tableau $\quad 50$

Notes 51

CLERMONT-FERRAND

Tableau $\quad 52$

Notes $\quad 53$

DIJON

Tableau $\quad 54$

Notes $\quad 55$ 


\section{GRENOBLE}

Tableau

Notes

LILLE (et DOUAI)

Tableau

Notes

LYON

Tableau

64

Notes

65

MONTPELLIER

Tableau

68

Notes

69

NANCY

Tableau

72

Notes

73

POITIERS

Tableau

78

Notes

\section{RENNES}

Tableau

Notes

STRASBOURG

Tableau et notes

TOULOUSE

Tableau

Notes

87

INDEX 


\title{
INTRODUCTION
}

\author{
ENSEIGNANTS ET ENSEIGNEMENTS \\ Facultés et universités \\ Les facultés de lettres \\ Les postes \\ PRESENTATION DU TRAVAIL \\ NOTATIONS \\ BIBLIOGRAPHIE
}




\section{ENSEIGNANTS ET ENSEIGNEMENTS}

Le champ universitaire français, au XIX ${ }^{e}$ siècle, a bénéficié d'un surcroît d'attention récent qui nous en donne une connaissance approfondie ( l'enquête de Victor Karady y aura contribué de manière décisive). Nous nous contenterons donc, dans cette introduction, de rappeler quelques points de détail afin de prévenir les lectures anachroniques tout en situant la logique particulière d'une institution dans la production de ce dont nous avons fait notre objet : les affiches de cours.

Tout d'abord, il faut souligncr lc caractère nominalcment trompcur des nomenclatures administratives et de bien des intitulés qui dissimulent, pour le chercheur d'aujourd'hui, la spécificité historique des représentations des agents : le caractère peu formalisé des études qui rend aléatoire l'identification imaginaire d'une population étudiante (et tout autant l'assurance d'un public); la rareté des postes qui est au principe de tous les calculs stratégiques; la constitution des jurys de thèse par l'ensemble des professeurs ${ }^{1}$; trois exemples hétérogènes mais qui permettent de mesurer l'ampleur de différences qui passeraient inaperçues du fait de l'identité des noms si le travail de l'historien et du sociologue ne veillait à rappeler constamment leur existence et comment ce fut vécu². Aussi familière que puisse sembler aujourd'hui cette université, elle l'est beaucoup du fait d'une lecture prématurée.

\section{FACULTES ET UNIVERSITES}

Durant tout le $\mathrm{XIX}^{\mathbf{e}}$ siècle, et depuis Napoléon $\mathrm{I}^{\mathrm{er}}$ pour la définition postrévolutionnaire, la faculté désigne donc un corps professoral ${ }^{3}$, c'est-à-dire un groupe très restreint de professeurs chargé de délivrer des grades (baccalauréat, licence et doctorat) et de faire un cours public. Elle n'est liée ni à un lieu, ni à un public étudiant ( les examens peuvent n'avoir qu'un rapport très lointain avec le cours public ), ni -et surtout pas- à un travail de recherche.

Les droits d'examen représentant une part essentielle des revenus de l'enseignement supérieur, la faculté vit en bonne partie par et pour cette fonction. Autour des années 1880 , le mouvement "réformiste" de l'enseignement supérieur,en cristallisant les mécontentements autour d'une redéfinition en "Université" bouleverse la représentation

1. Une thèse se soutient devant la faculté, c'est-à-dire devant un collège de professeurs de lettres, comprenant, quelle que soit la thèse, un historien, un philosophe, etc.

2. C'est-à-dire, au même titre que la lecture anachronique que nous en faisons, sur le mode de l'évidence, du moins, entre deux crises de l'université. 
reçue des facultés et la réforme de 1896 accomplira ce que le mouvement social, et particulièrement la transformation du corps enseignant, avait engagé de redéfinition des contenus et des fonctions.

Restent constants dans la définition des facultés (puis des universités) les traits suivants :

- la spécificité post-baccalauréat du recrutement (par opposition aux lycées, à l'exception des classes préparatoires);

- le monopole de collation des grades qui les distingue aussi bien des grandes écoles, qui ne délivrent que des titres particuliers, que des facultés catholiques ou protestantes;

- la reconnaissance institutionnelle qui les départage d'établissements au statut précaire comme 1"“Ecole préparatoire des Sciences et des Lettres" de Rouen ou de l"'Ecole Supérieure" d'Alger.

\section{LES FACULTES DES LETTRES}

Si l'on se réfere au répertoire de l'AUPELF', ou à Minerva ${ }^{5}$ dont les indications se recouvrent presque totalement, il existerait 14 facultés des lettres en 1809, à savoir Aix, Besançon, Bordeaux, Clermont-Ferrand, Dijon, Douai, Grenoble, Montpellier, Orléans, Paris, Rennes, Rouen, Strasbourg et Toulouse. Leur nombre est ramene à 10 en 1816 (fermeture de Clermont-Ferrand, Grenoble, Montpellier et Rouen), à 9 en 1826 (suppression de Douai) avant une croissance continue jusqu'à aujourd'hui en dépit de la fermeture d'Orléans (en 1848) et de la perte de Strasbourg qui devient une université allemande à partir de 1872. Ainsi sont ouvertes (ou réouvertes) les facultés de :

- Lyon et Montpellier (1838);

- Caen et Poitiers (1845);

- Grenoble (1847);

- Clermont-Ferrand, Douai et Nancy (1854).

Les seize facultés de lettres de 1854 seront réduites à 15 en 1871 et il n'y aura aucune création nouvelle jusqu'à l'entre-deux-guerres. Une seule modification à signaler : le transfert de la faculté du Nord de Douai à Lille en 1887. Rappelons que jusqu'au Second Empire, les créations répondent le plus souvent à une demande de capitale régionale, relayée par la pression de notables locaux. Les trois facultés créés par Fortoul en 1854 relevaient en outre d'une intcntion affichée d'accroître la collecte financière tout en favorisant des enseignements d'avenir comme la linguistique comparée à Nancy.

4. Répertoire international des Universités partiellement ou entièrement de langue française, publié par l'AUPELF (1976).

5. Minerva, "Jahrbuch der Gelehrten Welt : Abteilung Universitäten und Fachhochschulen", Tome I : Europe, W. Schuder (ed), Walter de Gruyter \& Co, Berlin (1966). 


\section{LES POSTES}

Une faculté de lettres comprend quatre chaires :

- "littérature française";

- "littérature ancienne";

- "histoire";

- "philosophie" (ou "littérature étrangère").

D'autres peuvent y être adjointes, par partition, en fonction de la croissance des effectifs : ainsi, les chaires de littérature ancienne sont peu à peu divisées en une chaire de "langue et littérature grecques" et une de "langue et littérature latines".

Le titulaire d'une chaire est un professeur, ayant le grade de docteur ès-lettres. Une fois élu à ce poste et nommé par le ministre de l'Instruction Publique, il y peut rester sa vie durant ${ }^{6}$, il n'y a pas de limite d'âge. Les obligations de service se limitent à un cours public et à l'organisation des examens, surtout le baccalauréat.

En général, c'est au professeur le plus ancien qu'échoit le titre de doyen, mais des considérations de personne ou de discipline peuvent contrevenir à cette règle. Un professeur ne souhaitant pas assurer ses cours tout en conservant sa chaire peut, de sa propre autorité, appeler un professeur suppléant qui se chargera de son magistère.

L'un des plus sûrs indices de la transformation de l'enseignement supérieur, et l'un des moyens mis en place pour contoumer l'inertie et la rigidité du système, fut l'institution de maîtres de conférences qui, recrutés, à partir de 1877, parmi les docteurs ès-lettres, assurent les enseignements de spécialité, se substituant progressivement aux anciens répétiteurs, professeurs agrégés assurant la préparation aux examens.

Quelques cours, dits "cours libres", peuvent être assurés par des personnes n'ayant aucun de ces deux titres, pour des disciplines non institutionnelles (hébreu, breton...). 


\section{PRESENTATION DU TRAVAIL}

On lira à la suite une présentation des cours de langue et de littérature dans les universités françaises entre 1845 et 1898 . Quelques informations sur d'autres enseignements qui ont pu interférer avec la philologie ou les sciences du langage ont été jointes en note.

La source en est unique (et exhaustivement dépouillée) puisqu'il s'agit de la collection des affiches annonçant les cours des facultés de lettres, classées par ordre chronologique, et conservées aux Archives Nationale à Paris. Elles sont recensées sous les cotes :

F 1713126 : Paris, Aix, Besançon;

F 1713127 : Bordeaux, Caen, Clermont et Dijon;

F 1713128 : Grenoble, Lille-Douai, Lyon et Montpellier;

F 1713129 : Nancy, Poitiers, Rennes, Toulouse, Strasbourg.

Chacun de ces numéros ${ }^{7}$ correspond à un peu maniable et poussiéreux carton d'affiches (annuelles ou semestrielles) pliées en huit. Ces affiches avaient pour fonction de porter à la connaissance du public -et d'abord des étudiants- l'intitulé, le jour, l'heure et le lieu de chaque cours, quel enseignant l'assurait et sur quel(s) thème(s). Il s'agit donc d'une déclaration publique dont il n'est pas possible de mesurer à quelle pratique effective elle correspondait, sinon par d'autres sources. La collection de ces affiches répondait à un souci de surveillance administrative de chaque université.

La lacune la plus marquante est l'irrégularité de la collecte entre 1845 et 1877 , témoignage, entre autres, de la lâcheté du contrôle ministériel. La conservation s'arrêle brusquement en 1897-1898 comme un indice supplémentaire de l'autonomie pédagogique conquise lors de la réforme universitaire. En revanche, les collections sont complètes de 1877 à 1897, si l'on excepte deux défaillances ( Nancy en 1878-79 et Bordeaux en 1896-97); il est vrai que les services du ministère n'ont parfois conservé qu'une affiche semestrielle par an, sans qu'une explication raisonnée puisse le justifier. Nous avons visualisé sur le tableau 1 les affiches dépouillées et, dans le tableau 2, nous avons figuré par un histogramme le taux de réponse.

7. Rappelons que "F 17" est l'intitulé des séries correspondant à l'enseignement (entre autres) dans la classification des Archives Nationales. 
Tel qu'il est, ce travail demande à être complété par une présentation comparable des autres secteurs de l'enseignement supérieur où furent impliquées les langues (E.N.S., Ecole des Carmes, facultés catholiques et protestantes, école du rabbinat, Collège de France, E.P.H.E. IV ${ }^{e}$ section, Ecole des Chartes, Langues O, Ecole Supérieure d'Alger, etc.). A terme, une approche régionale pourrait seule permettre d'achever ce travail.

Il reste à signaler que la série exploitée aux Archives regroupe toutes les informations (et d'autres encore) qui sont consignées dans les séries :

F 1713137 - F 1713138 : "Tableaux généraux des cours et conférences" (1886 - 1897); F 1713141 - F 1713156 : "Programme imprimé des cours et conférences classés par Académie (1883 - 1898)".

Nous en avons vérifié par sondage les informations : elles concordent. 
Représentation des réponses rapportées ò l'ensemble des universités

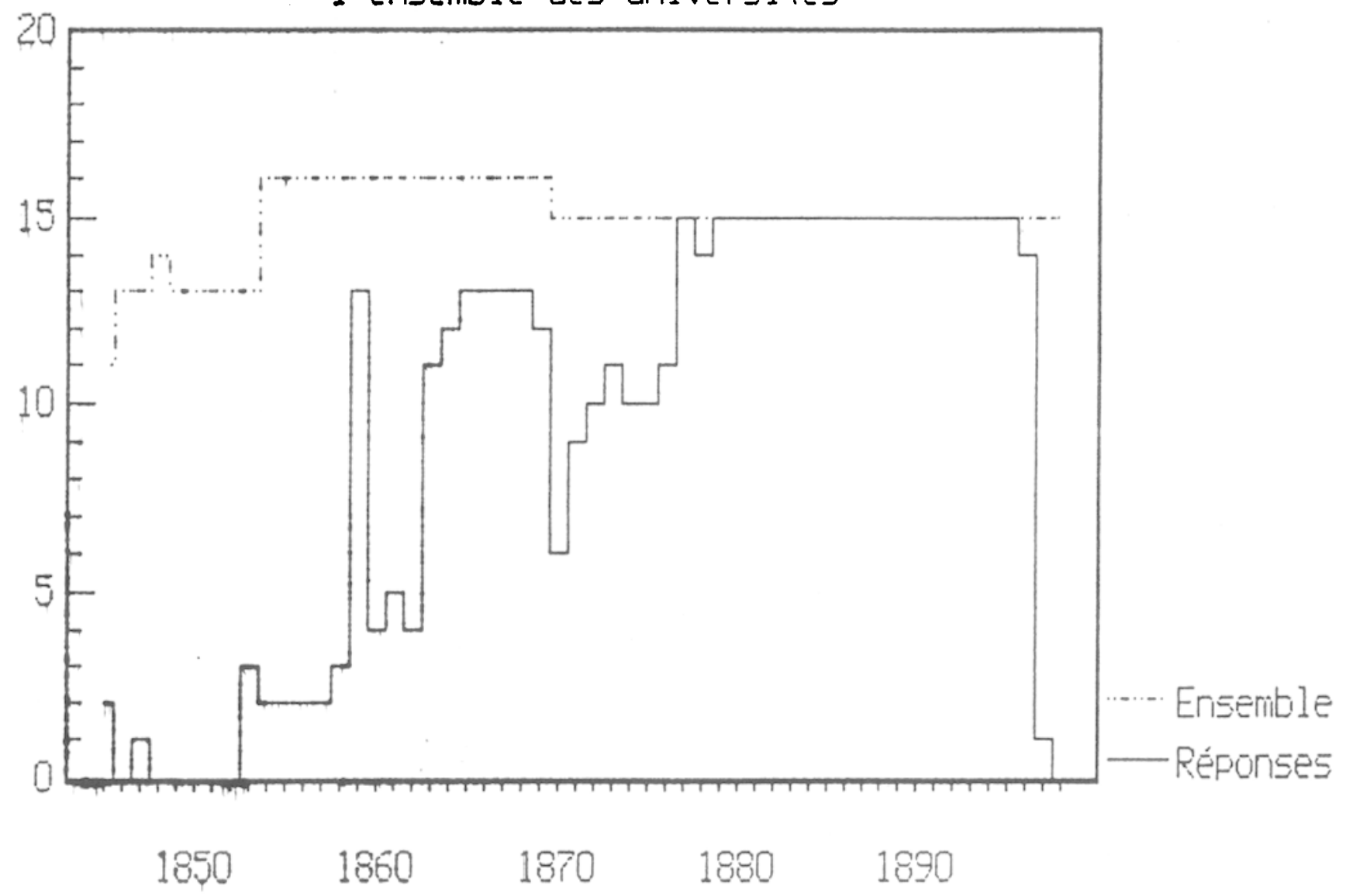


45464748495051525354555657585960616263646566676869707172737475767778798081 (..) 959697 111111111111111111111111111111111111111 $46474849505152535455565758596051626364656667686970717273747576777879808182 \ldots \ldots 969798$

Paris

dix

Besançon

Bordeadx

Caen

Clernont-Pd

Dijon

Grenoble

Lille/Douai

Lyon

Uontpellier

Mancy

Poitiers

Pennes

Torlouse

Strasbourg

FOILL 21

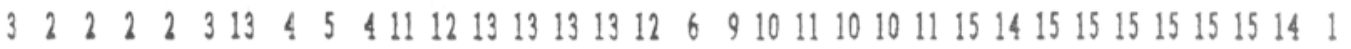

AFTCESS DES COORS PAR DUIVERSITE - REPOISES PAR AMIEE 


\section{NOTATIONS}

\section{TITRES}

AUBERTIN : professeur ou professeur suppléant;

AUBERTIN ; doyen

Aubertin : maitre de conférences ou chargé de cours (ou autre statut)

\section{ANNEES}

$1864-1865$

1865-1866 : années universitaires (octobre à juillet)

1866-1867

1869-1870 : les années 1867-1868 et 1868-1869 ne figurent pas aux Archives

1870-1874 : aucune modification n'est intervenue entre 1870-1871 et $1873 \cdot 1874$. 


\section{BIBLIOGRAPHIE}

BERGOUNIOUX Gabriel : Histoire sociale de la linguistique en France (1789-1914), Thèse de $3^{e}$ cycle dactylographiée, Université Paris-VII, 1981.

BERGOUNIOUX Gabriel : "La science du langage en France de 1870 à 1885 : du marché civil au marché étatique", in Langue Française, nº3, septembre 1984.

CHARLE Christophe : Les professeurs de la faculté des lettres de Paris, "dictionnaire biographique 1809-1908", vol. 1, Paris. INRP/CNRS. 1985.

CHARLE Christophe et FERRE Régine : Le personnel de l'enseignement supérieur en France aux XIX, et XX siècles, Paris, C.N.R.S., 1985.

CHARLE Christophe : Les élites de la République, 1880-1900, Paris, Fayard, 1987.

CHARLE Christophe, NAGLE Jean, PERRICHET Marc, RICHARD Michel, WORONOFF Denis: Prosopographie des élites françaises (XVIo-XX. siècles), "Guide de recherche", CNRS, Paris, 1980 (spécialement les pages 149 à 153).

CHARLE Christophe ; "Le champ universitaire parisien à la fin du XIX" siècle", in Actes de la Recherche en Sciences Sociales, $n^{\circ} 47 / 48$, juin 1983, p. 77-89.

DROUARD Alain et WEISZ George : Processus de changement et mouvements de réforme dans l'enseignement supérieur français, ATP n²5, Paris, CNRS, 1978.

FOX R., WEISZ George (ed) : The Organization of Science and Technology in France, 1808-1914, Cambridge et New-York, Cambridge University Press, 1980.

KARADY Victor : Stratégies de carrière et hićrarchie des études chez les universitaires littéraires sous la III République, Rapport d'enquête, Centre de Sociologie Européenne, 1973.

KARADY Victor : "Recherches sur la morphologie du corps universitaire littéraire sous la III ${ }^{\mathrm{e}}$ République”, in Le mouvement social, 96, juillet-septembre 1976, pp.51 sq.

KARADY Victor : "Les professeurs de la République : le marché scolaire, les réformes universitaires et les transformations de la fonction professorale à la fin du XIX $X^{\mathfrak{e}}$ siècle", in Actes de la Recherche en Sciences Sociales, $n^{\circ}$ 47-48, juin 1983, pp. 90-112. 
PROST Antoine : Histoire de l'enseignement en France, 1800-1967, Paris, Armand Colin, 1967.

WEISZ George : The Academic Elite and the Movement to Reform French Higher Education, Stony Brook, New-York, 1976.

WEISZ George : The Emergence of Modern Universities in France, 1863-1914, Princeton, Princeton University Press et Paris, M.S.H., 1983. 
"Si les professeurs des lycées et collèges n'ont pas toujours suffisamment approfondi la grammaire française, c'est parce qu'on a négligé de la leur apprendre. Dans nos Facultés des lettres, on enseigne les langues latine et grecque, allemande, anglaise, italienne, espagnole... On n'a oublié que le français. Ce n'est pas un paradoxe : dans nos quatorze Universités de province, il y a vingt chaires ou conférences de littérature française, et pas une seule qui soit consacrée exclusivement à l'étude et à l'enseignement de notre langue . Pardon! il y en avait une, à Caen, mais elle a été supprimée en 1910 pour être transformée en chaire d'histoire.

(1) Il y a trois conférences mixtes de langue et littérature françaises (Clermont, Nancy, Poitiers) ; a Besançon, Lyon et Grenoble, on éludie le vieux français et la phonétique expérimentale; les grammaires française et gréco-latine sont amalgamées à Aix ; enfin les professeurs de philologie romane, à Rennes, à Montpellier, peuvent, s'il leur plaît, étudier la langue française, mais ils s'occupent généralement de la littérature médiévale."

\footnotetext{
Albert DAUZAT La défense de la langue française

Première partie : "La crise de la culture française"

Paris, Amand Colin, 1912 pp. 74-75
} 
UNIVERSITE DE PARIS

FRANCAIS ET GRAMMAIRE

LATIN ET GREC

SANSCRIT ET LANGUES VIVANTES 


\section{PARIS}

\section{(Français et Grammaire)}

\begin{tabular}{|c|c|c|c|c|c|c|c|}
\hline & $\begin{array}{l}\text { Eloquence } \\
\text { Franf̧aise }\end{array}$ & $\begin{array}{l}\text { Poésie } \\
\text { Française }\end{array}$ & $\begin{array}{l}\text { Lg \& Litté Fse du } \\
\text { moyen-âge " }\end{array}$ & $\begin{array}{l}\text { Littérature } \\
\text { Française }\end{array}$ & $\begin{array}{l}\text { Philologie } \\
\text { Romane }^{\text {b }}\end{array}$ & $\begin{array}{l}\text { Grammaire } \\
\text { Comparée }^{c}\end{array}$ & $\begin{array}{l}\text { Grammaire et } \\
\text { Philologie }^{\mathrm{d}}\end{array}$ \\
\hline $1853-57$ & NISARD & ST-MARC-G. ${ }^{e}$ & & & & HASE $^{f}$ & \\
\hline $1857-61$ & $\begin{array}{l}\text { NISARD } \\
\text { Demogeot }\end{array}$ & ST-MARC-G. & & & & HASE & \\
\hline $1861-62$ & $\begin{array}{l}\text { NISARD } \\
\text { Gandar } 8\end{array}$ & $\begin{array}{l}\text { ST-MARC-G. } \\
\text { Caboche }\end{array}$ & & & & HASE & \\
\hline $1863-64$ & $\begin{array}{l}\text { NISARD } \\
\text { Gandar }\end{array}$ & $\begin{array}{l}\text { ST-MARC-G. } \\
\text { St-René-T. h }\end{array}$ & & & & HASE & \\
\hline $1864-67^{i}$ & $\begin{array}{l}\text { NISARD } \\
\text { Gandar }\end{array}$ & $\begin{array}{l}\text { ST-MARC-G. } \\
\text { St-René-T. }\end{array}$ & & & & & \\
\hline $1867-68$ & ST-RENE-T. & ST-MARC-G. & & & & & \\
\hline $1868-69$ & ST-RENE-T. & $\begin{array}{l}\text { ST-MARC-G. } \\
\text { Lénient }\end{array}$ & & & & & \\
\hline $1869-73$ & $\begin{array}{l}\text { ST-RENE-T. } \\
\text { Etienne }\end{array}$ & $\begin{array}{l}\text { ST-MARC-G. } \\
\text { Lénient }{ }^{j}\end{array}$ & & & & & \\
\hline $1873-77$ & ST-RENE-T. & LENIENT & & & & & \\
\hline $1877-79$ & $\begin{array}{l}\text { ST-RENE-T. } \\
\text { Crouslé }\end{array}$ & LENIENT & Darmesteter ${ }^{k}$ & & & & \\
\hline $1879-80^{1}$ & $\begin{array}{l}\text { CROUSLE } \\
\text { Marcou }\end{array}$ & LENIENT & Darmesteter & Feugère & & & \\
\hline $1880-82$ & $\begin{array}{l}\text { CROUSLE }^{\mathrm{m}} \\
\text { Marcou }\end{array}$ & LENIENT & Darmesteter & Gazier & & & \\
\hline $1882-83$ & $\begin{array}{l}\text { CROUSLE } \\
\text { Petit de J. }{ }^{n}\end{array}$ & LENIENT & Darmesteter & Gazier & & & \\
\hline $1883-84$ & $\begin{array}{l}\text { CROUSLE } \\
\text { Petit de J. }\end{array}$ & LENIENT & DARMESTETER ॰ & Gazier & & & \\
\hline $1884-87^{\mathrm{P}}$ & $\begin{array}{l}\text { CROUSLE } \\
\text { Petit de J. }\end{array}$ & LENIENT & DARMESTETER & $\begin{array}{l}\text { Gazier } \\
\text { Larroumet }\end{array}$ & & & \\
\hline $1887-88$ & CROUSLE & LENIENT & DARMESTETER & $\begin{array}{l}\text { PETIT DE J. } \\
\text { Gazier }\end{array}$ & & & \\
\hline $1888-89$ & CROUSLE & LENIENT & DARMESTETER & $\begin{array}{l}\text { PETIT DE J. } \\
\text { Dejob }^{r}\end{array}$ & Thomas & & \\
\hline $1889-91$ & CROUSLE & LENIENT & PETIT DE J. १ & $\begin{array}{l}\text { Gazier } \\
\text { Dejob }\end{array}$ & Thomas & & \\
\hline $1891-92$ & CROUSLE & LENIENT & PETIT DE J. & $\begin{array}{l}\text { Gazier } \\
\text { Larroumet }\end{array}$ & Thomas & & \\
\hline $1892-95$ & CROUSLE & LENIENT & PETIT DE J. & Gazier & Thomas & & Brunot ${ }^{t}$ \\
\hline $1895-96$ & CROUSLE & $\begin{array}{l}\text { LENIENT } \\
\text { Faguet }{ }^{*}\end{array}$ & PETIT DE J. & $\begin{array}{l}\text { GAZIER } \\
\text { Dejob }\end{array}$ & Thomas & & Brunot \\
\hline $1896-97$ & CROUSLE & FAGUET & PETIT DE J. & $\begin{array}{l}\text { GAZIER } \\
\text { Dejob }\end{array}$ & Thomas & & Brunot \\
\hline
\end{tabular}

Manque le premier semestre des années 53/54, 55/56, 60/61,71/72, 76/77;

Manque le second semestre des années 56/57, 61/62, 64/65, 67/68, 70/71,78/79, 81/82, 89/90, 90/91, 92/93, 93/94,94/95 95/96. 


\section{NOTES SUR PARIS}

\section{(Français et grammaire )}

a : "Langue et littérature françaises du moyen-âge", maîtrise de conférences. Transformation en chaire en 1883 avec l'intitulé: "Littérature française du moyen-âge et histoire de la langue française".

b : "Philologie romane" (conférence).

c : "Grammaire comparée"; cette chaire disparaît à la mort de Hase.

d : "Grammaire et philologie": cette maîtrise de conférences a été obtenue pour le français en décolorant un poste attribué au latin et au grec précédemment (cf tableau PARIS (latin et grec)).

e : Saint-Marc-Girardin

f : L'affiche de 1853-1854 (deuxième semestre) précise:

"M. Hase, professeur, continuera d'exposer les rapports et les dissemblances entre les deux langues classiques et la langue française aux différentes époques de leur durée, et s'occupera particulièrement de la théorie des formes grammaticales des trois langues et d'autres idiomes, tant anciens que modemes". Cet intitulé reviendra à l'identique jusqu'à la rentrée de 1858 où il devient:

"M. Hase, professeur, tracera le tableau ethnographique des idiomes, tant anciens que modernes, qui ont pu avoir de l'influence sur la formation et le développement des trois langues classiques, grecque, latine et française." De 1859 à 1861, Hase reprend l'intitulé originel qu'il remplace à la rentrée de 1861 par:

"M. Hase, professeur, tracera le tableau ethnographique des idiomes indo-européens, et traitera particulièrement des rapports et des dissemblances entre les deux langues classiques et la langue française aux différentes ćpoques de leur durée." L'année 62/63 manque; en 1863 on retrouve l'intitulé originel au premier semestre et, au second semestre, il y a un blanc. Hase est mort, l'enseignement de la grammaire comparée en Sorbonne a vécu, le nom même de la chaire disparaît.

g : GANDAR est "professeur à la faculté des lettres de Caen, chargé de cours" en remplacement de Demogeot.

h : SAINT-RENE-TAILLANDIER, présentć comme "professeur de littérature française à la faculté des lettres de Montpellier, suppléant". 
i : En 1865, Géruzez qui était, comme Villemain, professeur honoraire, disparaît.

j : En 1870/71 (premier semestre, le second manque) et 1871/72 (second semestre, le premier manque), LENIENT choisit un sujet de circonstance -il en souligne lui-même la pertinence voulue en préambule de son cours- : "M. Lénient, docteur ès-lettres, suppléant, traitera,le samedi, de la poésie patriotique en France, jusqu'à la fin du XVle siècle".

k : A la rentrée de 1877, Arsène DARMESTETER reçoit une maîtrise de conférence en "langue et littérature françaises du moyen-âge" dans laquelle il "exposera les origines de la littérature française jusqu'à la fin du XIe siècle, el commencera l'histoire de la littérature épique" au premier semestre el, au second, "le mercredi, à trois hcures et demie, M. Darmesteter, docteur ès-lettres, continuera l'étude des traditions mérovingiennes dans la littérature épique du moyen-âge. Le samedi, à midi et quart, il exposera les principes de l'étymologie française".

L'année 1878/79, il la consacre à la Chanson de Roland et "il commencera l'histoire de la formation du lexique français" (le second semestre manque),reprenant le même programme jusqu'en 1881/82 avec des modifications dans le cours de lexicologie pour suivre les recherches dont l'aboutissement sera l'introduction du Dictionnaire Général, dit le "Hatzfeld-Darmesteter".

En 79/80:"formation populaire des mots" ct "dérivation populaire des mots"; en 80/81:"la formation des mots composés ct des mots d'origine celtique et germanique" et "le lexique du latin populaire et l'action qu'ont excrcée sur lui les idiomes celtiques et germaniques";

en 81/82: "il continuera l'histoire de la formation du lexique français et étudiera spécialement l'élément grec et l'ćlément germanique dans le latin populaire et dans le français".

1 : En 1879, Fustel de Coulanges devient professcur de l'histoire du moyen-âge après avoir été suppléant,en 1875 sq. dans la chairc d'histoire ancienne.

m : En 1881, "M. Crouslé, professeur (...) expliquera, le mercredi, les auteurs pour la licence et l'agrégation, notamment Montesquicu ct Joinville (Vie de Saint Louis)".

n : PETIT DE JULEVILLE : il explique la Chanson de Roland à partir du second semestre.

0 : Au cours de l'année 82/83, la maîtrise de conférences d'Arsène Darmesteter est transformée en chaire de:"Littérature française du moyen-âge et histoire de la langue française". A partir de cette même annće, "il traitcra de l'histoire de la syntaxe française" et, à partir du second semestre "M. A. Darmesteter, professeur, expliquera, les lundis, à 
neuf heures,les passages de La Chanson de Roland inscrits au programme de l'agrégation de grammaire. Les mercredis, à trois heures et demie, il traitera de l'histoire de la syntaxe française. Il exposera, en outre, la grammaire comparée des langues romanes, les mercredis, à cinq heures (phonétique), et les lundis, à cinq heures (déclinaison et conjugaison)."

En 1883/84, Darmesteter fait "l’histoire de la poésie épique au moyen-âge" et "la grammaire historique de la langue française" en assurant "l'explication des passages de La Chanson de Roland portés aux programmes de la licence ès-lettres et de l'agrégation de grammaire".

En 1885/86, "M. A. Darmesteter, professeur,exposera, le jeudi, l'histoirc de la conjugaison française. Le lundi, il expliquera, à huit heures trois quarts, des textes d'auteurs français du moyen-âge, et dirigera (à dix heures) des exercices pratiques sur diverses questions de l'histoire de la langue ou de l'ancienne littérature (cours fermés)".

En 1886/87, "M. A. Darmesteter fera, les jeudis, I'histoire de la dérivation française; les lundis, il expliquera des textes d'ancien français, et les samedis, dirigera des exercices pratiques sur diverses questions de l'histoire de la langue ou de l'ancienne littérature (cours fermés)". Le même intitulé est repris l'année suivante.

En 1888/89, "M. A.Darmesteter, professeur, expliquera, le lundi (neuf heures), des textes d'ancien français portés au programme de l'agrégation ; à dix heures, il dirigera des travaux sur l'histoire littéraire du moyen-âge et sur l'histoire de la langue; le mercredi, il fera l'histoire des mots invariables en français." Avant de commencer ce programme, Darmesteter disparaît et est remplacé par Petit de Juleville.

p : En 1885, parmi les cours complémentaires créés, on note:"Psychologie expérimentale" pqur Ribot et "Sciences auxiliaires de l'histoire" pour Luchaire.

q : En 1887, Petit de Juleville est présenté comme "professeur adjoint, directeur d'études". Il récupère la chaire d'Arsène Darmesteter en 1888 et figure sur l'affiche des programmes du second semestre (avril-juillet 1889):"M.Petit de Juleville, professeur, traitera, le lundi, des études relatives à la littérature française du moyen-âge;le jeudi, il expliquera les Extraits de Joinville portés au programme de l'agrégation de grammaire."

En 1889/90, il traitera de "la littérature française du XVe siècle" et du Grand Testament de Villon. La même année, Petit de Juleville est nommé "directeur d'études pour les lettres et la philologie".

En 1890/91, il "fera l'histoire de la grammaire française" et se chargera du programme de littérature médiévale de la licence et de l'agrégation.

En 1891/92, c'est l'"Histoire littéraire du XIVe sic̀cle en France, et (il) traitera d'abord de Froissart." 
En 1892/93, c'est l'"histoire de la poésie française au XIVe siècle" et la "Śatire Ménippée".

En 1893/94, "M. Petit de Juicville, professeur, commencera le lundi, l'histoire de la littérature française au moyen-âge et traitcra des origines et des chansons de geste(...)"Cette reprise de l'histoire littéraire à ses commencements est à mettre en relation avec l'édition par Petit de Julcville de sa monumentale Histoire de la langue et de la littérature francaises.

En 1894/95, il est traité de "la vie et l'ocuvre de Charles d'Orléans et de Villon".

En 1895/96, de l'“Histoire des origines de la Renaissance en France durant le moyen-âge".

En 1896/97, ce sont les "recherches récentes, concernant l'histoire du théâtre en France au moyen-âge".

Durant toutes ces années, Petit de Julcville consacre une part de son enseignement aux exercices de licence el d'agrégation (littérature française du moyen-âge).

r : De 1888 à 1891, Larroumet prend un congé cl est remplacé par Dejob.

$\mathrm{s}$ : Antoine THOMAS rę̧oit, au deuxic̀me semestre de 1888/89, un cours complémentaire de "philologie romane": "M. A.Thomas, professeur à la faculté des lettres de Toulouse,étudiera,le samedi, la vie et les ocuvres de Bertrand de Bom (...)", auxquels s'ajoutent les exercices pour l'agrégation.

En 1889/90, “M. A. Thomas, professcur à la faculté des lettres de Toulouse, exposera, le vendredi, à neuf heures, la grammaire comparéc des langues romanes et particulièrement du français et du provençal (première partic: phonétique); le vendredi, à dix heures, il expliquera les plus anciens monuments de la littćrature provençale, et le samedi, les textes d'ancien français inscrits au programme de l'agrégation de grammaire."

En 1890/91, Thomas continue la "grammaire comparée des langues romanes" et les exercices d'agrégation; il fait en outre un cours sur "le dialecte gascon au moyen-âge".

En 1891/92, Thomas étudie L'Enfer de Dante et "l'histoire de la littérature provençale au moyen-âge", avec toujours les exercices d'agrégation.

En 1892/93, en cours complémentaire, Thomas "étudiera, le vendredi (une heure) la déclinaison et la conjugaison en ancien français et en provençal et (deux heures) continuera l'histoire sommaire de la littérature provençale (poésie narratrice)", et encore l'agrégation.

En 1893/94, il y a une lacune et il faut se reporter à 1894/95: "M. A. Thomas, professeur à la faculté des lettres de Toulouse, ćludicra, lc jeudi (une heure et quart) la dérivation dans les langues romanes (suite), et (deux hcures et quart) expliquera des textes d'ancien français (programme de l'agrégation de grammaire); le vendredi (deux heures), il 
expliquera des textes d'anglo-normand et étudiera les rapports de l'anglais avec l'ancien français."

En 1895/96, "phonétique comparée du français et du provençal" et exercices d'agrégation, comme en 1896/97.

$t$ : En 1891/92, une conférence de "grammaire et philologie est créée. On la trouve pourvue en 1892/93 par Ferdinand Brunot (mais il est peut-être installé depuis le second semestre de 91/92 dont l'affiche manque): "M. Brunot,maître de conférences, traitera, le jeudi, de la syntaxe française du XVIIe siècle" tout en assurant des exercices pour la licence et l'agrégation, et en $1893 / 94$ et en 1894/95.

En 1895/96, il étudie "l'histoire de la langue française au XVIe siècle" et, en 1896/97, "M. Brunot fera, le lundi,une explication élémentaire d'ancien français; le mardi (une heure), il étudiera l'histoire de la langue française au XVIIe siècle (...)" avec toujours et encore l'agrégation.

u : Aux côtés de Lénient, qui conserve son titre de professeur, est nommé "Faguet, docteur ès-lettres, chargé du cours", en 1895. La même année, Gazier est nommé professeuradjoint. Tous deux sont nommés professeurs l'année suivante. 
PARIS

\section{Latin et Grec}

\begin{tabular}{|c|c|c|c|c|c|c|c|c|c|}
\hline & $\begin{array}{l}\text { Eloquence } \\
\text { Grecque }\end{array}$ & $\begin{array}{l}\text { Poésie } \\
\text { Grecque }\end{array}$ & $\begin{array}{l}\text { Eloquence } \\
\text { Latine }\end{array}$ & $\begin{array}{l}\text { Poésie } \\
\text { Latine }\end{array}$ & $\begin{array}{l}\text { Lg \& Lit } \\
\text { Lat. }{ }^{b}\end{array}$ & $\begin{array}{l}\text { Lg \& Lit } \\
\text { Grec }^{b}\end{array}$ & $\begin{array}{l}\text { Philolo- } \\
\text { gie }^{b}\end{array}$ & $\begin{array}{l}\text { Gram- } \\
\text { maire }^{b}\end{array}$ & $\begin{array}{l}\text { Lit \& } \\
\text { Inst Gr. }\end{array}$ \\
\hline $1853-54$ & BOISSONADE & & $\frac{\text { LE CLERC }}{\text { Havet E. }{ }^{c}}$ & PATIN & & & & & \\
\hline $1854-55$ & $\begin{array}{l}\text { BOISSONADE } \\
\text { Egger }^{c}\end{array}$ & & $\frac{\text { LE CLERC }}{\text { Berger }}$ & PATIN & & & & & \\
\hline $\begin{array}{l}1855-65 \\
{[-62 / 63]}\end{array}$ & EGGER $^{d}$ & & $\frac{\text { LE CLERC }}{\text { Berger }}$ & PATIN & & & & & \\
\hline $1865-66$ & EGGER & & Berger & $\frac{\text { PATIN }}{\text { Martha C. }}$ & & & & & \\
\hline $1866-68$ & EGGER & & BERGER & $\frac{\text { PATIN }}{\text { Martha C. }}$ & & & & & \\
\hline $1868-69$ & EGGER & & BERGER & $\frac{\text { PATIN }}{\text { Martha C. }}$ & & Girard J. & & & \\
\hline $1869-73$ & EGGER & & MARTHA C. & $\frac{\text { PATIN }}{\text { Girard J. }}$ & & & & & \\
\hline $1873-75$ & EGGER & GIRARD J. 8 & MARTHA & $\frac{\text { PATIN }}{\text { Benoist } 8}$ & & & & & \\
\hline $1875-76$ & EGGER & GIRARD & MARTHA & Benoist & & & & & \\
\hline $1876-77$ & $\mathrm{EGGER}^{h}$ & GIRARD & MARTHA & BENOIST & & & & & \\
\hline $1877-79$ & EGGER & GIRARD & MARTHA & BENOIST & & Croiset $^{i}$ & & & \\
\hline $1879-80$ & EGGER & GIRARD & $\begin{array}{l}\text { MARTHA } \\
\text { Cucheval }\end{array}$ & $\begin{array}{l}\text { BENOIST } \\
\text { Lantoine }\end{array}$ & & Croiset & & & \\
\hline $1880-81$ & EGGER & GIRARD & $\begin{array}{l}\text { MARTHA } \\
\text { Cucheval }\end{array}$ & $\begin{array}{l}\text { BENOIST } \\
\text { Lantoine }\end{array}$ & Havet $L^{j}$ & Croiset & & & \\
\hline $1881-82$ & EGGER & GIRARD & MARTHA & $\begin{array}{l}\text { BENOIST } \\
\text { Lantoine }\end{array}$ & Riemann & Croiset & Havet $\mathrm{L}$ & & \\
\hline $1882-83^{k}$ & EGGER & GIRARD & MARTHA & BENOIST & Lallier & Croiset & Havet & Goelzer & \\
\hline $1883-84^{1}$ & EGGER & GIRARD & MARTHA & BENOIST & Lallier & CROISET & Havet & Goelzer & Girard P \\
\hline $1884-85$ & EGGER & GIRARD & MARTHA & BENOIST & Lallier & CROISET & Havet & Goelzer & Girard $P$ \\
\hline $1885-86$ & CROISET & GIRARD & MARTHA & BENOIST & Martha J & Hauv-B m & Havet $^{n}$ & Goelzer & Girard \\
\hline $1886-87$ & CROISET & $\begin{array}{l}\text { GIRARD } \\
\text { Decharme }\end{array}$ & MARTHA & $\begin{array}{l}\text { BENOIST } \\
\text { Cartault }\end{array}$ & Martha J & Hauv-B. & Havet & Goelzer & Girard \\
\hline $1887-91$ & CROISET & $\begin{array}{l}\text { GIRARD } \\
\text { Decharme }\end{array}$ & MARTHA & CARTAULT & Martha & Hauv-B. & Havet & Goelzer $^{\circ}$ & Girard \\
\hline $1891-93$ & CROISET & DECHARME & $\begin{array}{l}\text { MARTIIA C. } \\
\text { Martha J. }\end{array}$ & CARTAULT & Lafaye & Hauv-B. & Havet & $* * *$ & Girard \\
\hline 1893-94 & CROISET & DECHARME & $\begin{array}{l}\text { MARTHA C. } \\
\text { Martha J. }\end{array}$ & CARTAULT & Lafaye & Hauv-B. & Havet & Goelzer & \\
\hline 1894-95 & CROISET & DECHARME & $\begin{array}{l}\text { MARTHA C. } \\
\text { Martha J. }\end{array}$ & CARTAULT & Lafaye & $\begin{array}{l}\text { HAUV-B } \\
\text { Puech }\end{array}$ & Havet & Goelzer & \\
\hline $1895-96$ & CROISET & DECHARME & MARTHA J. & CARTAULT & Lafaye & HAUV-B & Havet & Goelzer & \\
\hline $1896-97$ & CROISET & DECHARME & MARTHA J. & CARTAULT & rEdet & HAUV-B & Havet & Goelzer & \\
\hline
\end{tabular}

*** Pendant ces deux années, la conférence de Goelzer est transféréc en français et confiée à Brunot. 


\section{NOTES SUR PARIS}

(latin et grec)

a : "Littérature grecque" jusqu'à la division de la chaire en 1874 entre "Eloquence grecque" et "Poésie grecque".

b : Intitulé des conférences:

"Langue et littérature latines" de 1880 à 1896; transformée en "Langue latine" en 1896;

"Langue et littérature grecques" de 1877 à 1883; transformée en "Lettres et philologie" dc 1883 à 1885 puis en "philologie" en 1885 avant de reprendre immédiatement l'intitulé d'origine "Langue et littérature grecques" pour Hauvette-Besnault, et d'être transformée en chaire pour son titulaire en 1895.

"Philologie latine" en 1881, conférence successivement rebaptisée par Louis Havet: "Philologie et métrique" en 1882 puis "Métrique" scule en 1895.

"Grammaire et philologie" de 1882 à 1891 avant qu'à la suite d'une vacance de deux ans, Goelzer ne récupère sa conférence sous l'intitulé: "Grammaire comparée du grec et du latin"(1893).

"Littérature et institutions grecques", conférence confiéc à Paul Girard.

c : Les enseignants qui assistent les titulaires de chaire( Emile Egger de 1854 à 1856, jusqu'à ce qu'il reçoive la chaire, Ernest Havet en 1853/54 et son successeur, Berger,de 1854 à 1866, avant qu'à son tour il ne devienne professeur) sont uniformément désignés comme "agrégés de la faculté".

d : En 1861/62, "M. Egger, professeur, traitera de la renaissance des lettres grecques en Occident, et particulièrement en France."

e : En 1865, Patin remplace Victor Le Clerc comme doyen et son suppléant est présenté ainsi: "M. Martha, ancien professeur de facultć, suppléant (...)".

f : "Jules Girard, docteur ès-lettres, suppléant" est attaché à la chaire de "Poésie latine" à partir du second semestre de 1868/69.

g : En 1873, Girard se voit confier la nouvelle chaire de "Poésie grecque", restreignant la chaire d'Egger de "Littérature grecque" à "Eloquence grecque". "M. Benoist,professeur à la faculté des lettres d'Aix, suppléant" de Patin, recevra sa succession à la rentrée de 1876. 
h : Au second semestre de 1876/77 (lc premier fait défaut aux Archives), l'affiche annonce, à propos d'Egger qu'"il achèvera d'exposer, les samedis, l'histoire sommaire de la langue grecque, en expliquant, à ce point de vue spécial,les programmes de la licence et des agrégations."

En 1877/78, "il étudiera, les samedis, l'histoire de la langue grecque dans quelques textes choisis parmi ceux des auteurs inscrits aux programmes des concours universitaires, et dans le Delectus Inscriptionum Graecorum de Lauer (Leipzig, 1877).

Si en 1878/79, les cours seront strictement littéraires, en 1879/80, "M. Egger, professeur, présentera un aperçu général de la langue et de la littérature grecques, et appréciera les diverses méthodes appliquées à cet enseignement."

En 1880/81, il "complètera, les lundis, par des développements nouveaux, l'aperçu général de la langue et de la littérature grecques, qu'il a présenté dans les cours de l'année dernière (...)" avant d'en revenir à des préoccupations littéraires et de n'en plus sortir.

i : L'institution des maîtres de conférences dans les disciplines classiques est destinée à soulager les titulaires de chaire (dont la formation est strictement littéraire) de l'enseignement de grammaire et de philologie qui requiert une compétence technique et ne bénéficie d'aucun prestige universitairc. Le cas de Croiset est exemplaire: nommé maître de conférences à la rentrée de 1877/78, il annonce au deuxième semestre: "M. Croiset, docteur ès-lettres,continuera l'explication grammaticale du Protagoras de Platon (...)" et, les années suivantes, il semble se consacrer exclusivement à des exercices de thème et de version, au moins jusqu'à ce qu'il rç̧oive une chaire qui lui soit propre.

La même remarque vaudrait pour les conférences créćes en 1879/80 pour Cucheval (éloquence latine) ou Lantoine (poćsie latine).

j : Louis Havet est recruté comme maître de conférences à la rentrée de 1880/81 où il est annoncé qu'il "traitera, le lundi, de la syntaxe latine (...)" avant d'étudier, au second semestre Nonius Marcellus. En 1881/82, il rç̧oit une conférence de "philologie latine": "M. Louis Havet,docteur ès-lettres, traitera, les mardis de la métrique grecque et latine. Les mercredis, il expliquera le Rudens de Plautc. Son ancienne conférence est confiée à Riemann:

"Monsieur Riemann, docteur ès-lettres, expliqucra, les lundis, à midi, le premier livre de Tite-Live; à cinq heures, il exposera la thćoric des formes grecques et latines. Le mardi, il expliquera le XIVe livre des Annales de Tacite, et, le jeudi, il exposera la syntaxe grecque et syntaxe latine." 


\section{$k$ : En 1882-1883:}

“M. Benoist, professeur, étudiera, le samedi, les Ménechmes de Plaute au point de vue de la littérature et de la philologie(...)".

Lallier, qui remplace Riemann, est présenté comme "professeur" Louis Havet annonce, entre autres, de la "métrique grecque et latine".

Dans la nouvelle conférence de "grammaire et philologie" créé à son intention, "M. Goelzer, agrégé de l'université, étudiera les lundis et les jeudis,la théorie de la formation des mots et la syntaxe des trois langues classiques (...)".

\section{I : En 1883-1884:}

La conférence de Croiset, "langue et littérature grecques",est transformée en chaire sous l'intitulé "Lettres et Philologie" avec un descriptif des cours strictement identique d'une année sur l'autre.

Philologie et métrique: "M. Louis Havet, docteur ès-lettres, étudiera la versification des poètes grecs et latins inscrits au nouveau programme de la licence".

Grammaire et philologie: "M. Goelzer, agrégé de l'université, étudiera, les mardis à une heure, et les jeudis à midi, les mots invariables et la syntaxe des langues grecque et latine". Il continuera son enseignement de grammaire les années suivantes, à destination principalement des étudiants préparant l'agrégation, annonçant, par exemple, en 1885-1886 de la "syntaxe grecque et latine" ou, en 1887-1888: “(...) les origines et le développement de la syntaxe de l'infinitif et du participe en grec et en latin (...)".

$\mathrm{m}$ : La conférence de "langue et littérature grecques" est créée au deuxième semestre de 1884/85 pour Hauvette-Besnault qui reprend l'enseignement que Croiset avait abandonné en récupérant la chaire d'Egger -"Eloquence grecque"- en 1885/86 alors qu'il venait de rebaptiser sa chaire de "Lettres et philologie" (1883) en "Philologie" (1885), désignation qui n'eut donc pas d'application.

n : A partir de $1885 / 86$, les cours de L. Havet, qui avait concilié la préparation des examens et concours et une approche semi-phonétique du latin, changent d'orientation:

en 1885/86 (second semestre): "M. L. Havet, professeur au Collège de France, docteur ès-lettres, étudiera les mercredis, la versification des poc̀tes grecs et latins inscrits au programme de la licence; les vendredis, il traitera de l'usage des éditions, collections et manuscrits."

Jusqu'à 1895, où sa conférence change d'intitulé, (de "Philologie et métrique" à "Métrique"), L. Havet évolue d'unc ćtude prosodique des textes à une critique des éditions à laquelle il finira par se consacrer tout entier. 
o : Comme Havet est le métricien de la Sorbonne, Goelzer en est le grammairien:

en $1887 / 88$, il est écrit qu'il "étudiera, le jeudi, la théorie sur laquelle repose la syntaxe des cas en grec et en latin (...)".

En 1888/89, "M. Goelzer, docteur ès-lettres, examinera, le jeudi, les diverses théories relatives à l'emploi des modes en grec et en latin (...)".

En 1889/90, ce sont les "théories relatives à l'emploi des cas en grec et en latin (...)", etc.

En 1891, la conférence de Goclzer est interrompue avant d'être transférée avec le même intitulé à Ferdinand Brunot pour la grammaire historique du français moderne. Elle sera rétablic avec un autre intitulé: "Grammaire comparée du grec et du latin" en 1893, quand Paul Girard, abandonnant sa conférence de "littérature et institutions grecques", libèrera un poste (à noter que l'abandon de Paul Girard intervient au moment où Jules Girard rétrocède sa chaire à Decharme).

A partir de 1894, Goelzer n'annonce plus que "Questions de syntaxe grecque et latine”. 
PARIS

\section{Sanscrit et Langues Vivantes}

$\begin{array}{lllll}\text { Littérature } & \text { Lit Eur } & \text { Lg \& Lit } & \text { Lg \& Lit. } & \text { Lg \& Lit } \\ \text { Etrangère } & \text { Mér }^{a} & \text { Germ } & \text { b } & \text { Angl }\end{array}$

\begin{tabular}{|c|c|c|c|c|c|}
\hline $1853-56$ & Amould ${ }^{\mathrm{e}}$ & & & & \\
\hline $1856-60$ & ARNOULD & & & & \\
\hline $1860-62$ & Mézières ${ }^{\mathrm{f}}$ & & & & \\
\hline $1863-65$ & MEZIERES g & & & & \\
\hline $1865-68$ & MEZIERES & Chasles ${ }^{h}$ & & & \\
\hline $868-77$ & MEZIERES & & & & \\
\hline $1877-80$ & MEZIERES & & & & Bergaigne $^{i}$ \\
\hline $1880-81$ & MEZIERES & GEBHART & Lichtenberger & & Bergaigne \\
\hline $1881-82$ & MEZIERES & GEBHART ${ }^{j}$ & & Beljame & Bergaigne \\
\hline & Lichtenberger & & & & \\
\hline $882-85$ & MEZIERES & GEBHART & Lange & Beljame & Bergaigne \\
\hline & Lichtenberger & & & & \\
\hline $885-87$ & MEZIERES & GEBHART & Lange & Beljame & BERGAIGNE \\
\hline & Lichtenberger & & & & \\
\hline $1887-88$ & MEZIERES & GEBHART & Lange & Beljame & BERGAIGNE \\
\hline & Lichtenberger & & & Baret & \\
\hline $1888-89$ & MEZIERES & GEBHART & Lange & Beljame & Henry k \\
\hline & Lichtenberger & & & Baret & \\
\hline 389-95 & MEZIERES & GEBHART $^{m}$ & Lange & Beljame & Henry \\
\hline & Lichtenberger & & & Baret & Lévi ${ }^{1}$ \\
\hline 1895-97 & MEZIERES & GEBHART & Lange & BELJAME & HENRY \\
\hline & Lichtenberger & & & Baret & \\
\hline
\end{tabular}




\title{
NOTES SUR PARIS
}

(Sanscrit et langues vivantes )

\author{
a : "Littérature de l'Europe méridionale". \\ b : "Langues et littératures d'origine germanique". \\ c: "Langue et littérature anglaisc". \\ d: "Langue et littérature sanscrite".
}

e : Amould est présenté comme "professeur à la facultć des lettres de Poitiers, délégué".

f : "M. Mézières, professeur à la faculté des lettres de Nancy, chargé du cours".

g : En 1864/65, "M. Mézières, professeur, traitcra de la littérature italienne au XIIle et au XIVe siècles, et particulièrement des oeuvres de Dante."

En 1865/66, il "traitera de la littérature italienne au XIVe siècle, et particulièrement des oeuvres de Pétrarque."

h : En 1865, Chasles, "professeur de littérature étrangère à la faculté des lettres de Nancy" assure un cours complémentaire "sur la poćsie populaire en Espagne".

En 1866/67 et 1867/68, il se consacre aux satiristes italiens puis disparait des affiches de la Sorbonne.

i : En 1877/78:

"M. Bergaigne, docteur ès-lettres, conmencera l'exposition de l'histoire littéraire de l'Inde; il étudiera la religion védique dans les hymnes du Rig-Veda" au premier semestre et, au second semestre,il "étudiera les principales divinités védiques. Le jeudi, à deux heures,il exposera, d'après la méthode comparative, la déclinaison et la conjugaison sanscrites".

En 1878/79:il "étudiera le théâtre indien; le jcudi, à dcux heures, il exposera les principes de la grammaire sanscrite et expliquera un choix de textes faciles".

En 1879/80: "M. Bergaigne, docteur ès-lettres, les vendredis, exposera les principes de la grammaire sanscrite dans leurs rapports avec ccux des grammaires grecque et latine; les jeudis, à unc heurc trois quarts, il fera l'explication grammaticale et étymologique de quelques hymnes védiques". 
En 1880/81:"les jeudis, (il) exposera la grammaire sanscrite. Les samedis,il appliquera les principes de la grammaire comparée à l'étude de la déclinaison et de la conjugaison grecques".

En 1881/82:il "fera, les lundis, l'analyse grammaticale d'un fragment de Mahâbhârata. Le vendredi, il traitera de l'ordre des mots dans les langues indo-européennes".

En 1882/83: il "expliquera, les lundis, la phonétique comparée des langues indoeuropéennes, et les samedis, la grammaire sanscrite".

En 1883/84:il "exposera, le lundi, les principes de l'étymologie grecque et latine. Le samedi, il expliquera des textes compris dans son Manuel pour étudier la langue sanscrite".

En 1884/85: il "traitera, le lundi, des principales familles de mots grecs et latins. Le samedi, il expliquera les premiers textes compris dans son Manuel pour étudier la langue sanscrite".

En 1885/86:la conférence change de titre pour s'appeler: "Sanscrit et grammaire comparée des langucs indo-europécnnes": "M. Bcrgaigne, docteur ès-lettres, exposera, le lundi, la phonétique comparće du grec et du latin. Le samedi, il expliquera la VedaChrestomathic de M. Hillebrand".

En 1886/87: "M. Bergaigne, professcur, exposera, le samedi (deux heures trois quarts), l'histoire de la conjugaison dans les langues grecque etlatine, et (cinq heures) dirigera des exercices de languc sanscrite à l'usage des commençants. Le lundi, il expliquera des textes védiques." Au second semestre, au cours du lundi, il "étudiera les principales dates de la chronologie indienne".

En 1887/88: "M. Bergaigne, professeur, cxposcra, le samedi (deux heures trois quarts), les principes généraux de l'ćtymologic dans lcur application au grec et au latin; le lundi (cinq heures) il exposera sommairement l'histoire de la littérature sanscrite; le samedi (cinq heures), il expliquera les premiers textes compris dans son Manuel pour étudier la langue sanscrite" au premicr scmestre,et au sccond, il "continuera d'exposer, le lundi (cinq heures) l'histoire de la littćrature indiennc; à quatre heures, il expliquera des textes épigraphiques sanscrits. Le samedi, il cxpliquera des textes sanscrits pour les commençants." Un accident de montagne interrompit le travail commencé.

j : En 1881/82:"M. Gcbhar, professcur, ćtudiera, Ic mardi, l'histoire du drame religieux en Italie au moyen-âge. Le mercredi, il expliqucra quelques chants du Roland furieux".

En 1883/84: "M. Gebhart, professeur, étudiera, le mardi, la civilisation religieuse de l'Italie au XIIIe siècle. Le mercredi, il expliquera l'Enfer de Dante".

En 1884/85, il passe au Purgatoire avant de s'attacher à la Renaissance. 
k : Dès le second semestre de $1888 / 89$, Victor Henry, qui est un des élèves préférés de Bergaigne, récupère sa charge d'enseignement: " $M$. V. Henry, docteur ès-lettres, chargé du cours de grammaire comparée, exposera, le lundi, à trois heures trois quarts, la théorie générale de la dérivation dans les langues indo-européennes, particulièrement en sanscrit, en grec et en latin, et, à cinq heures, les éléments de la grammaire sanscrite étudiée spécialement au point de vue de la comparaison avec les grammaires grecque et latine; le mardi, explication grammaticale des auteurs de la licence et de l'agrégation".

En 1889/90: il "expliquera, le mercredi, à trois heures trois quarts,des textes védiques empruntés au Manuel de Bergaigne et Henry, et exposera, à cinq heures, la grammaire historique et comparée du grec homérique, cnvisagé spécialement dans les chants d'Homère portés aux programmes de licence et d'agrégation."

En 1890/91: il "expliquera, le mercredi, à trois heures et demie, la Chrestomathie védique de Bergaigne et Henry, et exposera, à cinq hcures, d'après les données de l'étymologie indo-européenne, les éléments de l'ćtude comparée des mythologies de l'Inde, de la Grèce et de l'Italie (...)".

En 1891/92 : il "expliquera, le mercredi (trois hcures et demie),divers textes védiques et exposera (cinq heures) la grammaire historique ct comparće du dialecte attique."

En 1892/93: il modifie son cours de cinq heures en: "syntaxe comparé du verbe en grec, en latin et subsidiairement dans les autres langues indo-européennes". Il assure en outre des exercices d'agrégation, cette année-ci et les suivantes.

En 1893/94: il "expliquera, le mercredi (quatre heures), divers textes védiques et exposera (cinq heures et quart), la prosodic quantitative gréco-latine ramenée à ses origines indo-européennes (...)"

En 1894/95:il "exposera, le mercredi, à trois heures trois quarts,les principes généraux de la grammaire historique des langues germaniques (...); à cinq heures, il expliquera des textes de sanscrit védique (...)".

En 1895/96, la conférence est rétablic cn chairc: "M. V. Henry, professeur, exposera, le mercredi, à trois heures trois quarts, les ćléments de la grammaire comparée de l'anglosaxon et du vieux haut-allemand (...)". Le même intitulé est repris en 1896/97 avec simplement l'addition du gotique.

1 : En 1889/90:"M. Sylvain Lévi, maître de conférences à l'Ecole des Hautes Etudes, étudiera, le mardi, les relations historiques de l'Inde avec la Grèce; le vendredi, il expliquera des textes de la Chrestomathie de Bergaigne". Quoiqu'il s'agisse du même manuel que celui utilisé la même annće par V. Henry, le nom de celui-ci est "oublié". Lévi renonce à sa conférence l'année même où celle de Henry est transformée en chaire. 
En 1890/91, Lévi étudie "les relations de l'Inde avec les peuples étrangers à partir de l'ère chrétienne" et, comme les années suivantes des textes empruntés à la Chrestomathie de Bergaigne.

En 1891/92 et en 1892/93, ce sont les "relations de l'Inde avec l'Occident", en 1893/94, des "notions de littérature sanscrite", en $1894 / 95$ enfin des "éléments de l'archéologie indienne".

En un mot, Bergaigne disparu, il se produit une sćparation entre le comparatisme indoeuropéen et l'indianisme (à rapprocher aussi des conséquences de la mort prématurée de James Darmesteter).

m : En 1894/95, Gebhart étudie, entre autres, lc Purgatoirc de Dante. 


\title{
UNIVERSITES DE PROVINCE
}

\author{
AIX-EN-PROVENCE \\ BESANCON \\ BORDEAUX \\ CAEN \\ CLERMONT-FERRAND \\ DIJON \\ GRENOBLE \\ LILLE ( et DOUAI ) \\ LYON \\ MONTPELLIER \\ NANCY \\ POITIERS \\ RENNES \\ STRASBOURG \\ TOULOUSE
}




\section{AIX EN PROVENCE}

\begin{tabular}{|c|c|c|c|c|c|c|c|c|}
\hline & Litté Fse. & Litté Etr. & Litté Anc " & Lit \& Inst Gr. & Philologie ${ }^{u}$ & Hébreu & Lg Lt Mér. " Lg Lit Prov " & L.E. ${ }^{x}$ \\
\hline $1847-48$ & FORTOUL & Méry & BONAFOUS & & & & & \\
\hline $1859-60$ & Joly b & MERY & BONAFOUS & & & & & \\
\hline $1863-66$ & De Suckau & MERY & BONAFOUS & & & & & \\
\hline $1866-67$ & DE SUCKAU & MERY & BONAFOUS & & & & & \\
\hline $1867-68$ & Reynald & MERY & BONAFOUS & & & & & \\
\hline $1868-70$ & REYNALD & MERY & BONAFOUS & & & & & \\
\hline $1871-74$ & REYNALD & BENOIST $^{c}$ & BONAFOUS & & & & & \\
\hline $1874-75$ & REYNALD & & BONAFOUS & & & & & \\
\hline $1875-77$ & REYNALD & Joret $^{\mathrm{d}}$ & BONAFOUS & & & & & \\
\hline $1877-78$ & & JORET & BONAFOUS & & & & & \\
\hline $1879-81$ & Bizos & JORET & Lehanneur & & & & & \\
\hline $1881-82$ & BIZOS $^{\circ}$ & JORET ${ }^{f}$ & Lehanneur 8 & Lafaye ${ }^{8}$ & & & & \\
\hline $1883-85^{\mathrm{i}}$ & BIZOS & JORET & Constans & Lafaye & Rigal $^{\mathrm{h}}$ & & & \\
\hline $1885-86^{j}$ & $\begin{array}{l}\text { BIZOS } \\
\text { Léna }\end{array}$ & JORET & CONSTANS ${ }^{k}$ & Boissière & Rigal & & & \\
\hline $1886-87$ & BIZOS & JORET & CONSTANS & Boissière & & & & \\
\hline & Léna & & & Clerc & Rigal & & & \\
\hline $1887-89^{4}$ & $\frac{\text { BIZOS }}{\text { Léna }}$ & JORET & CONSTANS & $\begin{array}{l}\text { BOISSIERE } \\
\text { Maury }\end{array}$ & Rigal & & & \\
\hline $1889-90^{\mathrm{m}}$ & $\underline{B I Z O S}$ & JORET & CONSTANS & $\begin{array}{l}\text { BOISSIERE } \\
\text { Maury }\end{array}$ & Rigal & & & \\
\hline $1890-91^{\mathrm{n}}$ & DUCROS & JORET & CONSTANS & $\begin{array}{l}\text { BOISSIERE } \\
\text { Maury }\end{array}$ & Rigal & de Duranti & & \\
\hline $1891-92^{\circ}$ & DUCROS & JORET & CONSTANS & $\begin{array}{l}\text { BOISSIERE } \\
\text { Maury }\end{array}$ & & de Duranti & & DUCROS \\
\hline $1892-93^{P}$ & DUCROS & JORET & CONSTANS & $\begin{array}{l}\text { BOISSIERE } \\
\text { Maury }\end{array}$ & Fabia & de Duranti & & DUCROS \\
\hline $1893-949$ & DUCROS & JORET & CONSTANS & $\begin{array}{l}\text { BOISSIERE } \\
\text { de Ridder }\end{array}$ & Chambry & de Duranti & & DUCROS \\
\hline $1894-95^{\mathrm{r}}$ & $\underline{\text { DUCROS }}$ & JORET & CONSTANS & $\begin{array}{l}\text { BOISSIERE } \\
\text { de Ridder }\end{array}$ & Chambry & de Duranti & & DUCROS \\
\hline $1895-96^{s}$ & $\underline{\text { DUCROS }}$ & JORET & CONSTANS & $\begin{array}{l}\text { de Ridder } \\
\text { Brenous }\end{array}$ & & de Duranti & Bonafous CONSTANS & \\
\hline $1896-97^{t}$ & $\frac{\text { DUCROS }}{\text { Bonafous }}$ & JORET & CONSTANS & de Ridder & & de Duranti & Bonafous CONSTANS & \\
\hline
\end{tabular}




\section{AIX-EN-PROVENCE : Notes}

a :En 1881, cette chaire est subdivisée en "Littćrature et institutions grecques" et en "Littérature et institutions romaines" dont le titulaire figure dans la colonne de l'intitulé primitif.

b :Intitulé du cours: "Histoire des lettres en France au moyen-âge (XIIIle siècle)".

c :Intitulé du cours: "Les origines de la littérature allemande" (1872-1873); "La poésie lyrique et la poésie épique en Allemagne au moyen-âge" (1873-1874).

d :Intitulé du cours: "Conférence de philologie romane avec explications d'ancien textes français, provençaux, italiens et espagnols" (1876-1877) et "conférence de grammaire comparée et de philologie classique et romanc"(1877-1878). Il ne s'agit que d'une partie des enseignements dispensés par Joret. Joret est supplćant de 1875 à 1877 et professeur à partir de 1877, assurant successivement "Grammaire historique de la langue allemande et anglaise" (1879-1880); "Histoire de la poćsic ćpique et lyrique au moyen-âge, principalement en Allemagne et en Italic; ćtude comparće de la langue et de la littérature allemandes et anglaises; grammaire comparće de l'ancien-français et du provençal et explication de la Chanson de Roland" (1880-1881).

e :Intitulé du cours: "Histoire de la langue et de la littćrature françaises au moyen-âge".

f :Intitulé du cours: "Elude historique de la languc allemande (premier semestre), anglaise (deuxième semestre); grammaire comparćc des langues classiques et des langues romanes. Explication de la_Chanson de Roland (p. (sic) 1017-1422)" (1881-1882). Le cours de l'année suivante indique seulement, entre autres: "Grammaire".

$\mathrm{g}$ :Les charges d'enseignement de Lafaye et Lchanncur sont spécialisées dans leur objet mais restent groupées dans une seule chairc. Lchanneur assure un enseignement de "Grammaire et métrique latines", Lafayc fait des "conférences sur la grammaire grecque"

h :En 1883, trois postes de maîtres de conférences sont créćs, dont un pour la "philologie grecque et latine" confić à Rigal qui fait de la "grammaire" pour l'agrégation. Les contenus des conférences ne sont plus, par la suite, précisés.

i :Lafaye, Constans et Joret annoncent de la "grammaire" ; le cours de Joret porte spécialement sur la grammaire allemande. 
j :En 1885, création de deux maîtrises de conférences supplémentaires: l'une en langue française, attribuée à Léna, l'autre en littćrature grecque, non pourvue en 1885.

k :"Le professeur étudiera les légendes d'origine classique au moyen-âge". Rigal assure la philologie grecque et latine (Clerc ne s'occupant que de littérature grecque).

\section{$1:$ En 1887-1888:}

BIZOS: "Histoire de la poésie française au moyen-âge" (entre autres);

JORET: "Histoire de la languc allemande", "grammaire allemande", "grammaire anglaise", "la littérature du moyen-âge".

RIGAL: maître de conférences en philologie grecque et latine: "étude de la métrique grecque et latine", "grammaire comparće des langues grecque et latine.

MAURY: "langue grecque".

En 1888-1889:

JORET consacre la moitié de son enscignement de "littérature étrangère à l'ancien français:

- au premier semestre: "la langue et la littérature au moyen-âge et au seizième siècle";

- au second semestre:"Grammaire historique du français. Chanson de Roland."

CONSTANS : "Syntaxe comparće des langues grecque et latine", "morphologie grecque et latine", "explication des textes d'ancien français portés au programme del'agrégation". RIGAL: "Etude de grammaire grecque el latine", "grammaire comparée des langues grecque et latine".

MAURY: sa maîtrise de conférences s'intitule désormais:"langue et littérature grecques".

$\mathrm{m}:$ En 1889-1890:

JORET: "Explication de la Chanson de Roland ct exposition des règles historiques de la grammaire française".

RIGAL: au premier semestre, "grammairc comparće des langues grecque et latine, étude des formes", "grammairc comparćc. Syntaxe.", "Mćtrique grecque et latine.", entre autres;au second semestre, Rigal, en congé, est remplacé par Audoin,"chargé de fonctions", qui doit faire:"Morphologie grecque ct latine.", "Syntaxe du grec et du latin." et "Métrique". 
$\mathrm{n}$ : En 1890-1891, alors que Ducros remplace Bizos ct que Rigal reprend les mêmes intitulés que l'année précédente, JORET fait, entre autres, au premier semestre une "Exposition des règles historiques de la grammaire française et explication de textes." et, au second semestre, une "Histoire de la poésie française au moyen-âge" en même temps que de la "Grammaire historique du français", cependant que CONSTANS fait une "Explication de textes de la Chrestomathie de l'ancien français. La même année, DE DURANTI LA CALADE commence un cours de "langue hébraïque" le samedi à dix heures quarantecinq.

o : En 1891-1892:

DUCROS assure un cours complémentairc de "langue française",

JORET, entre autres, au premier semestre, "Grammaire historique du français. La

Chanson de Roland." et, au second semestre, "Grammaire historique de l'allemand" et "Grammaire historique du français au XVIe sic̀cle";

CONSTANS, entre autres, au second semestre "Explication des textes d'ancien français pour l'agrégation de grammaire" et, pendant toute l'année, un cours complémentaire de "Langue et littérature provençales".

Le poste de "philologie grecque et latine" n'est plus pourvu: il est remplacé par un cours de "Langue et littérature latines" assuré par FABIA avec, entre autres, de la "Syntaxe latine".

J. DE DURANTI assure une "conférence fermée" d'hébreu avec entre autres "Explication du Livre des Juges. Commentaire philologique et grammatical".

p : En 1892-1893:

JORET assure entre autres un cours de "Grammairc historique de la langue française.

Explication de la Chanson de Roland et des extraits de Joinville".

CONSTANS reprend ses cours pour l'agrégation comme l'année précédente et, en cours complémentaire,traite de l'"Influence de la littérature des Troubadours en Italie, en Espagne, en France et en Allemagne".

FABIA s'occupe entre autres de "Syntaxe latine" au premier semestre avant d'être remplacé pour le second semestre par CHAMBRY qui fait, au titre d'un enseignement de "Grammaires grecque et latine" de la "métrique" et de la "grammaire",entre autres.De Duranti la Calade continue ses cours d'hćbrcu et Ducros ses cours de français "pour les étudiants en droit de nationalité étrangère". 
$\mathrm{q}:$ En 1893-1894:

DUCROS, qui continue ses cours de français langue étrangère, est nommé doyen au second semestre.

JORET assure, entre autres, "Grammaire historique du français. Explication de La Chanson de Roland et de Villchardouin". CONSTANS fait, entre autres, l" Explication des morceaux de la Chrestomathie Constans inscrits au programme de l'agrégation".

CHAMBRY assure entre autres "Mćtrique ct grammaire" et DE DURANTI continue ses cours d'hébreu, le vendredi désormais.

$r$ : En 1894-1895:

JORET fait la "Grammaire historique du français", entre autres.

CONSTANS, sous le même intitulé, reprend pour l'agrégation sa Chrestomathie et étudie, dans son cours complémentaire, "Le théâtre provençal".

CHAMBRY étudie la "Syntaxe des cas en grec et en latin". Ducros et de Duranti la Calade poursuivent leurs cours respectifs.

s : En 1895-1896:

JORET poursuit les mêmes cours que l'annéc précédente.

En "Littérature et institutions grecques", BRENOUS assure une conférence de "Philologie classique": "Grammaire et mćtrique des deux langues classiques".

En "Langues et littératures de l'Europe méridionale", BONAFOUS étudie les "Origines de la littérature italienne".

En "Langue et littérature provençales", CONSTANS traite de "La littérature didactique en provençal".

De DURANTI continue son cours d'hćbreu.

$t:$ En 1896-1897:

BONAFOUS est chargé des conférences de littérature française auprès de Ducros et il occupe à titre de chargé de cours la chaire de "Langue et littérature italiennes" qui remplace celle de "Langues et littératurcs de l'Europe méridionale"; à ce titre, il fait un cours sur "Le XIIle siècle italien et Dante".

CONSTANS, JORET et de DURANTI assurent les mêmes enseignements que l'année précédente.

u : "Philologie grecque et latine", conférence transforméc en "Langue et littérature latines" en 1892 et en "Grammairc grecque ct laline" cn 1893.

v : "Langues et littératures de l'Europe méridionale" en 1895 puis "Langue et litérature italienne" en 1896. 
w : "Langue et littérature provençale"

x :"Français pour étudiants étrangers" (cours destinés aux étudiants de la faculté de droit). 


\section{BESANCON}

\begin{tabular}{|c|c|c|c|}
\hline & $\begin{array}{l}\text { Littérature } \\
\text { Française }\end{array}$ & $\begin{array}{l}\text { Littérature } \\
\text { Ancienne }\end{array}$ & $\begin{array}{l}\text { Littérature } \\
\text { Etrangère }\end{array}$ \\
\hline $1853-58$ & $\underline{\text { PERENNES }}^{*}$ & WEIL & \\
\hline $1858-60$ & PERENNES & WEIL & Boré \\
\hline $1860-61$ & PERENNES & WEIL & Soupé ${ }^{b}$ \\
\hline $1863-64$ & PERENNES & WEIL & Courdaveaux \\
\hline $1864-70$ & $\underline{\text { PERENNES }}^{c}$ & WEIL & WIDAL \\
\hline $1871-72$ & PERENNES & WEIL & WIDAL \\
\hline $1873-75$ & TIVIER $^{d}$ & WEIL & $\begin{array}{l}\text { WIDAL } \\
\text { Gérard }\end{array}$ \\
\hline $1875-77$ & TIVIER & WEIL & Boucher \\
\hline $1877-78$ & $\underline{\text { TIVIER }}$ & Lantoine & BOUCHER \\
\hline $1879-80$ & $\underline{\text { TIVIER }}$ & Nageotte & BOUCHER \\
\hline $1881-82 *$ & TIVIER & $\begin{array}{l}\text { NAGEOTTE } \\
\text { Droz }\end{array}$ & BOUCHER \\
\hline $1882-83 * *$ & $\frac{\text { TIVIER }}{\text { Lemaître }}$ & $\begin{array}{l}\text { NAGEOTTE } \\
\text { Vernier }{ }^{f}\end{array}$ & $\begin{array}{l}\text { BOUCHER } \\
\text { Kontz }\end{array}$ \\
\hline $1883-85$ & $\frac{\text { TIVIER }}{\text { Jeanroy } \mathrm{g}}$ & $\begin{array}{l}\text { NAGEOTTE } \\
\text { Vernier } \\
\text { Droz }\end{array}$ & $\begin{array}{l}\text { BOUCHER } \\
\text { Kontz }\end{array}$ \\
\hline $1885-88$ & $\frac{\text { TIVIER }}{\text { Parigot }}$ & $\begin{array}{l}\text { NAGEOTTE } \\
\text { Vernier } \\
\text { Droz }^{h}\end{array}$ & $\begin{array}{l}\text { BOUCHER } \\
\text { Kontz }\end{array}$ \\
\hline $1888-92$ & $\mathrm{DROZ}^{\mathrm{i}}$ & $\begin{array}{l}\text { NAGEOTTE } \\
\text { Vernier } \\
\text { Ferté }^{j}\end{array}$ & $\begin{array}{l}\text { BOUCHER } \\
\text { Kontz }^{k}\end{array}$ \\
\hline $1892-96$ & $\mathrm{DROZ}^{\mathrm{I}}$ & $\begin{array}{l}\text { NAGEOTTE } \\
\text { VERNIER } \\
\text { Roy }\end{array}$ & $\begin{array}{l}\text { BOUCHER } \\
\text { Kontz }\end{array}$ \\
\hline $1896-97$ & DROZ & $\begin{array}{l}\text { NAGEOTTE } \\
\text { VERNIER } \\
\text { Lévy-Wogue }^{\mathrm{m}}\end{array}$ & \\
\hline
\end{tabular}




\section{NOTES SUR BESANCON}

a : "Le professeur traitera de la littérature française depuis le XIIe siècle jusqu'au XVIIe." en 1853/54 et, en 1856/57:"le professeur traitera, le vendredi, de la littérature française depuis son origine jusqu'à la fin du XVIe sic̀cle".

b : "Le professeur examinera, d'après les Romanceros, les principales légendes héroïques et chevaleresques relatives à l'histoire d'Espagne du XIIIe au XVe siècle".

c : "Le professeur étudiera la littérature française à son origine et en suivra le développement progressif jusqu'à l'époque de la Renaissance."

d : "Le professeur fera l'histoire de l'ćloquence française depuis ses origines jusqu'au XVIIe inclusivement".

e : "Le professeur fera l'histoire de la poésie italienne du XIVe au XVIe".

f : Fait, outre des exercices destinés à la prćparation de l'agrégation et de la licence, une conférence sur "notions de grammaire et de métrique" en 1882/83 et "grammaire et métrique" en 1883/84.

g : Jeanroy, "chargé de conférences complémentaircs", assure un "cours de littérature française du moyen-âge".

h : En 1887/88, Droz assure une conférence sur l'"Histoire de la rhétorique latine".

i : Droz est professeur au second semestre de $1888 / 89$.

j : En 1888/89, Vernier est maître de conférences en "philologie grecque et latine" et Ferté, "chargé de conférences de littérature latine". Vernier est promu professeur adjoint en $1890 / 91$.

k : Kontz est "chargé de conférences de langue el de littérature allemandes".

1 : Droz assure un cours fermé consacré à l'“Explication de la Chanson de Roland" en $1891 / 92$ et à l"“Explication d'anciens textes français" en 1892/93.

m : "Chargé d'un cours complémentaire de langue ct littćrature latines". 
BORDEAUX

\begin{tabular}{|c|c|c|c|c|c|c|c|}
\hline & $\begin{array}{l}\text { Littérature } \\
\text { Française }\end{array}$ & $\begin{array}{l}\text { Littérature } \\
\text { Etrangère }\end{array}$ & $\begin{array}{l}\text { Lg \& Littér. } \\
\text { Allemandes }\end{array}$ & $\begin{array}{l}\text { Littérature } \\
\text { Ancienne }\end{array}$ & $\begin{array}{l}\text { Lg \& Litté } \\
\text { Latines }\end{array}$ & $\begin{array}{l}\text { Philologie } \\
\text { Gr.\& Lat.u }\end{array}$ & $\begin{array}{l}\text { Lg et Litté } \\
\text { du Sud-Ouest }\end{array}$ \\
\hline $1845-46$ & ROUX & FR-MICHEL * & & DABAS & & & \\
\hline $1859-60$ & ROUX & FR-MICHEL a & & $\underline{\mathrm{DABAS}}$ & & & \\
\hline $1863-64$ & ROUX & FR-MICHEL & & $\underline{\mathrm{DABAS}}$ & & & \\
\hline $1866-67$ & ROUX & FR-MICHEL ${ }^{b}$ & & $\underline{D A B A S}$ & & & \\
\hline $1868-69$ & $\begin{array}{l}\text { ROUX } \\
\text { Lefranc }\end{array}$ & FR-MICHEL & & DABAS & & & \\
\hline $1869-70^{d}$ & $\begin{array}{l}\text { ROUX } \\
\text { Lefranc }\end{array}$ & TREVERRET & & DABAS & & & \\
\hline $1873-74$ & ROUX & TREVERRET & & DABAS & & & \\
\hline $1877-78$ & $\frac{\text { ROUX }}{\text { Luchaire }^{c}}$ & TREVERRET & & COUAT $^{f}$ & FROMENT & & \\
\hline $1878-798$ & $\frac{\text { ROUX }}{\text { Luchaire }_{\text {Benoist }^{h}}}$ & TREVERRET & & COUAT & FROMENT & & \\
\hline $1879-80$ & $\frac{\text { ROUX }}{\text { Benoist }}$ & TREVERRET & & COUAT & FROMENT & & \\
\hline $1880-81$ & ROUX & TREVERRET & & COUAT & FROMENT & Beaudoin ${ }^{i}$ & \\
\hline $1881-82$ & $\begin{array}{l}\text { ROUX } \\
\text { Faguet }\end{array}$ & TREVERRET & & COUAT & FROMENT & Beaudoin & \\
\hline $1882-83$ & $\begin{array}{l}\text { ROUX } \\
\text { Faguet }\end{array}$ & TREVERRET & Ducros & COUAT & FROMENT & Beaudoin & \\
\hline $1883-85^{j}$ & $\begin{array}{l}\text { STAPFER } \\
\text { Faguet } \\
\text { Bourciez k }\end{array}$ & TREVERRET & Ducros & COUAT & FROMENT & Beaudoin & \\
\hline $1885-86$ & $\begin{array}{l}\text { STAPFER } \\
\text { Bourciez }\end{array}$ & TREVERRET & Erhard & $\frac{\text { COUAT }}{\text { Paris }}$ & $\begin{array}{l}\text { WALTZ } \\
\text { dlVdM ** }\end{array}$ & Boulin & \\
\hline $1886-87$ & $\begin{array}{l}\text { STAPFER } \\
\text { Bourciez }\end{array}$ & TREVERRET ${ }^{\prime}$ & Erhard & $\frac{\text { COUAT }}{\text { Ouvré }^{m}}$ & $\begin{array}{l}\text { WALTZ } \\
\text { dlVdM }\end{array}$ & Boulin $^{n}$ & \\
\hline $1887-88^{\circ}$ & $\begin{array}{l}\text { STAPFER } \\
\text { Bourciez }\end{array}$ & TREVERRET & & $\frac{\text { COUAT }}{\text { Ouvré }}$ & $\begin{array}{l}\text { WALTZ } \\
\text { dlVdM }\end{array}$ & Boulin & \\
\hline $1888-91$ & $\begin{array}{l}\text { STAPFER } \\
\text { Bourciez }\end{array}$ & TREVERRET & Denis & $\begin{array}{l}\text { COUAT } \\
\text { Ouvré } \\
\text { Cucuel }\end{array}$ & $\begin{array}{l}\text { WALTZ } \\
\text { dlVdM } \\
\text { Plessis }\end{array}$ & Boulin $^{\mathrm{P}}$ & \\
\hline $1891-92$ & $\frac{\text { STAPFER }}{\text { Bourciez }}$ & TREVERRET & Besson & $\begin{array}{l}\text { CUCUEL } \\
\text { Ouvré }\end{array}$ & $\begin{array}{l}\text { WALTZ } \\
\text { dlVdM }\end{array}$ & Masqueray ${ }^{r}$ & \\
\hline $1892-93$ & $\frac{\text { STAPFER }}{\text { Bourciez }}$ & TREVERRET & Besson & $\begin{array}{l}\text { Ouvré } \\
\text { Zyromski }\end{array}$ & $\begin{array}{l}\text { WALTZ } \\
\text { dlVdM }\end{array}$ & Masqueray & \\
\hline $1893-94$ & $\frac{\text { STAPFER }}{\text { Le Breton }}$ & TREVERRET & Besson $^{t}$ & $\begin{array}{l}\text { Ouvré } \\
\text { Zyromski }\end{array}$ & $\begin{array}{l}\text { W ALTZ } \\
\text { dlVdM }\end{array}$ & Masqueray & BOURCIEZ ' \\
\hline $1894-96$ & $\frac{\text { STAPFER }}{\text { Le Breton }}$ & TREVERRET & Legras & $\begin{array}{l}\text { OUVRE } \\
\text { Zyromski }\end{array}$ & $\begin{array}{l}\text { WALTZ } \\
\text { dlVdM }\end{array}$ & Masqueray & BOURCIEZ \\
\hline $1896-97$ & $\frac{\text { STAPFER }}{\text { Le Breton }}$ & TREVERRET & Legras & $\begin{array}{l}\text { OUVRE } \\
\text { MASQUERAY } \\
\text { ZYROMSKI }\end{array}$ & $\begin{array}{l}\text { WALTZ } \\
\text { DLVDM }\end{array}$ & Cirot & BOURCIEZ \\
\hline
\end{tabular}

\footnotetext{
* "FR-MICHEL" : "Francisque-Michel"

** "dlVdM" [ou "DLVDM"]: "de la Ville de Mirmont"

[de la Ville de Mirmont devient professeur-initiales portées en majuscules - en 1896 ].

Il manque le premier semestre de 1845-46.
} 


\section{NOTES SUR BORDEAUX}

a : "Le professeur traitera de la littérature italienne depuis ses origines jusqu'à Dante inclusivement".

b : "Le professeur traitera, le vendredi, de la poćsic populaire dans les temps modemes, chez les différents peuples".

c : "Le professeur traitera de la littérature française du moyen-âge".

d : En 1869/70, il y a une tentative pour diversificr les enscignements : de Tréverret assure en outre une conférence de prose latine, Roux de poćsic latine, Combes -un enseignant d'histoire- traite du "XVIIIe siècle littéraire"...

e : Luchaire, maître de conférences, fait un cours sous l'intitulé: "Histoire et langues du Midi de la France" en 1877/78, "lc lundi, à cinq heures du soir: histoire de la France méridionale, depuis les origines jusqu'à l'apparition des conquérants germains; le jeudi, à cinq heures du soir: étude de la formation de l'ancien provençal"; en 1878/79,il poursuit avec "Histoire de la réunion des pays de languc d'oc au domaine royal" et "Etude des idiomes parlés dans les Pyrénćes"; en 1879/80, il prend la chaire de géographie où il traite, au demeurant, de l'histoire du moyen-âge.

f : En 1877/78, l'enseignement des langucs classiques est complété par un enseignement d'histoire intitulé: "Antiquités grecques et latines" confié à Collignon.

g : Victor-Emile Egger est nommé en philosophic.

h : Benoist assure, entre autres, une conférence de "grammaire générale".

i : Beaudoin, en philologie grecque ct latinc, assure un "cours de grammaire".

j: Il y a deux affiches pour la même annćc, les mêmes scmestres, l'une, prodigue en cours et conférences qui semble avoir étć refusée par le ministère, l'autre que nous avons reprise dans notre tableau. A noter qu'en géngraphic,sur la première affiche, Luchaire annonçait: "Explication de Villehardouin, La conquête de Consıantinople", ce qui ne figure plus sur l'affiche "officielle". 
k: Bourciez assure un cours complémentaire dans lequel il traite :

en 1883/84: "Origines et formation de l'ancicn français. Explication de La Chanson de Roland 1-365";

en 1885/86: "Phonétique de l'ancien français (...)";

en 1886/87: "Morphologie de l'ancien français(...)";

en 1887/88: "Formation historique de l'ancienne syntaxe française(...)";

en 1888/89: "Phonétique comparćc du provençal ct de l'ancien français (...)";

en 1889/90: "Morphologie de l'ancien français (...)";

en 1890/91, après qu'il a été nommé professcur adjoint: "Les origines de la syntaxe française (...)";

en 1891/92: "Principes de phonćtique romane"ct,

en 1892/93: "Phonétique française ct provençale". Voir suite notes

I : Cours : "Les origines de la littćraturc anglaise jusclu’à la Renaissance".

m : En 1886/87, l'enscignement classique esı réparti cntre quatre chaires, deux à dominante historique: "Archéologic et institutions grecques" cl "Antiquités grecques et latines"; deux à dominante littérairc: "Langue grecque" cl "Languc et littérature latines".

n : Boulin annonce deux "Cours de grammairc comparćc", l'un consacré aux "formes" et l'autre à la "syntaxe". Ces exercices sont officicllement destinés à la préparation de l'agrégation et de la licence.

0 : Durkheim reçoit son premicr posıc à l'universitć.

p : Boulin fait, en 1889/90: "Syntaxe comparće des temps et des modes" et, en 1890/91: "Phonétique comparéce du grec el du latin: histoire des voyclles."

q : Stapfer fait, entre autres, en 1891/92: "Histoirc de la littérature française depuis le XVe siècle"; et, en 1892/93: "L'ćpopćc françaisc".

$\mathrm{r}$ : Masqueray assure, comme maître de conférences :

en 1892/93:"Elude de différentes questions de syntaxe comparće"; en 1893/94: "Cours de grammairc comparéc: les mots invariables";

en 1894/95: "Cours de grammaire comparćc: formation des mots(...)"; en 1895/96: Cours de grammaire comparéc: théoric de la déclinaison (...)";

en 1896/97, nommé professcur adjoint, chargé d'un cours de littérature grecque, Masqueray abandonne l'enseignement de la grammaire. 
S : En 1893/94, Bourciez reçoit une chaire fondće par la municipalité de Bordeaux et intitulée: "Langue et littérature du Midi de la France"; il y traite de "l'idiome gascon, étude historique et géographique des sons et des formes"; en 1894/95: c'est "Jasmin" et "L'idiome gascon de Bordeaux" auxqucls s'ajoutent les cours d'agrégation, tout comme en 1895/96. En 1896/97, Bourciez traite de "La langue française au XIXe siècle" et des "Contes populaires de la Gascogne".

$\mathrm{t}$ : Besson, maître de conférences, traite de "La littérature allemande jusqu'au XVle siècle (...)".

u : Intitulé des chaires :

-"Littérature française" : sans changement de 1847 à 1897.

-"Littérature étrangère" devient "Langues et littératures étrangères (Anglais)" à partir de 1883;

-"Langue et littérature allemandes" inclut, à partir de 1894, une conférence de russe;

- "Littérature ancienne" devient "Langue ct littćraturc grecques" à partir de 1877, la chaire se dédoublant par création d'une chaire dc

-"Langue et littérature latines";

- La conférence de "Philologie grecque ct latine", ouverte en 1880, devient conférence de "Grammaire" en 1885, de "Grammairc comparće" en 1887 et de nouveau de "Grammaire" en 1888;

- La chaire de "Langue et littérature du Sud-Ouest de la France" est une fondation municipale, ouverte en 1892. 


\section{CAEN}

\begin{tabular}{|c|c|c|c|c|c|}
\hline & $\begin{array}{l}\text { Litté } \\
\text { Française }\end{array}$ & $\begin{array}{l}\text { Litté } \\
\text { Latine * }\end{array}$ & $\begin{array}{l}\text { Litté } \\
\text { Grec ** }\end{array}$ & $\begin{array}{l}\text { Litté } \\
\text { Etrangère }\end{array}$ & $\begin{array}{l}\text { Grammaire } \\
\text { \& Phil. }\end{array}$ \\
\hline $1845-46$ & DELAVIGNE & TRAVERS & BERTRAND & & \\
\hline $1852-53$ & HIPPEAU a & TRAVERS & BERTRAND & & \\
\hline $1859-60$ & HIPPEAU & & BERTRAND & GANDAR $^{b}$ & \\
\hline $\begin{array}{l}1863-64 \\
1864-66 \\
1866-67 \\
1867-68 \\
1868-78\end{array}$ & $\begin{array}{l}\text { JOLY } \\
\text { JOLY } \\
\text { JOLY } \\
\text { JOLY } \\
\text { JOLY }^{\mathrm{e}}\end{array}$ & & $\begin{array}{l}\text { BERTRAND } \\
\text { DENIS } \\
\text { DENIS } \\
\text { DENIS } \\
\text { DENIS }\end{array}$ & $\begin{array}{l}\text { HIPPEAU } \\
\text { HIPPEAU }^{\mathrm{c}} \\
\text { REYNAUD } \\
\text { BUCHNER }\end{array}$ & \\
\hline $\begin{array}{l}1879-81 \\
1881-82\end{array}$ & $\begin{array}{l}\text { JOLY } \\
\text { JOLY } 8\end{array}$ & $\begin{array}{l}\text { Gasté } \\
\text { GASTE }\end{array}$ & $\begin{array}{l}\text { DENIS } \\
\text { DENIS } \\
\text { Haussoulier }\end{array}$ & $\begin{array}{l}\text { BUCHNER }^{\mathrm{f}} \\
\text { BUCHNER }\end{array}$ & \\
\hline $1882-83$ & $\frac{\text { JOLY }}{\text { Charpy }}{ }^{\text {h }}$ & GASTE & $\begin{array}{l}\text { DENIS } \\
\text { Haussoulier }\end{array}$ & BUCHNER & \\
\hline $1883-84$ & $\frac{\text { JOLY }}{\text { Charpy }}$ & $\begin{array}{l}\text { GASTE }^{i} \\
\text { Mellerio }\end{array}$ & $\begin{array}{l}\text { DENIS } \\
\text { Auerbach } \\
\text { Faure }\end{array}$ & BUCHNER & \\
\hline $1884-85$ & $\begin{array}{l}\text { GASTE }^{j} \\
\text { Souriau }\end{array}$ & $\begin{array}{l}\text { LEHANNEUR } \\
\text { Plessis }{ }^{k}\end{array}$ & $\begin{array}{l}\text { DENIS }^{\mathrm{m}} \\
\text { Auerbach } \\
\text { Dorison }^{1}\end{array}$ & BUCHNER & \\
\hline $1885-86$ & $\begin{array}{l}\text { GASTE } \\
\text { Souriau }\end{array}$ & $\begin{array}{l}\text { LEHANNEUR } \\
\text { Plessis }\end{array}$ & $\frac{\text { DENIS }}{\text { Dorison }}$ & BUCHNER & \\
\hline $1887-88$ & $\begin{array}{l}\text { GASTE } \\
\text { Souriau }\end{array}$ & $\begin{array}{l}\text { LEHANNEUR } \\
\text { Plessis }\end{array}$ & $\frac{\text { DENIS }}{\text { Dorison }}$ & BUCHNER & \\
\hline 1888-91 & $\begin{array}{l}\text { GASTE } \\
\text { Souriau }\end{array}$ & LEHANNEUR & $\frac{\text { DENIS }}{\text { Dorison }}$ & BUCHNER & \\
\hline 1891-92 & $\begin{array}{l}\text { GASTE } \\
\text { Bédier }\end{array}$ & LEHANNEUR & $\begin{array}{l}\text { Durrbach } \\
\text { Dorison }\end{array}$ & BUCHNER & \\
\hline $92-93$ & $\begin{array}{l}\text { GASTE } \\
\text { Bédier }\end{array}$ & LEHANNEUR & $\begin{array}{l}\text { DURRBACH } \\
\text { Lemercier }\end{array}$ & BUCHNER & \\
\hline 393-94 & $\begin{array}{l}\text { GASTE } \\
\text { Chamard }\end{array}$ & LEHANNEUR & Lemercier & BUCHNER & Derroja $^{\mathrm{n}}$ \\
\hline 1894-95 & $\begin{array}{l}\text { GASTE } \\
\text { Chamard }\end{array}$ & LEHANNEUR & LEMERCIER & BUCHNER & Huguet $^{\circ}$ \\
\hline 1895-96 & $\begin{array}{l}\text { GASTE } \\
\text { Souriau }\end{array}$ & $\begin{array}{l}\text { LEHANNEUR } \\
\text { Chamard }\end{array}$ & LEMERCIER & BUCHNER & Huguet \\
\hline 96-97 & GASTE $P$ & $\begin{array}{l}\text { LEHANNEUR } \\
\text { Chamard }\end{array}$ & LEMERCIER & BUCHNER & Huguet \\
\hline
\end{tabular}

En 1897, création d'une chaire de littérature normande pour SOURIAU

*: "Littérature latine" est supprimée dès 1859 pour être rattachée à

"Littérature ancienne" jusqu'en 1883 où est recréée une chaire de

"Langue et littérature latines";

**: "Littérature grecque" devient "Littérature ancienne" en 1859 puis

"Langue et littérature grecques" en 1884. 


\section{NOTES SUR CAEN}

a : Intitulé du cours: "Histoire de la littérature française, depuis le XIIe siècle jusqu'à l'établissement de l'Académie Française".

b : Intitule du cours: "Commentaire des classiques italiens du XIVe siècle".

c : Cours: "La littérature italienne, depuis Charlemagne,jusqu'à la fin du XVe siècle".

d: Cours: "Histoire de la poésie française au moyen-âge".

e : En 1876/77: "Le thêâtre en France au moyen-âge".

f: En 1880/81: "Aperçu de la littérature anglaise depuis la fin du moyen-âge jusqu'à nos jours".

$\mathrm{g}$ : "Histoire de la comédie et de la satire au moyen-âge".

h : En 1882/83, Charpy, dont le cours inclut l'enseignement de la grammaire, annonce "Phonétique et morphologie" et "syntaxe"; de même en 1883/84.

i : La chaire de "Littérature latine", rebaptisce "Langue et littérature latines", comprend, entre autres, enseigné par Gasté, un "cours élémentaire de métrique latine".

j : En 1884/85, Gasté traite "Des origines de la littérature française jusqu'au XIIIe siècle"; et, en 1885/86, de la "Littérature française du XIIIe au XVIe siècle (...)".

k : Plessis, maître de conférences, est chargé de la grammaire latine; en 1885/86, il enseigne: "Syntaxe historique. Métrique latine; comparaison avec la métrique grecque".

1 : Dorison, maître de conférences en grammaire grecque, enseigne,en 1885/86 la "Syntaxe des cas. Cours de grammaire grecque".

m : "Variation de l'idiome et de l'esprit grecs depuis la pćriode alexandrine jusqu'à l'époque byzantine exclusivement"

n : Derroja, maître de conférences, assure des cours, entre autres, sur "la flexion verbale" et "la syntaxe des cas", dans sa conférencc de "Grammairc ct philologie" (1893 sq).

o : En "Grammaire et philologic", Huguet, maître de conférences, fait, en 1894/95: "Les pronoms dans les trois langues (...)"; en 1895/96: "L'infinitif (...)" et, en 1896/97: "La langue française au XVIIIe siècle".

p : Fait, entre autres, un cours sur "Villshardouin et Joinville" qui sont inscrits au programme de l'agrégation. 
CLERMONT - FERRAND

\begin{tabular}{|c|c|c|c|c|}
\hline & $\begin{array}{l}\text { Littérature } \\
\text { Française }\end{array}$ & $\begin{array}{l}\text { Littérature } \\
\text { Ancienne * }\end{array}$ & $\begin{array}{l}\text { Littér. } \\
\text { Grecque }\end{array}$ & $\begin{array}{l}\text { Littér. } \\
\text { Etrangère }\end{array}$ \\
\hline $1859-60$ & GRENIER & THUROT & & BARET \\
\hline $1862-66$ & DAMIEN & Siguier & & BARET \\
\hline $1866-68$ & DAMIEN & SIGUIER & & BARET $^{\text {a }}$ \\
\hline $1868-70$ & SIGUIER $^{b}$ & DAMIEN & & BARET \\
\hline $1871-73$ & SIGUIER $^{c}$ & DAMIEN & & BARET \\
\hline $1873-74$ & Pinguaud & DAMIEN & & Hanriot \\
\hline $1877-79$ & DES ESSARTS & DAMIEN & & DE GRISY \\
\hline $1879-81$ & DES ESSARTS $^{d}$ & DAMIEN & & SCHEURER \\
\hline $1881-82$ & DES ESSARTS & DAMIEN & Boully & SCHEURER \\
\hline $1882-83$ & $\begin{array}{l}\text { DES ESSARTS } \\
\text { Dorison }^{\mathrm{e}}\end{array}$ & $\begin{array}{l}\text { DAMIEN } \\
\text { Brenous ** }\end{array}$ & Roy & SCHEURER \\
\hline $1883-84$ & $\begin{array}{l}\text { DES ESSARTS } \\
\text { Allais }\end{array}$ & $\begin{array}{l}\text { LEHANNEUR } \\
\text { Brenous }\end{array}$ & Roy & SCHEURER \\
\hline $1884-85$ & $\begin{array}{l}\text { DES ESSARTS } \\
\text { Allais } \mathrm{f} \\
\text { Leclerc }\end{array}$ & $\begin{array}{l}\text { LEHANNEUR } \\
\text { Brenous }\end{array}$ & Roy & SCHEURER \\
\hline $1885-86$ & $\begin{array}{l}\text { DES ESSARTS } \\
\text { Allais } \\
\text { Leclerc }\end{array}$ & $\begin{array}{l}\text { Dosson } \\
\text { Fournier }\end{array}$ & Colardeau & SCHEURER \\
\hline $1886-87$ & $\begin{array}{l}\text { DES ESSARTS } \\
\text { Allais } \\
\text { Leclerc }\end{array}$ & Dosson & Durrbach & SCHEURER \\
\hline $1887-88$ & $\begin{array}{l}\text { DES ESSARTS } \\
\text { Allais } \\
\text { Leclerc } 8\end{array}$ & Dosson & Baron & SCHEURER \\
\hline $1888-89$ & $\begin{array}{l}\text { DES ESSARTS } \\
\text { Allais } \\
\text { Leclerc }\end{array}$ & DOSSON & Baron & SCHEURER \\
\hline $1889-92$ & $\begin{array}{l}\text { DES ESSARTS } \\
\text { Allais } \\
\text { Leclerc }\end{array}$ & DOSSON & Baron & Erhard \\
\hline $1892-93$ & $\begin{array}{l}\text { DES ESSARTS } \\
\text { ALLAIS } \\
\text { Leclerc }\end{array}$ & DOSSON & Baron & Erhard \\
\hline $1893-94$ & $\frac{\text { DES ESSARTS }}{\text { Leclerc }}$ & Audollent & Baron & Erhard \\
\hline $1894-95$ & $\begin{array}{l}\text { DES ESSARTS } \\
\text { Leclerc }\end{array}$ & Audollent & BARON & Erhard \\
\hline $1895-96$ & $\begin{array}{l}\text { DES ESSARTS } \\
\begin{array}{l}\text { Colardeau } \\
\text { Leclerc }^{\mathrm{h}}\end{array}\end{array}$ & Audollent & BARON & Erhard \\
\hline $1896-97$ & $\begin{array}{l}\text { DES ESSARTS } \\
\text { Colardeau } \\
\text { Leclerc }\end{array}$ & Audollent & BARON & $\begin{array}{l}\text { Erhard } \\
\text { Mahieu }^{\text {i }}\end{array}$ \\
\hline
\end{tabular}




\section{NOTES SUR CLERMONT-FERRAND}

a:"Le professeur traitera de l'épopéc chevaleresque, particulièrement en Espagne et en Italie".

b : "Le professeur étudiera l'éloquence politique de la France du XIVe jusqu'au XVIIe".

c : "Le mardi, le professeur étudicra l'éloquence religieuse de la France pendant le moyen-âge".

d : En 1880/81: "M. Des Essarts, professcur, ćtudicra l'histoire de la poésie française au moyen-âge"; en 1881/82, il "exposcra l'histoirc de la poćsie en France, depuis la seconde moitié du XIIIe jusqu'au commencement du XVIe".

e : L'enseignement de Dorison est plus spécialement consacré à la grammaire.

f: Une conférence de "Grammaire" est créćc en 1883, pourvue en 1884 par Leclerc, puis en 1895 par Colardeau après qu'clle a été rebaptisćc en 1886: "Grammaire et métrique".

g : Le cours de Leclerc, défini comme "cours de grammaire pour l'agrégation et la licence ès-lettres", traite des "adjectifs, pronoms, verbes, conjugaisons et diverses propositions" en $1887 / 88$, des "diverses propositions" en $88 / 89$ et $89 / 90$, "des particules invariables" en 90/91, de la "phonétique grecque, latine et française. Parties du discours,commencement." en 91/92 et, en 92/93 et 93/94, des "parties du discours (suite)".

h : A partir de 1895/96, Leclerc fait un cours libre sous l'intitulé: "Langue et littérature du moyen-âge".

i : Mahieu assure des conférences en "Langue el littćrature anglaises". 


\section{DIJON}

\begin{tabular}{|c|c|c|c|c|c|}
\hline & $\begin{array}{l}\text { Littérature } \\
\text { Française }\end{array}$ & $\begin{array}{l}\text { Littér. }{ }^{*} \\
\text { Ancienne }\end{array}$ & $\begin{array}{l}\text { Littér. } \\
\text { Latine }\end{array}$ & $\begin{array}{l}\text { Lingui- } \\
\text { stique }\end{array}$ & $\begin{array}{l}\text { Littérature } \\
\text { Etrangère }\end{array}$ \\
\hline $1853-54$ & LODIN DL ${ }^{\circ}$ & \multicolumn{3}{|l|}{$\underline{\text { STIEVENART }}$} & BENLOEW \\
\hline $1856-57$ & LODIN DL ${ }^{a}$ & \multicolumn{3}{|c|}{$\underline{\text { STIEVENART }}$} & BENLOEW ${ }^{b}$ \\
\hline $1859-62$ & Aubertin & \multicolumn{3}{|l|}{ BENLOEW ${ }^{c}$} & BORE $^{d}$ \\
\hline $1863-70$ & AUBERTIN $^{\mathrm{d}}$ & \multicolumn{3}{|l|}{ BENLOEW } & BORE \\
\hline $1871-72$ & $\begin{array}{l}\text { AUBERTIN } \\
\text { Tivier }^{e}\end{array}$ & \multicolumn{3}{|l|}{$\underline{\text { BENLOEW }}$} & Jeannel $^{\mathrm{f}}$ \\
\hline $1872-74$ & $\begin{array}{l}\text { AUBERTIN } \\
\text { Des Essarts }\end{array}$ & \multicolumn{3}{|l|}{ BENLOEW } & Hallberg \\
\hline $\begin{array}{l}1874-77 \\
1877-79 \\
1879-80 \\
1880-82\end{array}$ & $\begin{array}{l}\text { PT DE J }{ }^{\circ} 8 \\
\text { PT DE J } \\
\text { AUBERTIN }{ }^{\mathrm{i}} \\
\text { AUBERTIN }\end{array}$ & $\begin{array}{l}\text { BENLOEW } \\
\text { Hinstin } \\
\text { Hinstin } \\
\text { BOUGOT }\end{array}$ & \multirow{7}{*}{$\begin{array}{l}\text { Bougot } \\
\text { Bougot } \\
\text { Royer } \\
\text { Martha }^{j} \\
\text { ROYER } \\
\text { ROYER }{ }^{1} \\
\text { Noël } \\
\text { Cucuel } \\
\text { ROYER } \\
\text { Cointe } \\
\text { Durand } \\
\text { ROYER } \\
\text { Durand } \\
\text { Lapierre } \\
\text { ROYER } \\
\text { Macé } \\
\text { ROYER } \\
\text { Dottin }{ }^{\mathrm{m}} \\
\text { ROYER }\end{array}$} & & $\begin{array}{l}\text { HALLBERG }{ }^{\mathrm{h}} \\
\text { HALLBERG } \\
\text { D'HUGUES } \\
\text { D'HUGUES }\end{array}$ \\
\hline $\begin{array}{l}1882-84 \\
1884-86\end{array}$ & $\begin{array}{l}\text { AUBERTIN } \\
\text { AUBERTIN } \\
\text { Lame }\end{array}$ & $\begin{array}{l}\text { BOUGOT } \\
\underline{\text { BOUGOT }}^{k}\end{array}$ & & & $\begin{array}{l}\text { D'HUGUES } \\
\text { D'HUGUES }\end{array}$ \\
\hline $1886-87$ & $\begin{array}{l}\text { AUBERTIN } \\
\text { Lame }\end{array}$ & BOUGOT & & & D'HUGUES \\
\hline $1887-88$ & $\begin{array}{l}\text { AUBERTIN } \\
\text { Lame }\end{array}$ & BOUGOT & & & D'HUGUES \\
\hline $1888-91$ & \multirow{3}{*}{$\begin{array}{l}\text { AUBERTIN } \\
\text { Lame } \\
\text { AUBERTIN } \\
\text { Lame } \\
\text { AUBERTIN }\end{array}$} & BOUGOT & & & D'HUGUES \\
\hline $1891-92$ & & BOUGOT & & & D'HUGUES \\
\hline 1893-94 & & DORISON & & GRAMMONT & T'HUGUES \\
\hline $1895-96$ & \multirow{2}{*}{$\begin{array}{l}\text { Lame } \\
\text { Royo } \\
\text { Lame } \\
\text { Roy } \\
\text { Lame }\end{array}$} & DORISON & ROYER & Lambert $^{p}$ & \multirow[t]{2}{*}{ D'HUGUES } \\
\hline 1896-97 & & DORISON & ROYER & Lambert & \\
\hline \multicolumn{6}{|c|}{$\begin{array}{l}\text { * :"Littérature ancienne" devient "Littérature grecque" en } 1877 \text { lorsqu'une } \\
\text { chaire de "littérature latine" en permet le dédoublement. }\end{array}$} \\
\hline \multicolumn{6}{|c|}{ ॰: "LODIN DL" = "LODIN DE LALAIRE" } \\
\hline \multicolumn{6}{|c|}{ : "PT DE J “ = "PETIT DE JULEVILLE”) } \\
\hline
\end{tabular}




\section{NOTES SUR DIJON}

a : Cours: "Continuation de l'histoire critique des lettres françaises depuis l'origine jusqu'à l'établissement de l'Académie".

b : Annonce, entre autres: "Chaque jeudi sera consacré à la grammaire comparée".

c : En occupant la chaire de "littératurc ancienne", Benlocw y adjoint un cours de grammaire comparée où il enseigne,en 1859/60: "Le français dans ses rapports avec le grec,le latin et le sanscrit; explication du Nalus et de quelques hymnes du Rig-Véda et du Sama Véda. En 1863/64, il fait un "Cours élćmentairc de sanscrit, comparaison de cette langue avec nos trois langues classiques" et, à partir de 1864/65, il renonce à ce cours.

d : En 1863/64, Boré traite "De la formation des littératures européennes au moyen-âge, particulièrement en Allemagne et en Angletcrre". En 1868/69, Aubertin se consacre à l'"Histoire de la satire en France au moyen-âge".

e : Tivier, chargé de cours: "De la poćsic dramatique en France, depuis ses origines jusqu'à nos jours".

f : Jeannel, chargé de cours: "Les origines de la littćraturc italienne".

g : Petit de Juleville, professeur, enseigne en 1874/75: "De l'épopée française au moyen-âge", en 1875/76: "Histoirc du théâtrc cn France", en 1878/79, entre autres: "les mardis, à quatre heures, histoire de la languc française"(au premier semestre) et "histoire de la langue française,du XIVe au XVIIc sic̀cle" (au second semestre).

h : En 1876/77, Hallberg traite de "l'ćpopćc chrétienne dans les littératures étrangères".

i : Aubertin devient professeur de "littérature française" au second semestre de l'année 1879/80, Aulard ayant occupé la chaire au titre de chargé de cours pendant le premier semestre. En 1881/82, Aubertin traite de l'"Histoire de la littérature française depuis les origines jusqu'au siècle de Louis XIV" (premier semestre) et de "La poésie épique et l'histoire au moyen-âge"' (second semcstrc).

En 1886/87, c'est, au premier semestre, "La question des origines de la poésie hérö̈que française au moyen-âge" et,en 1888/89 ct 1889/90, au second semestre, "Les origines,les principes et les règles de la versification française".

j : Martha n'est chargé de cours en "littérature grecque" que pendant l'année 1881/82. 
k : Bougot, qui devient doyen en 1884, annonce des "conférences de métrique".

1 : En 1884/85, Royer annonce: "Formation de la langue latine".

m : En "conférence de grammaire et métrique", "M. Dottin, jeudi à neuf heures, la déclinaison dans les dialectes grecs. Vendredi à huit heures et demie: métrique. Samedi à huit heures et demic: exercices pratiques de syntaxe latine.Jeudi, à cinq heures, grammaire comparée du gothique et du vicux haut-allemand".

$\mathrm{n}$ : La conférence de "linguistique" est annoncée comme s'il s'agissait d'une chaire future. Pourvue au deuxième semcstre de 1892/93 par Grammont, maître de conférences,elle est consacrée à "La déclinaison et la conjugaison sanscrites comparées à celles du grec, du latin, du gothique el du gaulois. Explication de l'ćpisode du Mahabharata connu sous le nom de L'enlèvement de Draupadi".

En 1893/94, Grammont annonce "Phonćtique ct morphologie du lithuanien modeme" (au premier semestre) et"Explication de textes lituaniens" (au second semestre).

En 1894/95, il traite de "Phonćtique et morphologic comparées du gotique; explication de textes gotiques" sous le couvert d'unc chaire de linguistique à créer et, au titre d'une "conférence de grammaire et métrique": "Phonćtique du grec et du latin. Composition et dérivation en grec et en latin (...)".

A partir de 1895/96, il n'y a plus de "linguistique".

0 : En cours de licence, Roy traite, entre autres, de l'“'Origine du français: les dialectes".

p : Au deuxième semestre de 1895/96, Lambert assure un cours libre de sanscrit avec "Explication du Mahabharata;en 1896/97, au premier semestre, ce cours est devenu une conférence ouverte "Explication du Ve acte de Sakuntala" par opposition avec la conference pour l'agrégation de grammaire du même Lambert où il est question de la "Syntaxe de la proposition en grec el en latin. Le verbe grec et le verbe latin (...) Phonétique du français." Au second semestrc, la chaire de littérature étrangère n'est plus pourvue et, à la place, est porté "Philologie"; Lambert y annonce: "Sanscrit: Ve acte de Sakountala (...) Syntaxe grecque et latine."; "Prosodie et métrique";"Fragments de Villehardouin et de Joinville (explication grammaticale)". Le fait que le recteur de l'académic fut Bizos a pu joucr dans l'implantation d'enseignements si spécialisés. 


\section{GRENOBLE}

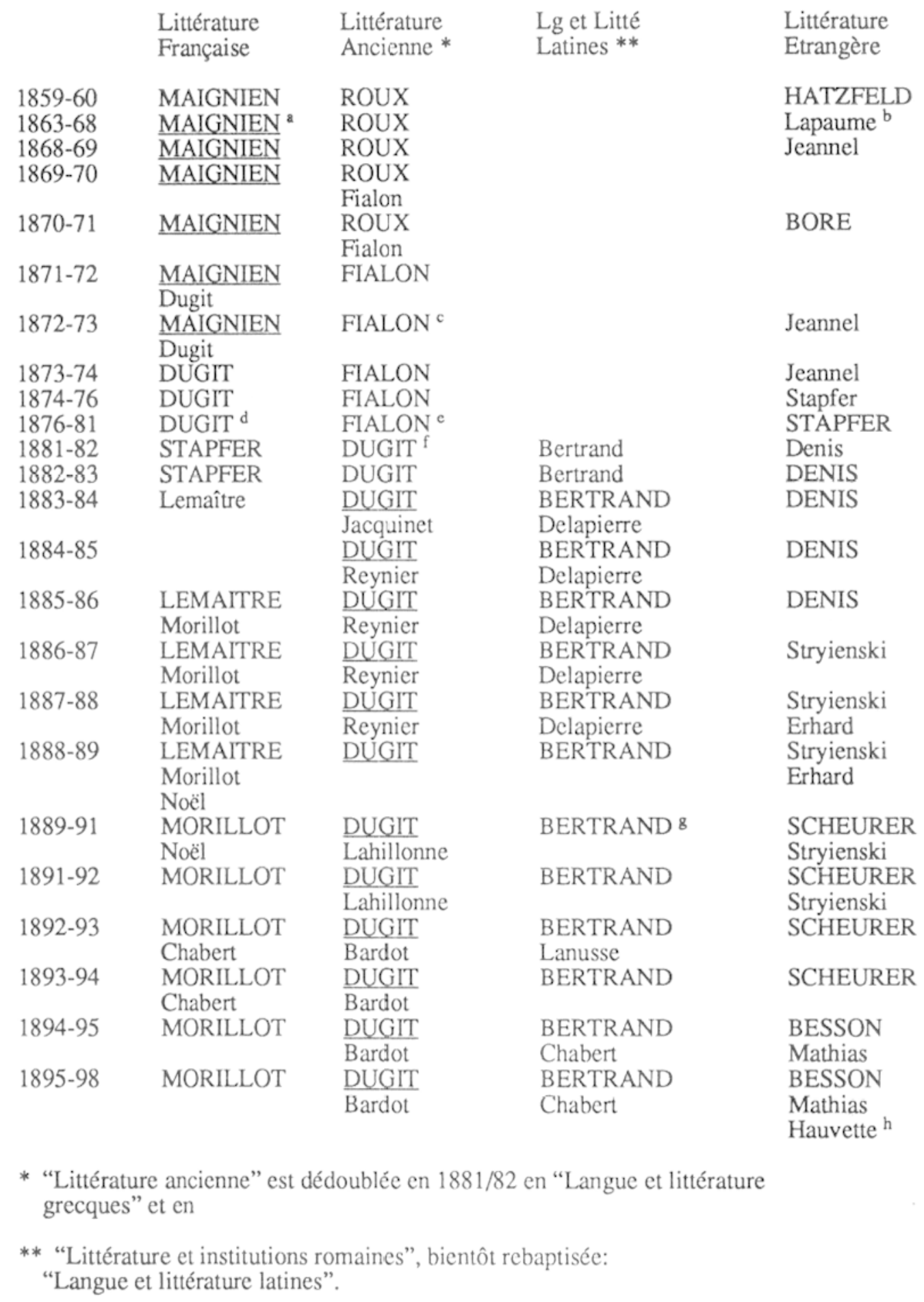




\section{NOTES SUR GRENOBLE}

a : En 1864/65, "M. Maignien, professeur, doyen de la faculté fera un tableau de la littérature française à partir de son origine jusqu'au XVIe siècle".

b : En 1863/64, "M. Lapaume, professeur, chargé du cours, appréciera, le mardi, l'influence du thêâtre espagnol sur le premier âge de la scène française; le jeudi, il comparera les Autos de Calderon avec nos mystères en langue d'oíl du XVe siècle".

c : Au deuxième semestre, "M. Fialon, professcur, ćtudiera:(...) le vendredi, la grammaire comparée (déclinaison et conjugaison dans les langues sanscrite, grecque et latine (...)".

d : En 1880/81, "M. Dugit, professcur, ćtudicra l'histoire de la langue française".

e : En 1879/80 et en $1880 / 81$, Fialon annonce, dans ses conférences, de la "grammaire comparée", sans plus de précision.

f : En 1881/82, au premier semestre, Dugit annonce entre autres de la "grammaire comparée".

g: "M. Bertrand, professeur: origine de la langue et de la littérature latines".

h : A partir de 1895/96, Hauvette ouvre un cours libre d'italien. 


\section{LILLE}

\section{( et DOUAI )}

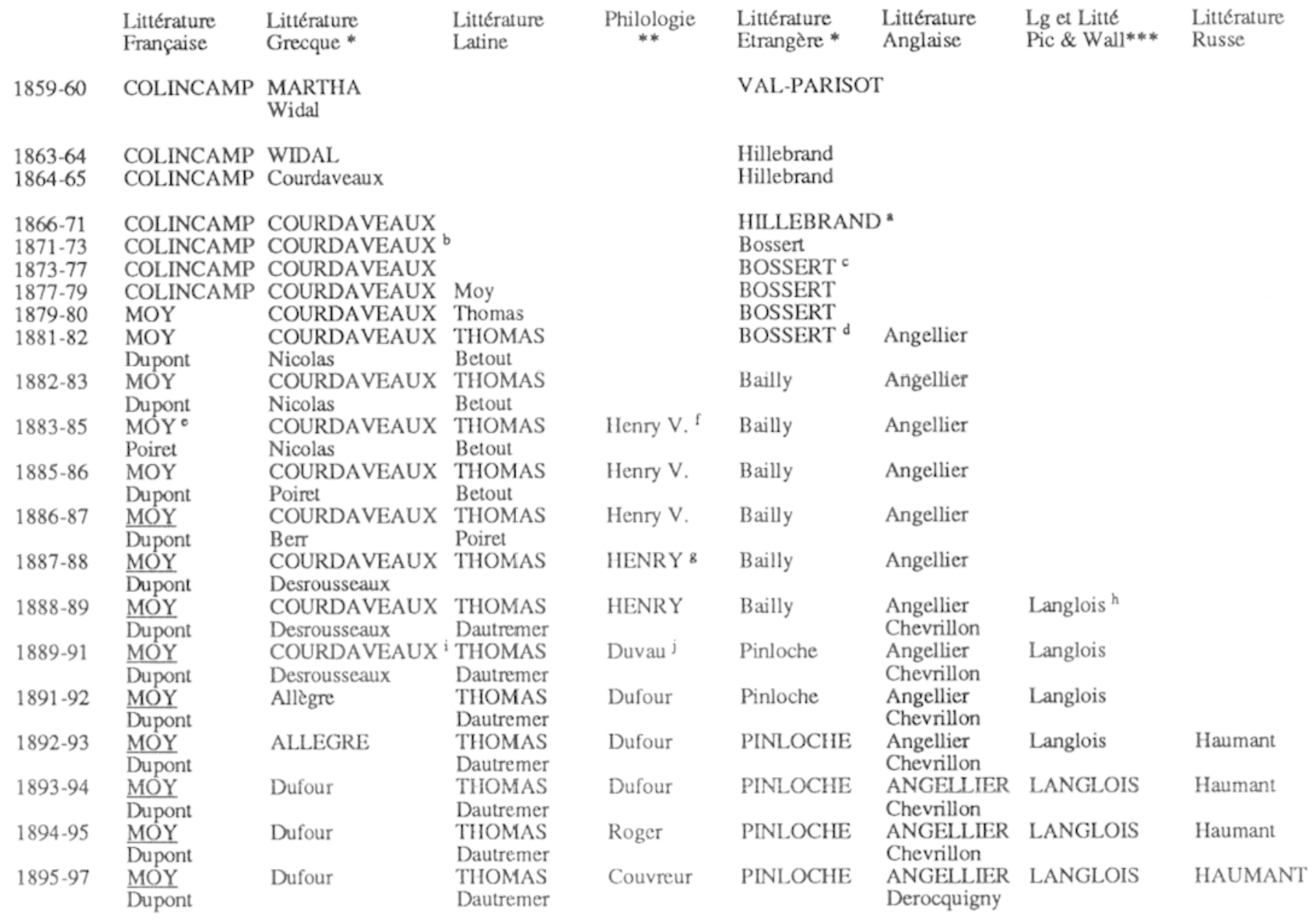

* : La chaire de "Littérature ancienne", dédoublée en 1877 en "Littérature grecque" et "Littérature latine";

** : Conférence de "Philologie et grammaire comparée" élevéc au rang de chaire en 1877 et rebaptisée conférence de "Philologie grecque et latine" en 1889.

***: "Langue et littérature picarde et wallone "-à partir de 1888- 


\section{NOTES SUR LILLE (et DOUAI)}

a : "M. Hillebrand, professeur, fera le mercredi l'histoire du thêâtre italien, depuis ses origines jusqu'à nos jours" en 1867/68 et, en 1869/70, “l'histoire de la langue allemande (...), l'histoire de la langue anglaise". En 1870/71, l'affiche indique: "L'ouverture de ce cours sera annoncée ultérieurement". Hillebrand, citoyen allemand, a été mis à la retraite d'office au début de la guerre: il y demeurera après les hostilités.

b : En 1871/72, “M. Courdaveaux, professcur, ćtudiera le lundi Les épopées indiennes".

c : En 1874/75, au second semestre, "M. Bossert, professcur,continuera le mercredi l'histoire comparée des littératures modernes. -Les poésies des Troubadours, les poêmes du Renard, etc."

d : Bossert annonce l'étude de "quelques pages détachées de Curtius".

e : Moy annonce, entre autres, l'étude de Joinville et de Chanson de Roland.

f : En "philologie et grammaire comparée", Victor Henry annonce entre autres: "Phonétique générale" et "le vendredi soir: cours public de sanskrit: élćments de grammaire sanskrite, notions générales d'histoire littéraire. Exercices de traduction." en 1883/84;

en 1885/86, "Etude approfondic de la déclinaison nominale et pronominale en grec et en latin (...)" avec un "N.B. (...) Eventuellement, conférence facultative de langue et de littérature sanscrites." Jusqu'à 1888, V. Henry renonce ensuite à enseigner le sanscrit, s'occupant exclusivement de grammaire ct d'ćtymologie du grec et du latin.

En 1888/89, il annonce entre autres: "La prosodie grecque et latine étudiée dans ses origines étymologique ct grammaticale" el "Langue et littérature sanscrites étudiées dans leurs rapports avec les langues et les littératures de l'Occident",au premier semestre et, au second semestre, "Phonćtique grecque ct latine" et "L'accent et le rythme dans les langues indo-curopécnnes".

Il est ensuite appelé à remplacer son maître Bergaigne à la Sorbonne.

g : V. Henry, nommé professeur adjoint, assure les cours de grammaire du grec avec Desrousseaux qui fait aussi ceux de grammaire latine. 
$\mathrm{h}$ : Entre autres, Langlois annonce "Grammairc comparce des dialectes wallons, picards et français" et "Le théâtre au moyen-âge, dans la région picarde et wallonne" en 1888/89; en 1891/92, c'est, avec l'"Explication des auteurs français du moyen-âge", un "Cours public de littérature picarde et wallonne. Histoire de la littérature en langue d'oïl depuis ses origines jusqu'à la Renaissance." et,

en 1894/95, "Les Fabliaux. Origine des contes et légendes", "Formation des dialectes français, picard et wallon" et "Origines et histoirc du thćâtre dans la France du Nord".

En 1895/96, c'est l'"Histoire du théâtre comique dans le nord de la France avant la Renaissance".

i : En 1889/90, Courdaveaux annonce unc conférence ouverte sur l" "Histoire de la prononciation grecque".

$\mathrm{j}$ : Il ne s'agit plus désormais que de conférences de grammaire pour l'agrégation (cf Dufour en 1893/94 qui assure ces conférences el fail les cours de littérature grecque en même temps). 


\section{LYON}

\begin{tabular}{|c|c|c|c|c|c|c|c|c|}
\hline & $\begin{array}{l}\text { Littérature } \\
\text { Française }\end{array}$ & $\begin{array}{l}\text { Lg et Litté } \\
\text { Latines }\end{array}$ & $\begin{array}{l}\text { Lg et Litté } \\
\text { Grecques* }\end{array}$ & $\begin{array}{l}\text { Littérature } \\
\text { Etrangère ** }\end{array}$ & $\begin{array}{l}\text { Lg et Litté } \\
\text { Fse du MA }\end{array}$ & $\begin{array}{l}\text { Langues } \\
\text { Orientales }\end{array}$ & $\begin{array}{l}\text { Lg et Litté } \\
\text { sanskrites }\end{array}$ & $\begin{array}{l}\text { Littérature } \\
\text { Anglaise }\end{array}$ \\
\hline $1859-60$ & DE LAPRADE & DEMONS & & Heinrich & & & & \\
\hline $1863-64$ & PHILIBERT-S ${ }^{\circ}$ & DEMONS & & HEINRICH & & & & \\
\hline $1864-65$ & PHILIBERT-S & $\begin{array}{l}\text { DEMONS } \\
\text { Hignard }\end{array}$ & & HEINRICH & & & & \\
\hline $\begin{array}{l}1866-67 \\
1867-70\end{array}$ & $\begin{array}{l}\text { PHILIBERT-S } \\
\text { PHILIBERT-S }^{b}\end{array}$ & $\begin{array}{l}\text { Hignard } \\
\text { HIGNARD }\end{array}$ & & $\begin{array}{l}\text { HEINRICH }{ }^{2} \\
\text { HEINRICH }\end{array}$ & & & & \\
\hline $\begin{array}{l}1875-79 \\
1879-80\end{array}$ & $\begin{array}{l}\text { PHILIBERT-S } \\
\text { PHILIBERT-S }\end{array}$ & $\begin{array}{l}\text { HIGNARD } \\
\text { HIGNARD } \\
\text { Dauriac }\end{array}$ & $\begin{array}{l}\text { ClAVEL } \\
\text { CLAVEL }\end{array}$ & $\begin{array}{l}\text { HEINRICH } \\
\text { HEINRICH }\end{array}$ & $\begin{array}{l}\text { Clédat }{ }^{\mathrm{c}} \\
\text { Clédat }\end{array}$ & Lefébure $^{\circ}$ & Régnaud d & \\
\hline $\begin{array}{l}1881-82 \\
1882-83\end{array}$ & $\begin{array}{l}\text { PHILIBERT-S } \\
\text { PHILIBERT-S }\end{array}$ & $\begin{array}{l}\text { FONTAINE } \\
\text { FONTAINE }\end{array}$ & $\begin{array}{l}\text { CLAVEL } \\
\text { CLAVEL } \\
\text { Leconte }\end{array}$ & $\begin{array}{l}\text { HEINRICH } \\
\text { HEINRICH }\end{array}$ & $\begin{array}{l}\text { Clédat } \\
\text { Clédat }\end{array}$ & & $\begin{array}{l}\text { Régnaud } \\
\text { Régnaud }\end{array}$ & \\
\hline $1883-84$ & PHILIBERT-S & $\begin{array}{l}\text { FONTAINE } \\
\text { Jullien/Bru- } \\
\text { not/Leconte }\end{array}$ & $\begin{array}{l}\text { CLAVEL } \\
\text { Martha }\end{array}$ & HEINRICH & Clédat & [Lefébure] & Régnaud & Quatrevaux \\
\hline $1884-85$ & FONTAINE & $\begin{array}{l}\text { Lafaye } \\
\text { Jullien/Bru- } \\
\text { not/Leconte }\end{array}$ & $\begin{array}{l}\text { CLAVEL } \\
\text { Martha } \\
\text { Allegre }\end{array}$ & $\frac{\text { HEINRICH }}{\text { Anstett }}$ & Clédal & Montet ${ }^{f}$ & Régnaud & Quatrevaux \\
\hline $1885-86$ & FONTAINE & $\begin{array}{l}\text { LAFAYE } \\
\text { Jullien } \\
\text { Brunot }\end{array}$ & $\begin{array}{l}\text { CLAVEL } \\
\text { Cucuel } \\
\text { Allegre }\end{array}$ & $\frac{\text { HEINRICH }}{\text { Anstett }}$ & CLEDAT $\mathbf{8}$ & $\begin{array}{l}\text { Montet } \\
\text { Loret }^{h}\end{array}$ & Régnaud & Legouis \\
\hline $1886-87$ & FONTAINE & $\begin{array}{l}\text { LAFA YE } \\
\text { Jullien } \\
\text { Brunot }\end{array}$ & $\begin{array}{l}\text { CLAVEL } \\
\text { Cucuel } \\
\text { Allegre }\end{array}$ & $\frac{\text { HIIINRICHI }}{\text { Anstett }}$ & CLEDAT & $\begin{array}{l}\text { Montet } \\
\text { Loret }\end{array}$ & REGNAUD ${ }^{i}$ & Legouis \\
\hline $1887-88$ & $\begin{array}{l}\text { FONTAINE } \\
\text { Brunot }{ }^{k}\end{array}$ & $\begin{array}{l}\text { LAFAYE } \\
\text { Jullien }\end{array}$ & $\begin{array}{l}\text { CLAVEL } \\
\text { Cucuel } \\
\text { Allegre }\end{array}$ & $\begin{array}{l}\text { Firmery } \\
\text { Gruber }\end{array}$ & CLEDAT & $\begin{array}{l}\text { Montet } \\
\text { Loret }\end{array}$ & REGNAUD & Legouis \\
\hline $1888-89$ & $\begin{array}{l}\text { FONTAINE } \\
\text { Brunot }\end{array}$ & $\begin{array}{l}\text { LAFAYE } \\
\text { Jullien/D }{ }^{\circ \circ}\end{array}$ & $\begin{array}{l}\text { CLAVEL } \\
\text { Allegre }\end{array}$ & $\begin{array}{l}\text { Firmery } \\
\text { Gruber }\end{array}$ & CLEDAT & $\begin{array}{l}\text { Montet } \\
\text { Loret }\end{array}$ & REGNAUD & Legouis \\
\hline 1889-91 & $\begin{array}{l}\text { FONTAINE } \\
\text { Brunot }\end{array}$ & $\begin{array}{l}\text { LAFAYE } \\
\text { Jullien/D }\end{array}$ & $\begin{array}{l}\text { CLAVEL } \\
\text { Allègre }\end{array}$ & $\begin{array}{l}\text { FIRMERY } \\
\text { Gruber }\end{array}$ & CLEDAT & Loret & REGNAUD & Legouis \\
\hline 1891-92 & $\begin{array}{l}\text { FONTAINE } \\
\text { Brunot }\end{array}$ & $\begin{array}{l}\text { JULLIEN } \\
\text { Plessis/D }\end{array}$ & $\begin{array}{l}\text { CLAVEL } \\
\text { Allègre }\end{array}$ & $\begin{array}{l}\text { FIRMERY } \\
\text { Gruber }\end{array}$ & CLEDAT & Loret & REGNAUD & Legouis \\
\hline $1892-93$ & $\begin{array}{l}\text { FONTAINE } \\
\text { Texte/D }\end{array}$ & $\begin{array}{l}\text { JULLIEN } \\
\text { Plessis/D }\end{array}$ & $\begin{array}{l}\text { CLAVEL } \\
\text { Legrand }\end{array}$ & $\begin{array}{l}\text { FIRMERY } \\
\text { Gruber }\end{array}$ & CLEDAT & Loret & REGNAUD & Legouis \\
\hline 1893-95 & $\begin{array}{l}\text { FONTAINE } \\
\text { Texte }\end{array}$ & $\begin{array}{l}\text { JULLIEN } \\
\text { FABIA/D }\end{array}$ & $\begin{array}{l}\text { ALLEGRE } \\
\text { Legrand }\end{array}$ & $\begin{array}{l}\text { FIRMERY } \\
\text { Gruber }\end{array}$ & CLEDAT & Loret & REGNAUD & Legouis \\
\hline $1895-96$ & $\begin{array}{l}\text { FONTAINE } \\
\text { TEXTE }\end{array}$ & $\begin{array}{l}\text { JULLIEN } \\
\text { FABIA/D }\end{array}$ & $\begin{array}{l}\text { ALLEGRE } \\
\text { Legrand }\end{array}$ & $\begin{array}{l}\text { FIRMERY }{ }^{n} \\
\text { Gruber }\end{array}$ & CLEDAT & Loret & REGNAUD & Legouis \\
\hline $1896-97$ & $\begin{array}{l}\text { FONTAINE } \\
\text { TEXTE }\end{array}$ & $\begin{array}{l}\text { JULLLIEN } \\
\text { FABIA }\end{array}$ & $\begin{array}{l}\text { ALLEGRE } \\
\text { Bourguet }\end{array}$ & $\begin{array}{l}\text { FIRMERY } \\
\text { Gruber }\end{array}$ & CLEDAT & Durand $* * *$ & REGNAUD & Legouis \\
\hline
\end{tabular}

\footnotetext{
${ }^{\circ}$ : PHILIBERT-SOUPE $\quad 0^{\circ}$ : Durand
}

* : "Littérature ancienne" est dédoublée en 1876 en "Langue et littérature latines" et "Langue et littérature grecques"

** : Devient: “Langue et littérature allemandes" en 1887

***: La conférence de Durand est en "grammaire comparée" et remplace,de facto, celle de Loret en "Langues orientales". 


\section{NOTES SUR LYON}

a : Heinrich annonce entre autres en 1866/67 qu' "il exposera,dans une conférence, la grammaire comparée des langues indo-europécnnes, d'après les ouvrages de Bopp et de Schleicher";

au deuxième semestre de 1875/76, dans une "conférence de grammaire comparée", "Classification des langues aryennes.Etude des racines, de l'étymologie, de la dérivation. Phonétique des langues classiques et des langucs romanes.Formation de la vieille langue française". Sous le même intitulé de "grammaire comparée", Heinrich annonce en 1876/77: "Grammaire générale des langues romanes considérées dans leurs rapports avec le latin. Révision, au point de vue des méthodes philologiques modernes, de la grammaire française" ct,

en 1877/78: "Classification des langucs de l'Europe. Principes généraux de l'étymologie, de la dérivation. Etude générale des langues germaniques."

b : En 1868/69, Philibert-Soupé "commencera l'histoire de la littérature en France au moyen-âge, depuis ses origines",ct, en 1869/70, "il étudiera les progrès de la prose et de la poésie françaises depuis la Ière Croisade jusqu'à la mort de Saint-Louis".

c : "Langue et littérature françaiscs du moyen-âge" est désigné comme "cours complémentaire".

En 1876/77,"M.Clédat, archiviste-palćographe, membre de l'Ecole Française de Rome, chargé du cours, traitera de la littératurc provençale et spécialement des poésies de Bertrand de Born" tout en assurant unc conférence sur l'"Etude de la grammaire de la vieille langue française";

en $1877 / 78$, Clédat fait "l'exposition de la grammaire historique et l'étude des plus anciens textes de la langue française";

en 1879/80, c'est l'"étude des épopées françaises du moyen-âge" et de "quelques anciens textes français";

en 1882/83, Clédat enseigne la "Grammairc historique de la langue française" et il étudie, à partir du second semestre, la Chanson de Roland.

Les années suivantes, il remplace cctıc ćpopéc par quelques auteurs du moyen-âge.

d : En 1879/80, il est annoncé que Régnaud "fera une leçon de grammaire comparée", qu"'il exposera les éléments de la grammairc sanscrite" ct les "institutions civiles et religieuses de l'Inde d'après les lois de Manou"; 
en 1882/83,"M. Régnaud, maître de conférences, traitera de la langue et de la littérature sanscrites" en assurant, en outre, une conférence de grammaire comparée et une de grammaire historique du grec et du latin";

en 1883/84, c'est l'"'Etude grammaticale de la langue et histoire de la littérature sanscrite", de même en 1885/86.

e : En 1879/80, Lefébure, maître de conférences, "traitera de la grammaire égyptienne" avant de partir en mission en Egypte. A son retour, il se consacre à l'enseignement de l'archéologie, dispensant néanmoins un cours sur l'égyptien avec des "Notions de grammaire et explication de textes" en 1883/84. Son enseignement est supprimé à la rentrée de l'automne 1884, avant d'être confić à Lorct.

f : En 1884/85, Montet traite de la "grammairc comparće de l'arabe littéral et vulgaire"; en 1887/88, de la "Grammaire comparće des langues sémitiques. Grammaire chaldaïque, syriaque, arabe (...)". Cet enseignement est supprimé à partir de 1889/90.

g : Clédat, qui est nommé professeur cettc annćc-là, annonce un cours sous le même intitulé, mot pour mot, que sa conférence de l'annće précédente.

Il annonce pour 1889/90: "Philologie française et provençale" et, les années suivantes, "Grammaire historique du français", enscignement complété par des "exercices pratiques de paléographie latine, française et provençalc"; lc cours est reformulé en "Morphologie historique du français" en 1895/96 et en "Phonćtique historique du français" en 1896/97, Clédat poursuivant ses cours de palćographie et assurant en permanence un enseignement pour la licence et l'agrégation.

h : A partir de 1885/86, Loret dispense un enseignement d'égyptologie qu'il consacre, en 1887/88 à l"“Ecriture et grammaire ćgypticnne".

i : Nommé professeur à la rentrće de 1886, Régnaud annonce en 1887/88 un "Exposé des principes de la grammaire sanscrite. Explication de textes empruntés au manuel de $\mathbf{M}$. Bergaigne, au Rasikajivana ct à la Pancadaci”, reprenant cet intitulé jusqu'en 1891/92 où il annonce: "Exposés des principes de la grammaire sanscrite d'après Whitney", complétant son enseignement en 1894/95 avec l'étude de "la mythologie védique "et, en 1895/96, avec une présentation de "la littératurc sanscrite", reformulée en 1896/97 "Littérature sanscrite et explication du Mahabharata". Régnaud assure de plus des cours de "syntaxe comparée du grec et du latin" de 1884 à 1886.

j : En 1887/88, Cucuel fait un cours sur la "Syntaxe comparée du grec et du latin". 
k : En 1887/88, Brunot assure, en parallèle avec Clćdat, une conférence sur la "Grammaire historique de la langue française" qu'il reconduit l'année suivante avant de préciser :

en 1889/90: "Formation de la langue classique. Les origines de l'Académie. La grammaire dans les salons et à la cour. Les philologues: Vaugelas, Chapelain, etc. Ensemble de la réforme."

En 1890/91, "M. Brunot, chargé de cours,étudiera l'histoire de la langue française" et, en 1891/92: "M. Brunot, docteur ès-lettres, chargé de cours, étudiera les origines de la langue française classique". L'annće d'après, Brunot est remplacé par Texte.

1 : De 1893 a 1896, Durand, maître de conférences, assure des cours de grammaire et de métrique du grec et du latin.

m : En 1894/95, sous la rubrique générale des enscignements d'“Histoire et Géographie", un "cours complémentaire subventionnć par la Socićıć des Amis de l'Université de Lyon" est créé en "ethnologie" et assuré par M. Chantre,sous-directeur du Muséum de Lyon. Au premier semestre,il est traité des "Origines ct civilisations primitives des peuples de l'Europe"; au second semestre, ce cours est remplacé par des conférences pratiques au Muséum. En 1895/96, Chantre traite de l'“Ethnologie de l'Europe orientale" et, en 1896/97 "Les peuples de l'Asie occidentale et de l'Afrique septentrionale".

n : En 1895/96, Firmery annonce: "Histoire de la littérature allemande: I. Les origines et le moyen-âge". 


\section{MONTPELLIER}

\begin{tabular}{|c|c|c|c|c|c|c|c|c|}
\hline & Littérature & Littérature & Littérature & Lg et Phil. & Littér. & Langue & Lg et Lit & Paléogra- Grammai \\
\hline & Française & Grecque * & Latine & Romanes ** & Etrangère & Allemande & Arabes *** & phie \& Phil. \\
\hline $1859-61$ & TAILLANDIER & $\underline{\text { SIGUY }}$ & & & MONDOT & & & \\
\hline $1863-67$ & $\begin{array}{l}\text { TAILLANDIER } \\
\text { Révillout }\end{array}$ & CAMBOULIU & & & MONDOT & & & \\
\hline $1868-69$ & REVILLOUT & CAMBOULIU & & MONDOT & & & & \\
\hline $1877-78$ & REVILLOUT & CROISET & BOUCHE-L. ${ }^{\circ}$ & & CASTETS & & & \\
\hline $1879-80$ & REVILLOUT & CROISET & $\begin{array}{l}\text { BOUCHE-L } \\
\text { Fontaine }\end{array}$ & $\begin{array}{l}\text { Chabaneau }{ }^{a} \\
\text { Boucherie }^{b}\end{array}$ & CASTETS & & Devic $^{c}$ & \\
\hline $1880-81$ & REVILLOUT & $\begin{array}{l}\text { CROISET } \\
\text { Martha }^{d}\end{array}$ & $\begin{array}{l}\text { BOUCHE-L } \\
\text { Bonnet }\end{array}$ & $\begin{array}{l}\text { Chabaneau } \\
\text { Boucherie }\end{array}$ & CASTETS & & Devic & \\
\hline $1881-82$ & REVILLOUT & CROISET & $\begin{array}{l}\text { BOUCHE-L } \\
\text { Bonnet } \\
\text { Dauphine }\end{array}$ & $\begin{array}{l}\text { Chabaneau } \\
\text { Boucherie }\end{array}$ & CASTET $^{*}$ & & Devic & \\
\hline $1882-83$ & REVILLOUT & $\begin{array}{l}\text { CROISET } \\
\text { Edet }\end{array}$ & $\begin{array}{l}\text { BOUCHE-L } \\
\text { Bonnet }\end{array}$ & $\begin{array}{l}\text { Chabaneau } \\
\text { Boucherie }\end{array}$ & CASTETS & Fécamp & Devic & \\
\hline $1883-85$ & $\begin{array}{l}\text { REVILLOUT } \\
\text { Dejean }\end{array}$ & $\begin{array}{l}\text { CROISET } \\
\text { Edet }\end{array}$ & $\begin{array}{l}\text { BOUCHE-L } \\
\text { Bonnet } \\
\text { Fabia }^{\mathrm{h}}\end{array}$ & Chabancau $^{\mathrm{e}}$ & CASTETS $^{f}$ & Fécamp ${ }^{8}$ & Devic & \\
\hline $1885-86$ & $\begin{array}{l}\text { REVILLOUT } \\
\text { Rabaud }\end{array}$ & $\begin{array}{l}\text { CROISET } \\
\text { Brenous }\end{array}$ & $\begin{array}{l}\text { BOUCHE-L } \\
\text { Bonnet }\end{array}$ & Chabaneau & CASTETS & Fécamp & Devic & \\
\hline $1886-88$ & $\begin{array}{l}\text { REVILLOUT } \\
\text { Rabaud }\end{array}$ & $\begin{array}{l}\text { CROISET } \\
\text { Brenous }\end{array}$ & $\begin{array}{l}\text { BOUCHE-L } \\
\text { Bonnet } \\
\text { Reynaud }\end{array}$ & Chabaneau & CASTETS & Fécamp & Devic & \\
\hline $1888-90$ & $\begin{array}{l}\text { REVILLOUT } \\
\text { Rabaud }\end{array}$ & $\begin{array}{l}\text { CROISET } \\
\text { Brenous }\end{array}$ & $\begin{array}{l}\text { BOUCHE-L } \\
\text { Bonnet } \\
\text { Reynaud }\end{array}$ & Chabaneau & CASTETS & Fécamp & & \\
\hline $1890-91$ & $\begin{array}{l}\text { REVILLOUT } \\
\text { Rabaud }\end{array}$ & $\begin{array}{l}\text { CROISET } \\
\text { Brenous }\end{array}$ & $\begin{array}{l}\text { BONNET } \\
\text { Reynaud }\end{array}$ & Chabaneau & CASTETS & Fécamp & & \\
\hline $1891-92$ & $\begin{array}{l}\text { Rigal } \\
\text { Rabaud }\end{array}$ & $\begin{array}{l}\text { Puech } \\
\text { Brenous }\end{array}$ & $\begin{array}{l}\text { BONNET } \\
\text { Reynaud }\end{array}$ & Chabaneau & CASTETS & Fécamp & & \\
\hline $1892-94$ & $\begin{array}{l}\text { RIGAL } \\
\text { Rabaud }\end{array}$ & $\begin{array}{l}\text { PUECH } \\
\text { Brenous }\end{array}$ & $\begin{array}{l}\text { BONNET } \\
\text { Reynaud }\end{array}$ & Chabaneau & CASTETS $^{i}$ & Fécamp & & Graud $^{j}$ \\
\hline $1894-95$ & $\begin{array}{l}\text { RIGAL } \\
\text { Vianey }\end{array}$ & $\begin{array}{l}\text { Maury } \\
\text { Brenous }\end{array}$ & $\begin{array}{l}\text { BONNET } \\
\text { Reynaud }\end{array}$ & Chabaneau & CASTETS & Fécamp & & Graud \\
\hline $1895-96$ & $\begin{array}{l}\text { RIGAL } \\
\text { Vianey }\end{array}$ & Maury & $\begin{array}{l}\text { BONNET } \\
\text { Reynaud }\end{array}$ & Chabancau & CASTETS & FEC $\triangle \mathrm{MP}$ & & Berthele ${ }^{1}$ Grammont ${ }^{k}$ \\
\hline $1896-97$ & $\begin{array}{l}\text { RIGAL } \\
\text { Vianey }\end{array}$ & $\begin{array}{l}\text { MAURY } \\
\text { de Bévotte }\end{array}$ & $\begin{array}{l}\text { BONNET } \\
\text { Reynaud }\end{array}$ & Chabaneau & CASTETS & FECAMP & & Berthelé Grammont \\
\hline
\end{tabular}

* :"Littérature ancienne" est scindée en 1877 en "Littérature Grecque" et "Littérature Latine", rebaptisées "Langue et littérature " [grecques et latines ] en 1980.

** :"Langues et philologie romanes" de 1879 à 1883 et "Langues et littératures françaises du moyen-âge" dès lors.

***: A partir de 1885, Devic joint à son cours de "langue et littérature arabes", un cours de "grammaire comparée des langues classiques".

$\circ$ BOUCHE-L. = BOUCHE-LECLERCQ 


\section{NOTES SUR MONTPELLIER}

a : En 1879/80, Chabaneau annonce son cours complémentaire: "Phonétique de la langue d'oc et explication de textes originaux" et "Grammaire historique de la langue française" (ce demier cours sera reconduit les années suivantes);

en 1880/81: "Formation des mots de la langue d'oc et explication de textes originaux"; en 1881/82: "Etude de la langue d'oc (Grammaire. Exercices pratiques.Histoire littéraire)", programme repris l'année suivante.

A partir de 1883, Chabaneau cumule son enseignement et celui de Boucherie (cf note ${ }^{\circ}$ ).

b : En 1879/80 ,Boucherie annonce:"Phonćtique(langue d'oïl)", "Explication de textes français antérieurs au XIIIe siècle" et "Préparation des auteurs prescrits pour l'agrégation (Chanson de Roland, Amyot)";

en 1880/81: "Grammaire du vieux français. Explication de textes français antérieurs au XIIIe siècle" et "Grammaire historique de la langue française";

en 1881/82: "Explication des auteurs français antérieurs à la Renaissance (agrégation des lettres et de grammaire): traduction en latin ćtymologique de Joinville et de La Chanson de Roland." "Grammaire du vieux français, et plus particulièrement histoire de la syntaxe" et "Histoire de la littérature du moyen-âge et versification française".

L'année suivante, Boucherie reprend le même programme, renonçant seulement à ses traductions "en latin étymologique".

c : En 1879/80, Devic annonce: "Grammaire. Explication des Fables de Lokman, du Coran et de morceaux choisis" et "Grammaire comparéc des langues classiques"; jusqu'en 1882/83, il reprend le même intitulé avant de reformuler le cours

en 1883/84: "Grammaire arabe. Explication de textes en arabe littéraire: Coran, morceaux choisis dans les chrestomathics de Saci et de Bel Kassem ben Sedira","Arabe moderne. Dialogues. Mille et une nuits." ct "Grammaire comparée des langues classiques. Phonétique. Etude de la formation des mots en grec et en latin."

En 1884/85 est annoncé: "Eléments de la grammaire. Traduction des Fables de Lokman et de morceaux choisis dans la Chrestomathic de Bel Kassem ben Sedira.", "Syntaxe, constitution des langues sémitiques comparće à cclle des langues aryennes. Explication du Ceran et du Divan d'Imrou'l Qaiis" et "Grammaire comparée des langues classiques. Etude de la formation des mots en grec et en latin", et de même en 1885/86.

En 1886/87 seuls demeurent: "Grammairc. Explication du Coran. Chrestomathie de Kosegarten" et "Grammaire comparće des langues classiques. Phonétique. Formation des mots. Déclinaison", de même qu'cn 1887/88, demic̀re année de cet enseignement. 
d : En 1880/81, Martha annonce: "Etude de la syntaxe grecque et applications pratiques" et "Etude de la langue et de la grammaire grecques dans les inscriptions" dans une conférence dite "Antiquités grecques ct latines".

e : A partir de 1883/84, Chabaneau cumule lcs enscignements d'ancien français et de langue d'oc, annonçant: "Etude des plus anciens monuments de la langue d'oîl et de la langue d'oc", "Explication des auteurs français antérieurs à la Renaissance, portés au programme des agrégations et de la licence" et "Grammaire historique et comparée de la langue française et de la langue d'oc (formation des mots et syntaxe)". S'il reprend les années suivantes les explications pour la licence et l'agrégation, il modifie ses autres cours:

en 1884/85: "Etude philologique et littéraire de textes français et provençaux du XIIle siècle" et "Grammaire historique ct comparéc de la langue d'oïl et de la langue d'oc (IXe-XVe siècle)";

en 1885/86 et 1886/87:"Grammaire historique de la langue d'oc";

en 1887/88 et 1888/89:"Grammaire historique el comparéc de la langue d'oc et de la langue d'oîl" et "Etude philologique et littérairc de textcs français et provençaux du XIIIc siècle";

en 1889/90: "Grammaire historique de la langue française" et "Le troubadour Amaut de Mareuil:étude philologique et littéraire de ses poćsies";

en 1890/91: "Grammairc provençale: phonćtique et morphologie" et "Le troubadour Amaut Danicl: étude philologique et littéraire de ses poćsies";

en 1891/92: "Grammaire historique et comparćc de la langue française et de la langue provençale. Morphologie" ct "Le troubadour Bertran de Born: étude historique et littéraire de ses poésies";

en 1892/93: "Grammairc historique ct comparće du français ct du provençal. Phonétique" et "Les premiers monuments de la langue provençale";

en 1893/94: "Grammaire historique el comparće du français et du provençal. Morphologie" et "Etude philologique ct littérairc des textes en langue d'oe du XVe, XVIe ct XVIle siècles";

en 1894/95: "Etude philologique el littćraire des morceaux choisis dans les chrestomathies provençales de Bartsch, Mcycr, ctc.";

en 1895/96: "Grammaire historique de la languc d'oc" et "Le troubadour Richart de Barbezieux. Etude philologique et littérairc de ses poćsies" et

en 1896/97: "Grammaire comparéc de la langue d'oc et de la langue d'oill" et "Le théâtre provençal au moyen-âge. Elude philologique ct littéraire de ce qui en reste". 
f : En 1884/85, Castets donne comme titre à l'un de ses cours: "L'école sicilienne ou la poésie lyrique en Italie au XIIIe siècle" au premier trimestre, le transformant au second semestre en "L'épopée italienne au moyen-âge", titre repris en 1885/86.

g : Au second semestre de l'annćc 1883/84, Fćcamp, "chargé de cours", annonce: "Explication et commentaire de la préface allcmande d'Aristophane, Les Grenouilles, édition KOCH. (Berlin, Weidmann)" et "Introduction à la grammaire comparée des langues germaniques". Il reprend ce dernier cours les années suivantes, y adjoignant, en 1884/85:"Explication et commentaire de morceaux choisis dans les principaux auteurs allemands critiques, philosophes, historiens"; Fćcamp renonce à son cours de grammaire comparée à partir de 1888/89.

h : Le cours de Fabia est intitulé:"Philologie grecque ct latine".

i : Annonce, entre autres, en 1892/93:"Lcs dcux premicrs siècles de la littérature italienne”.

j : Graud, "archiviste-paléographe", proposc un cours de palćographie: "Déchiffrement de textes latins, français et en langue d'oc du moyen-âge", de 1892 à 1894.

k : Il n'y a pas de tire du cours à la conférence de "Grammaire ct philologie" de Grammont en 1895/96; en 1896/97, l'affiche précisc: "Cours de grammaire", "Métrique. Exercices pratiques", "Etude scientifique du vicil-irlandais".

1 : En 1895/96, Berthelé, "archiviste-palćographe", annonce, entre autres: "Histoire de l'Ecriture" et, en 1896/97: "Palćographic. Diplomatique". 


\begin{tabular}{|c|c|c|c|c|c|}
\hline & $\begin{array}{l}\text { Littér. } \\
\text { Française }\end{array}$ & $\begin{array}{l}\text { Lg \& Lit. } \\
\text { Grecques* }\end{array}$ & $\begin{array}{l}\text { Lg \& Lit. } \\
\text { Latines }\end{array}$ & $\begin{array}{l}\text { Grammaire } \\
\text { \& Phil. }\end{array}$ & $\begin{array}{l}\text { Littér. } \\
\text { Etr. *** }\end{array}$ \\
\hline $1858-59$ & BENOIT $^{2}$ & BURNOUF & & & MEZIERES \\
\hline $\begin{array}{l}1863-65 \\
1865-67\end{array}$ & $\frac{\text { BENOIT }}{\text { BENOIT }}$ & $\begin{array}{l}\text { BURNOUF } \\
\text { BURNOUF }\end{array}$ & & & \multirow{3}{*}{$\begin{array}{l}\text { CHASLES } \\
\text { CHASLES } \\
\text { Gebhart } \\
\text { CHASLES } \\
\text { Gebhart }^{\mathrm{c}} \\
\text { CHASLES } \\
\text { Gebhart }\end{array}$} \\
\hline $1867-69$ & BENOIT & Benoist $^{d}$ & & & \\
\hline 1869-70 & $\frac{\text { BENOIT }}{\text { Hemar }^{\circ}}$ & BENOIST & & & \\
\hline $\begin{array}{l}1871-72^{\mathrm{e}} \\
1872-73\end{array}$ & $\begin{array}{l}\text { BENOIT } \\
\underline{\text { BENOIT }}\end{array}$ & $\begin{array}{l}\text { DECHARME } \\
\text { DECHARME }\end{array}$ & $\begin{array}{l}\text { CAMPAUXX }{ }^{\mathrm{f}} \\
\text { CAMPAUX }\end{array}$ & & $\begin{array}{l}\text { Gebhart } \\
\text { GEBHART }\end{array}$ \\
\hline $1877-78$ & $\underline{\text { BENOIT }}$ & DECHARME & CAMPAUX & Riemann $^{\mathrm{h}}$ & GEBHART 8 \\
\hline $1879-80$ & \multirow{6}{*}{ 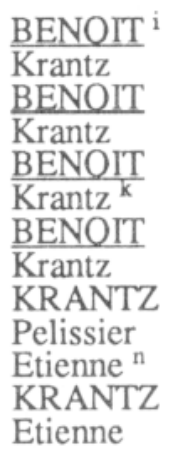 } & DECHARME & CAMPAUX & Riemann & \multirow{2}{*}{$\begin{array}{l}\text { GEBHART } \\
\text { Licht. }{ }^{\circ \circ} \mathrm{j} \\
\text { GRUCKER }\end{array}$} \\
\hline $1880-81$ & & DECHARME & CAMPAUX & Riemann & \\
\hline $1881-82$ & & DECHARME & CAMPAUX & $?$ & GRUCKER \\
\hline $1882-83^{\mathrm{m}}$ & & \multirow{11}{*}{$\begin{array}{l}\text { DECHARME } \\
\text { Pelissier } \\
\text { DECHARME } \\
\text { Pelissier } \\
\text { Martin } \\
\text { DECHARME } \\
\text { Pélissier } \\
\text { Martin } \\
\text { DECHARME } \\
\text { Pélissier } \\
\text { Martin } \\
\text { DECHARME } \\
\text { MARTIN } \\
\text { DECHARME } \\
\text { MARTIN } \\
\text { Lemerciers } \\
\text { DECHARME } \\
\text { MARTIN } \\
\text { Lemercier } \\
\text { DECHARME } \\
\text { MARTIN } \\
\text { MARTIN } \\
\text { Cousin } \\
\text { MARTIN } \\
\text { Cousin } \\
\text { MARTIN } \\
\text { Couve }\end{array}$} & \multirow{2}{*}{$\begin{array}{l}\text { CAMPAUX } \\
\text { Collignon }{ }_{1} \\
\text { CAMPAUX } \\
\text { Collignon }\end{array}$} & Thiaucourt & GRUCKER \\
\hline $1883-84$ & & & & Thiaucourt & GRUCKER \\
\hline 1884-85 & & & $\begin{array}{l}\text { CAMPAUX } \\
\text { Collignon }\end{array}$ & Thiaucourt & GRUCKER \\
\hline $1885-86^{q}$ & $\begin{array}{l}\text { KRANTZ } \\
\text { Etienne }\end{array}$ & & $\begin{array}{l}\text { CAMPAUX } \\
\text { Collignon }\end{array}$ & Thiaucourt & $\begin{array}{l}\text { GRUCKER } \\
\text { Basch P }\end{array}$ \\
\hline $1886-87$ & \multirow{2}{*}{$\begin{array}{l}\text { KRANTZ } \\
\text { Etienne } \\
\text { KRANTZ } \\
\text { Etienne }\end{array}$} & & \multirow{2}{*}{$\begin{array}{l}\text { CAMPAUX } \\
\text { Thiaucourt } \\
\text { CAMPAUX } \\
\text { Thiaucourt }\end{array}$} & Cousin $^{r}$ & \multirow{2}{*}{$\begin{array}{l}\text { GRUCKER } \\
\text { Basch } \\
\text { GRUCKER } \\
\text { Licht. }^{\text {t }}\end{array}$} \\
\hline $1887-88$ & & & & Cousin & \\
\hline 1888-91 & $\begin{array}{l}\text { KRANTZ } \\
\text { Etienne }\end{array}$ & & $\begin{array}{l}\text { THIAUCOURT } \\
\text { Collignon }\end{array}$ & Cousin & $\begin{array}{l}\text { GRUCKER } \\
\text { Licht. }\end{array}$ \\
\hline 1891-92 & \multirow{4}{*}{$\begin{array}{l}\text { KRANTZ } \\
\text { Etienne } \\
\text { KRANTZ } \\
\text { Etienne } \\
\text { KRANTZ } \\
\text { Etienne } \\
\text { KRANTZ } \\
\text { Etienne }\end{array}$} & & \multirow{4}{*}{$\begin{array}{l}\text { THIAUCOURT } \\
\text { Collignon } \\
\text { THIAUCOURT } \\
\text { Collignon } \\
\text { THIAUCOURT } \\
\text { COLLIGNON } \\
\text { THIAUCOURT } \\
\text { COLLIGNON }\end{array}$} & Cousin & \multirow{4}{*}{$\begin{array}{l}\text { GRUCKER } \\
\text { Licht. } \\
\text { GRUCKER } \\
\text { Licht. } \\
\text { GRUCKER } \\
\text { Licht. } \\
\text { GRUCKER } \\
\text { LICHT. }\end{array}$} \\
\hline $1892-93$ & & & & Cousin & \\
\hline 1893-94 & & & & Cousin & \\
\hline $1894-97$ & & & & Cousin & \\
\hline
\end{tabular}

A partir de 1894, Baldensperger assure un cours libre de "langue anglaise"

○: "Hemar." = "Hémardinquer" $\quad$ 0: "Licht." = "Lichtenberger"

* : La chaire de "Littérature ancienne" est dédoublée à partir de 1875 en "Langue et littérature grecques" et "Langue et litkérature latines".

**: La chaire de "Littérature étrangère" devient chaire de "Langue et de littérature allemandes" en 1882. 


\section{NOTES SUR NANCY}

a : Au second semestre, Charles Benoît: "continuera, lc samedi, de retracer l'histoire de l'esprit français et de la littérature au XIIIle, au XIVe ct au XVe siècles" entre autres; en 1864/65, "M. Charles Benoît, professeur, retracera, les samedis, l'histoire de l'esprit et des lettres en France au XIIIe siècle" et en 1865/66: "M. Ch. Benoît,professeur, en poursuivant, le samedi, l'histoire des lettres françaises au XIIIe siècle, y étudiera surtout la crise intellectuelle et morale, où le moyen-âge se transforme pour enfanter le monde moderne".

b : En 1864/65, “M. Emile Chasles, professeur, traitcra, les mardis, de la littérature italienne au moyen-âge et à la Renaissance, et ćtudiera spćcialement Dante et Pétrarque.Sa conférence du lundi aura pour objet la traduction de textes et l'analyse comparative des langues du Midi."

c : En 1868/69, "M. Emile Gebhart, supplćant, ćludicra, lcs mardis, la mythologie primitive, les légendes héroïques et la poésie de l'Allcmagne avant la Réforme", entre autres, et, en 1869/70, il "ćtudiera, le mardi, la poćsic allcmandc au moyen-âge".

d : En 1868/69, en "cours complémentairc de philologic", "M.Eugène Benoist, professeur de littérature ancienne, fera chaque jeudi une conférence spéciale de philologie, qu'on ne pourra suivre qu'à la condition de s'y être fait particulic̀rement inscrire. Cette année, il expliquera le dixième livre des Institutions oratoires de Quintilien avec les variantes de Spalding, Zumpt, Bonnell, et le manuscrit de la Bibliothèque Impériale".

En 1869/70, il "traitera des principes sur lesqucls doit s'ćtablir le texte des Commentaires de César. Il choisira pour sujct de démonstration le premier livre de La Guerre des Gaules (édition Dinter). Ce cours n'est pas public. Les Auditeurs y seront admis, en s'adressant particulièrement au Professcur".

e : Petit de Juleville est nommé suppléant de la chairc d'histoire en 1871; il y demeurera jusqu'en 1877.

f : Campaux "initiera ses auditeurs aux ćtudes philologiques", cntre autres.

g: Gebhart annonce entre autres comme sujct de cours: "I'histoirc de la littérature espagnole au moyen-âge".

h : En 1877/78, Riemann intitule son cours: "Cours sur la grammaire générale des langues classiques, grecque, latine et française"; cn 1879/80, est annoncé "syntaxe des trois langues classiques"; en 1880/81, "la déclinaison ct la conjugaison grecques et latines". 
i : En 1879/80, "M. Charles Benoît, les samedis, cxposcra le mouvement des lettres et des esprits en France au XIIe siècle" entre autres; cn 1880/81, il "complètera le tableau de l'état des lettres et des arts en France au temps de Saint-Louis (...). Dans celle (la conférence) du jeudi, pour l'agrégation de grammaire, il étudiera dans La Chanson de Roland, la langue française du XIIe siècle." En 1881/82, "M. Benoît, les samedis, retracera l'histoire des idées et des lettres françaises en France et à l'étranger pendant le XIVe et le XVe siècles", et, en 1882/83: "Dans sa conférence supplémentaire du lundi, il étudiera la langue française du XIIe siècle, ct commentera La Chanson de Roland".

j : En 1879/80, Lichtenberger assure une conférence dc "Langue et littérature allemandes".

k : "M. Krantz, dans sa conférence du vendredi, fera l'histoire de la littérature française depuis ses origines, conformément au nouvcau programme pour la licence" entre autres.

1 : En 1881/82, "M. Thiaucourt, les jeudis, ćtudicra la syntaxe des cas et le commencement de la syntaxe générale dans les trois langucs classiques", cntre autres;

en 1882/83, il annonce "Grammaire des trois langucs classiques ct métrique" et "Syntaxe générale, les propositions coordonnćcs cl les propositions subordonnées en vue de l'agrégation de grammaire";

en 1883/84, la conférence de "Grammaire" est rcbaptisće "Philologie ancienne" avec la "Grammaire comparće des trois langues classiques";

en 1884/85, c'est, entre autres, "Syntaxc des cas"; prépositions" au premier semestre et, au second: "Grammaire. Syntaxe de coordination ct de subordination";

en 1886/87, Thiaucourt se consacre à la "philologic latine" avant de recevoir la chaire de "Langue et littérature latines".

m : C'est en 1882 que la chaire de philosophic est confićc à Victor-Emile Egger, l'auteur de La parole intérieure.

La même année, on lit sur l'affiche annonçant les cours:"Concours littéraire institué par le Conseil Général avec la coopération des conscils municipaux de Nancy et de Lunéville. La faculté propose pour sujet du concours cn 1883 une étude comparée de l'lliade et de La Chanson de Roland".

n : En 1883/84,"M. Etienne, docteur c̀s-lettres: la languc française au moyen-âge. Explication du texte de La Chanson de Roland";

en 1884/85, "Grammaire historique de la langue française", entre autres, au premier semestre et, au second semestre, "Explication de La Chanson de Roland"; 
en 1885/86, "Histoire de la langue française depuis les origines jusqu'à la fin du XIe siècle" au premier semestre et, au second, "M. Etienne étudiera les textes d'ancien français du programme de l'agrégation de grammaire";

en 1886/87, au premier semestre "Explication de textes français d'avant 1500 " et, au second semestre, alors que la conférence est transformće en cours complémentaire de "Langue et littérature françaises": "Histoire de la langue française depuis les origines jusqu'à la fin du XIe siècle. (Continuation de la phonétique)".

En 1887/88, Etienne annonce: "Histoire de la langue française, depuis les origines jusqu'à la fin du XVIe siècle. Suite:la déclinaison ct la conjugaison";

en 1888/89, entre autres, "Histoire de la conjugaison française depuis les origines jusqu'à la fin du XIe siècle (...)";

en 1889/90, "Histoire de la langue française (...)",

en 1890/91: "Langue française du moyen-âge (syntaxe)";

en 1891/92: "La conjugaison française au moyen-âge (...)" et toujours les textes d'avant 1500 pour l'agrégation et la licence auxquels il se consacre en entier

jusqu'à 1895/96 où il reprend: "Syntaxe de l'ancien français (...)",

1896/97: “Ancien français (...) Qucstions de syntaxe ancienne et modeme".

o : Albert Martin reçoit une "conférence de philologie grecque" dans laquelle il annonce, entre autres, en 1884/85: "Grammaire et métrique grecques".

p : En 1885/86, Basch annonce, entre autres, une "Conférence de philologie allemande" dont il est précisée l'année suivante qu'elle cst destinćc à la préparation de l'agrégation.

q : Au second semestre de 1885/86, cst annoncéc une conférence de pédagogie: “M. Alexandre MARTIN, fera une conférence, suverle au public, sur les méthodes d'enseignement des langues classiques, le jcudi, à quatre heures".

r : L'annonce de la conférence de Cousin en 1886/87, porte: “Grammaire des langues classiques"; il conserve cette conférence pendant les onzc annćes qui suivent, faisant, par exemple, en 1894/95, "Le verbum infinitum".

s : La conférence de Lemercier est intitulćc: "Philologic grecque et latine".

$\mathrm{t}$ : En 1887/88, au second semestre, la conférence de Lichtenberger est intitulée: "Grammaire et histoire de la langue allemande", consacréc, en 1889/90, à l"'Histoire de la languc allemande (...)", en 1890/91, à des "Questions de philologic allcmande" au premier semestre et, au second, à "Hartmann d'Aue et les chevalicrs poc̀tes au moyen-âge (...)", en 1891/92 et, en 1892/93 à des "Principes de grammairc historique (...)"; 
en 1894/95, Lichtenberger,qui est devenu professeur-adjoint, annonce entre autres: "Le roman de chevalerie, en Allemagne, au XIle ct au XIIIle siècles";

en 1895/96, c'est: "Histoire de la littératurc allemande au moyen-âge" et, en 1896/97: "Questions de littérature et de philologic allemandes". 


\section{POITIERS}

\begin{tabular}{|c|c|c|c|c|c|}
\hline & $\begin{array}{l}\text { Littér. } \\
\text { Franç. }\end{array}$ & $\begin{array}{l}\text { Lg \& Lit. } \\
\text { Grecques }\end{array}$ & $\begin{array}{l}\text { Lg \& Lit } \\
\text { Latines * }\end{array}$ & $\begin{array}{l}\text { Littérature } \\
\text { Etrangère }\end{array}$ & Celtique \\
\hline $1859-60$ & ANOT $^{\mathrm{a}}$ & $\begin{array}{l}\text { MEYER } \\
\text { Huguenin }\end{array}$ & & Beaussire & \\
\hline $1860-63$ & ANOT & ALBERT & & BEAUSSIRE & \\
\hline $1863-66$ & ALBERT & Chaignet ${ }^{b}$ & & BEAUSSIRE & \\
\hline $1866-67$ & Monnier & Chaignet & & BEAUSSIRE & \\
\hline $1867-68$ & Monnier & CHAIGNET & & & \\
\hline $1868-71$ & MONNIER $^{c}$ & CHAIGNET & & Grucker & \\
\hline $1872-75$ & MONNIER & CHAIGNET & & GRUCKER & \\
\hline $1875-78$ & MONNIER & CHAIGNET & & GRUCKER & \\
\hline $1879-80$ & Aulard & MONNIER & & GRUCKER & \\
\hline $1881-82$ & Aulard & HANRIOT & Hild & Parmentier & \\
\hline $1882-83$ & Aulard $^{\mathrm{e}}$ & $\begin{array}{l}\text { HANRIOT } \\
\text { Bénard f } \\
\text { Guibal }\end{array}$ & $\begin{array}{l}\text { HILD } \\
\text { Plessis }{ }^{d} \\
\text { Bardinet }\end{array}$ & PARMENTIER & \\
\hline 1883-84 & AULARD & $\begin{array}{l}\text { HANRIOT } \\
\text { Bénard }\end{array}$ & $\begin{array}{l}\text { HILD } \\
\text { Plessis }\end{array}$ & PARMENTIER & \\
\hline $1884-85$ & & $\begin{array}{l}\text { HANRIOT } \\
\text { Bénard }\end{array}$ & $\begin{array}{l}\text { HILD } \\
\text { Ernault } 8\end{array}$ & PARMENTIER $^{\mathrm{j}}$ & Ernault $^{\mathrm{h}}$ \\
\hline $1885-86$ & DUCROS $^{\mathrm{i}}$ & HANRIOT & $\begin{array}{l}\text { HILD } \\
\text { Ernault }\end{array}$ & PARMENTIER & Ernault \\
\hline $1886-87$ & $\begin{array}{l}\text { DUCROS } \\
\text { Chaudey }\end{array}$ & $\begin{array}{l}\text { HANRIOT } \\
\text { Chevaldin }\end{array}$ & $\begin{array}{l}\text { HILD } \\
\text { Ernault }\end{array}$ & PARMENTIER & Ernault \\
\hline $1887-88$ & $\begin{array}{l}\text { DUCROS } \\
\text { Chaudey }\end{array}$ & $\begin{array}{l}\text { HANRIOT } \\
\text { Emault }\end{array}$ & $\begin{array}{l}\text { HILD } \\
\text { Chevaldin }\end{array}$ & PARMENTIER & Ernault \\
\hline $1888-89$ & $\begin{array}{l}\text { DUCROS } \\
\text { Chaudey }\end{array}$ & $\begin{array}{l}\text { Ernault } \\
\text { Jeanroy }\end{array}$ & $\begin{array}{l}\text { HILD } \\
\text { Chevaldin }{ }^{k}\end{array}$ & PARMENTIER & Ernault \\
\hline $1889-90$ & DUCROS $^{\mathrm{m}}$ & ERNAULT & $\begin{array}{l}\text { HILD } \\
\text { Chevaldin }\end{array}$ & PARMENTIER $^{1}$ & ERNAULT \\
\hline 1890-91 & $\begin{array}{l}\text { DUCROS } \\
\text { Arnould }\end{array}$ & ERNAULT & $\begin{array}{l}\text { HILD } \\
\text { Chevaldin }\end{array}$ & PARMENTIER & ERNAULT \\
\hline $1891-95$ & $\begin{array}{l}\text { SOURIAU }{ }^{n} \\
\text { Arnould }\end{array}$ & ERNAULT & $\begin{array}{l}\text { HILD } \\
\text { Chevaldin }\end{array}$ & PARMENTIER & ERNAULT \\
\hline $1895-96$ & $\begin{array}{l}\text { SOURIAU } \\
\text { Arnould }\end{array}$ & ERNAULT & $\frac{\text { HILD }}{\text { Chevaldin }}$ & PARMENTIER & \\
\hline $1896-97$ & $\begin{array}{l}\text { SOURIAU } \\
\text { Arnould }\end{array}$ & Audoin & $\frac{\text { HILD }}{\text { Chevaldin }}$ & PARMENTIER ${ }^{\circ}$ & \\
\hline
\end{tabular}

* : La chaire de "Littérature ancienne" est dédoublée en 1881 en une chaire de "Littérature et Institutions grecques" [ rebaptisée "Langue et littérature grecques" en 1884 ,"Littérature et Institutions grecques" en 1886 et "Antiquités et philologie classique" en 1895 ] et une chaire de "Littérature latine et Institutions romaines"[ rebaptisée de 1884 à 1886: "Langue et littérature latines"].Le celtique restera une "conférence"et ne sera jamais élevé à la dignité de chaire. 


\section{NOTES SUR POITIERS}

a : Cours: "Littérature française du XIIe au XVIIe sic̀cles".

b : En 1864/65, cours sur "De l'éloquence et de la rhćtorique chez les Anciens"; en 1873/74: "L'art de l'éloquence chez les Anciens". En 1879/80, Chaignet devient recteur de l'académie de Poitiers.

c : En 1868/69, cours: "Littérature française du XIIle au XVe siècle inclusivement".

d : Plessis annonce entre autres: "Mćtrique (...) Syntaxe des modes et des temps".

e : Aulard annonce, en 1882/83 et au premier semestre de 1883/84: "Notions sur l'histoire de langue et de la grammaire au XVIe siècle (...) au XVIIe siècle"; au second semestre de 1883/84: "Notions élémentaires sur l'histoire de la langue au moyen-âge et au XVIe siècle; explication du texte de La Chanson de Roland (Ies 365 premiers vers), et de Montaigne, Essais, II, 25" entre autres.

f : A côté de travaux sur la langue grecque, Bćnard enscigne "la grammaire comparée" de 1882 à 1884, avant de restreindrc ses ambitions à un cours de grammaire grecque (en $1884 / 85)$.

g : En 1884/85, Ernault annonce entre autres: "Syntaxe latine" et "Métrique latine", cours qu'il reprend les deux années suivantcs avant d'enseigner, à partir de 1887/88, la "Grammaire grecque", précisant, par exception, en 1890/91: "Phonétique et morphologie grecques. Métrique. Comparaison de la versification grccque ct de la versification latine" entre autres. Jusqu'à 1896/97, Ernault poursuivra l'enseignement de la grammaire grecque.

h : En 1884/85, "Langue celtique:le mardi, à trois heures, conférence publique de M. Emault: Etude sur nos origines celtiques; les noms gaulois d'hommes, de peuples, de villes, etc. dans César";

en 1885/86: "Les éléments celtiques dans les documents de l'Antiquité; rapport des Celtes avec les Grecs et les Romains";

en 1886/87 et en 1887/88: "Les éléments celtiques dans les documents de l'Antiquité classique";

en 1888/89 et 1889/90: "Reconstitution particllc des éléments de la langue gauloise. Le vocabulaire celtique étudié surtout dans ses rapports avec celui des langues classiques"; 
en 1890/91: "Le celtique et ses rapports avec les langues classiques (grec, latin, germain, français);

en 1891/92: "Les langues celtiques considérées principalement dans leurs rapports avec la philologie classique";

en 1892/93: "Etude des mots et des noms d'originc gauloise, dans le Poitou et les régions voisines";

en 1893/94: "Les éléments celtiques dans la géographie du Poitou et des provinces voisines".

A partir de 1895, la conférence de celtique est abandonnée.

i : En 1885/86, Ducros annonce entre autres: "Explication de Joinville (les six premiers chapitres)" et, en 1887/88 : "Histoire de la langue française des origines au XVIc sičcle inclusivement".

j : Intitulé du cours : "Histoire comparćc de la littérature allemande et de la littérature française depuis le XII siècle jusqu'à la Renaissance".

k : Dans l'intitulé de ses cours, Chevaldin annonce régulièment de la "Grammaire" latine, précisant en 1893/94: "Histoire de la composition et de la dérivation dans la langue française. Théorie des cas en grec et en latin".

1 : Cours: "Histoire de la littérature anglaise depuis les origines jusqu'à Chaucer".

m : En 1889/90, Ducros annonce un "Cours d'ancien français: Flexions et syntaxe. Répétition de la phonétique (...) Litlćraturc française du moyen-âge: l'épopée"; et en 1890/91: "Histoire de la langue française; formation de l'ancien français (...) Explication de Joinville".

n : En 1891/92, Souriau annoncc: "(...) Joinvillc, Vic de Saint-Louis".

o : Parmentier annonce, en 1895/96: "Lcs langues anglaisc et allemande comparées dans leur forme moderne" et, en 1896/97: "L'anglais ct l'allemand comparés au point de vue des racines communes aux deux langucs". 


\section{RENNES}

\begin{tabular}{|c|c|c|c|c|c|}
\hline & $\begin{array}{l}\text { Littérature } \\
\text { Française }\end{array}$ & $\begin{array}{l}\text { Lit \& Inst } \\
\text { Grecques * }\end{array}$ & $\begin{array}{l}\text { Lit \& Inst } \\
\text { Romaines }\end{array}$ & $\begin{array}{l}\text { Lit. } \\
\text { Etrangère }\end{array}$ & $\underset{* *}{\text { Celtique }}$ \\
\hline $1853-61$ & DELAUNAY $^{b}$ & MARTIN & & NICOLAS a & \\
\hline $1863-64$ & DELAUNAY & MARTIN & & NICOLAS & \\
\hline $1865-66$ & DELAUNAY & MARTIN & & NICOLAS & \\
\hline $1867-70$ & DELAUNAY & MARTIN & & NICOLAS & \\
\hline $\begin{array}{l}1871-72 \\
1872-75 \\
1875-78 \\
1878-80\end{array}$ & $\begin{array}{l}\text { DELAUNAY } \\
\text { Duchesne }^{\mathrm{d}} \\
\text { DUCHESNE } \\
\text { DUCHESNE }\end{array}$ & $\begin{array}{l}\text { MARTIN } \\
\text { MARTIN } \\
\text { MARTIN } \\
\text { MARTIN } \\
\text { Robiou }\end{array}$ & Delaunay & $\begin{array}{l}\text { NICOLAS } \\
\text { NICOLAS } \\
\text { NICOLAS } \\
\text { NICOLAS }\end{array}$ & \\
\hline $\begin{array}{l}1880-81 \\
1881-82 \\
1882-83\end{array}$ & $\begin{array}{l}\text { DUCHESNE } \\
\text { DUCHESNE } \\
\text { Robert } \\
\text { DUCHESNE } \\
\text { Robert }\end{array}$ & $\begin{array}{l}\text { Robiou } \\
\text { ROBIOU } \\
\text { Pottier } \\
\text { ROBIOU } \\
\text { Pottier }\end{array}$ & $\begin{array}{l}\text { DELAUNAY } \\
\text { DELAUNAY } \\
\text { Dosson } \\
\text { DELAUNAY } \\
\text { Dosson e }\end{array}$ & $\begin{array}{l}\text { NICOLAS } \\
\text { NICOLAS } \\
\text { NICOLAS } \\
\text { Firmery }\end{array}$ & \\
\hline 1883-84 & $\begin{array}{l}\text { DUCHESNE } \\
\text { Thirion }\end{array}$ & $\begin{array}{l}\text { ROBIOU } \\
\text { Robert }\end{array}$ & $\begin{array}{l}\text { DELAUNAY } \\
\text { Puech }\end{array}$ & FIRMÉRY & Loth 8 \\
\hline $1884-85$ & $\begin{array}{l}\text { DUCHESNE } \\
\text { Thirion } \\
\text { Loth }{ }^{\mathrm{h}}\end{array}$ & $\begin{array}{l}\text { ROBIOU } \\
\text { Robert }\end{array}$ & $\begin{array}{l}\text { DELAUNAY } \\
\text { Puech }\end{array}$ & FIRMERY & Loth \\
\hline $1885-86$ & $\begin{array}{l}\text { DUCHESNE } \\
\text { Thirion } \\
\text { Loth }\end{array}$ & $\begin{array}{l}\text { ROBIOU } \\
\text { Loth }\end{array}$ & $\begin{array}{l}\text { DELAUNAY } \\
\text { Puech }\end{array}$ & FIRMERY & Loth \\
\hline $1886-87$ & $\begin{array}{l}\text { DUCHESNE } \\
\text { Thirion }\end{array}$ & $\begin{array}{l}\text { ROBIOU } \\
\text { Loth }\end{array}$ & $\begin{array}{l}\text { DELAUNAY } \\
\text { Puech }\end{array}$ & FIRMERY & Loth \\
\hline $1887-88$ & $\begin{array}{l}\text { DUCHESNE } \\
\text { Thirion }\end{array}$ & $\begin{array}{l}\text { ROBIOU } \\
\text { Loth }\end{array}$ & $\begin{array}{l}\text { DELAUNAY } \\
\text { Puech }\end{array}$ & $\begin{array}{l}\text { Basch }^{\mathrm{i}} \\
\text { Pinloche }\end{array}$ & Loth \\
\hline $1889-90$ & $\begin{array}{l}\text { DUCHESNE } \\
\text { Thirion } \\
\text { DUCHESNE }\end{array}$ & LOTH & $\begin{array}{l}\text { DELAUNAY } \\
\text { Puech } \\
\text { DELAUNAY }\end{array}$ & $\begin{array}{l}\text { Basch } \\
\text { Pinloche } \\
\text { Basch }\end{array}$ & $\begin{array}{l}\text { Loth } \\
\text { LOTH }\end{array}$ \\
\hline $1890-91$ & $\begin{array}{l}\text { DUCHESNE } \\
\text { Rebelliau }\end{array}$ & $\begin{array}{l}\text { LOTH } \\
\text { Rebelliau }\end{array}$ & $\begin{array}{l}\text { Puech } \\
\text { DELAUNAY } \\
\text { Puech }\end{array}$ & $\begin{array}{l}\text { Pinloche } \\
\text { Basch }\end{array}$ & LOTH \\
\hline $1891-93$ & & ROTH $^{\mathrm{k}}{ }^{\mathrm{L}}$ & $\begin{array}{l}\text { DELAUNAY } \\
\text { Macé }\end{array}$ & Basch & $\underline{\mathrm{LOTH}}$ \\
\hline 1893-95 & $\begin{array}{l}\text { Allais } \\
\text { Dottin }\end{array}$ & LOTH & $\begin{array}{l}\text { DELAUNAY } \\
\text { Macé }\end{array}$ & Basch & $\underline{\mathrm{LOTH}}$ \\
\hline $1895-96$ & $\begin{array}{l}\text { ALLAIS } \\
\text { Dottin }\end{array}$ & $\frac{\text { LOTH }}{\text { Dottin }}$ & $\begin{array}{l}\text { DELAUNAY } \\
\text { Macé }\end{array}$ & Basch & $\underline{\text { LOTH }}$ \\
\hline $1896-97$ & $\begin{array}{l}\text { ALLAIS } \\
\text { Dottin }\end{array}$ & $\frac{\text { LOTH }}{\text { Dottin }}$ & $\begin{array}{l}\text { DELAUNAY } \\
\text { Macé }\end{array}$ & $\begin{array}{l}\text { Basch }{ }^{\mathrm{m}} \\
\text { Barbeau }\end{array}$ & $\underline{\text { LOTH }}$ \\
\hline
\end{tabular}

* "Littérature ancienne" est dédoublée en 1881 en "Littérature et Institutions Grecques"et en "Littérature et Institutions Romaines";

** "Langue et littérature celtiques" [fondée en 1883] devient en 1886 "Histoire des langues et des peuples celtiques". 


\section{NOTES SUR RENNES}

a : En 1854/55: "Histoire de la littérature allemande depuis ses origines jusqu'au XIXe siècle" entre autres.

b : En 1856/57: "Histoire de la littérature française, depuis l'origine jusqu'au premier tiers du XVIle siècle inclusivement", intitulé repris en 1859/60.

c : En 1865/66, Morin, qui occupe la chaire d'histoire, annonce une "Revue des temps anciens jusqu'au commencement de l'ère chrétienne, et particulièrement origine des peuples de la famille indo-celtique d'après lcs donnćes de la philologie moderne".

d : En 1872/73, Duchesne intitule l'un de scs cours: "Histoire de la poésie épique en France".

e : Dosson annonce une conférence de "Philologie classique: grammaire comparée du grec et du latin. Théorie de la conjugaison. Syntaxe des propositions subordonnées."

f : En 1883/84, Puech annonce, entre autres, "Philologie classique".

g : En 1883/84, le cours de "Langue et littérature celtiques" de Loth consiste en une "Introduction à l'étude des langues et des littćratures néo-celtiques. Histoire des dialectes britanniques";

en 1884/85: "Grammaire comparée du brcton armoricain et du gallois. Explications de textes en breton et en breton moderne";

en 1885/86: "Etude du breton armoricain depuis les origines jusqu'au XVIe siècle, d'après les chartes et les vies des saints".

A partir de 1886/87, le cours est rebaptisé: "Histoire des langues et des peuples celtiques" et il y est d'abord traité de l'"Etude du breton armoricain, d'après les noms de lieux et de personnes. Histoire de l'Armorique jusqu'au Vle siècle", puis,

en 1887/88: "Grammaire historique du comique. Explication de morceaux choisis de la littérature galloise";

en 1888/89: "Grammaire historique et pratique du breton moderne. Explication de morceaux choisis de la littérature comique";

en 1889/90: "Explication de morceaux choisis de la littćrature bretonne-armoricaine"; en 1890/91: "Grammaire pratique du breton moderne. Toponomastique bretonne"; en 1891/92: "Grammaire historique du brcton modeme. Explication de morceaux choisis de la littérature bretonne"; 
en 1892/93: "Grammaire du gallois moderne" ct "Explication de morceaux choisis en breton armoricain";

en 1893/94: "Grammaire du breton armoricain" cl "Explication de morceaux choisis en gallois";

en 1894/95: "La conjugaison bretonne. Explication de morceaux choisis des poètes gallois";

en 1895/96: "Explication de textes bretons. Grammaire comique";

en 1896/97: "Explication de textes comiques" ct "Phonétique comparée du gaèlique et du brittonique (gallois, cornique, breton-armoricain)".

h : En 1884/85, Loth fait une "Explication des ouvrages français (moyen-âge). Grammaire comparée des langues classiques. Grammaire historique du vieux français." et, en 1885/86: "Explication des ouvrages français (moyen-âge).Grammaire historique du vieux français".

i : Basch est "chargé du cours de langue et de littćrature allcmandes".

j : Pinloche est plus particulièrement chargé de l'anglais.

k : En 1892/93, Loth annonce, entre autres, "Principes de grammaire comparée du grec et du latin (phonétique)" ct, en 1896/97: "Eléments de grammaire comparée du grec et du latin".

1: Au second semestre de 1892/93, Rćbclliau devient professeur et dispense un enseignement de "Littérature et langue françaises" dans lequel il cst assisté par Dottin qui fait entre autres de la "Phonétique du vieux français"; cn 1896/97, Dottin annonce, entre autres, de la "Grammaire historique du français".

m : La répartition des tâches se fait entre "Littćrature et langue allemandes" pour Basch et "Littérature et langue anglaises" pour Barbeau. 


\section{STRASBOURG}

\begin{tabular}{|c|c|c|c|}
\hline & Littérature & Littérature & Littérature \\
\hline & Française & Ancienne & Etrangère \\
\hline $1858-59$ & LAFITE & COLIN & BERGMANN \\
\hline $1859-61$ & LAFITE $^{\mathrm{a}}$ & Cambouliu & BERGMANN \\
\hline $1861-62$ & LAFITE & CAMBOULIU & $\underline{\text { BERGMANN }}^{b}$ \\
\hline $1863-64^{c}$ & LAFITE & Campaux & BERGMANN \\
\hline $1865-67$ & LAFITE $^{\mathrm{d}}$ & CAMPAUX & $\underline{\text { BERGMANN }}^{\mathrm{e}}$ \\
\hline $1868-69$ & $\begin{array}{l}\text { LAFITE } \\
\text { Guibal }\end{array}$ & CAMPAUX & $\underline{\text { BERGMANN }}^{\mathrm{f}}$ \\
\hline
\end{tabular}

\section{NOTES SUR STRASBOURG}

a : En 1859/60, cours sur l'“Histoire de la littćrature française, depuis son origine jusqu'au premier tiers du XVIle siècle".

b : En 1861/62, "Le professeur expliquera La Divine Comédie de Dante et comparera les Poésies de Pétrarque avec celles des Troubadours."

c : En 1864, Fustel de Coulanges est nommć à Strasbourg.

d : En 1866/67, traite de l"'Histoire de la littćrature française depuis son origine jusqu'au XVIe siècle".

e : En 1866/67, fait entre autres une "Histoire comparćc de la langue anglaise et des idiomes germaniques".

f : Bergmann passera de l'université française de Strasbourg à l'université allemande de Strasbourg après 1871 . 


\section{TOULOUSE}

$\begin{array}{lllllll}\text { Littérature } & \text { Littérature } & \text { Littérature } & \text { Lit \& Lg } & \text { Littérature } & \text { Littérature } & \text { Lg \& Lit } \\ \text { Française } & \text { Ancienne } & \text { Ancienne* } & \text { Romanes } & \text { Etrangère } & \text { Grecque } & \text { Espagnol. Anglaises }\end{array}$

\begin{tabular}{|c|c|c|c|c|c|c|c|c|}
\hline $1859-60$ & DELAVIGNE a & SAUVAGE & HAMEL & & & & & \\
\hline $\begin{array}{l}1863-65 \\
1865-70\end{array}$ & $\frac{\text { DEL,AVIGNE }}{\text { DEL,AVIGNE }}$ & & $\begin{array}{l}\text { HAMEL } \\
\text { HAMEL }\end{array}$ & & $\begin{array}{l}\text { d'Hugues } \\
\text { d'HUGUES }\end{array}$ & & & \\
\hline $\begin{array}{l}1873-76 \\
1876-78\end{array}$ & $\frac{\text { DELAVIGNE }}{\underline{\text { DELAVIGNE }}}$ & Lallier & $\begin{array}{l}\text { BREDIF } \\
\text { BREDIF } \\
\text { Lebègue }\end{array}$ & & $\begin{array}{l}\text { d'HUGUES } \\
\text { d'HUGUES }\end{array}$ & & & \\
\hline $1878-79$ & DELAVIGNE & LALLIER & $\begin{array}{l}\text { BREDIF } \\
\text { Lebègue }\end{array}$ & & d'HUGUES & & & \\
\hline $1879-80$ & DELAVIGNE & $\begin{array}{l}\text { LALLIER } \\
\text { Girard }\end{array}$ & LEBEGUE & & $\begin{array}{l}\text { HALLBERG } \\
\text { Mabilleau }\end{array}$ & & & \\
\hline $1880-81$ & Benoist & $\begin{array}{l}\text { LALLIER } \\
\text { Girard }\end{array}$ & LEBEGUE & & $\begin{array}{l}\text { HALLBERG } \\
\text { Mabilleau }\end{array}$ & & & \\
\hline $1881-82$ & BENOIST & $\begin{array}{l}\text { LALLLIER } \\
\text { Constans }\end{array}$ & LFBEGUE & Thomas $^{c}$ & $\begin{array}{l}\text { HALLBERG }{ }^{b} \\
\text { Duméril }\end{array}$ & Girard ${ }^{d}$ & & \\
\hline $1882-83$ & BENOIST & $\begin{array}{l}\text { LALLIER } \\
\text { Constans } \\
\text { Mérimée }\end{array}$ & LEBEGUE & Thomas & $\begin{array}{l}\text { HALLBERG } \\
\text { Duméril }\end{array}$ & Girard & & \\
\hline $1883-84$ & BENOIST & $\begin{array}{l}\text { LALLIER } \\
\text { Dosson } \\
\text { Mérimée }\end{array}$ & $\begin{array}{l}\text { LEBEGUE } \\
\text { Pottier } \\
\text { Mazuel }\end{array}$ & Thomas & $\begin{array}{l}\text { HALLBERG } \\
\text { Duméril }\end{array}$ & & & \\
\hline $1884-85$ & BENOIST & $\begin{array}{l}\text { Antoine } \\
\text { Mérimée }\end{array}$ & $\begin{array}{l}\text { LEBEGUE } \\
\text { Duméril }\end{array}$ & Thomas & $\begin{array}{l}\text { HALLBERG } \\
\text { Duméril }\end{array}$ & & & \\
\hline $1885-87$ & $\begin{array}{l}\text { BENOIST } \\
\text { Mérimée }\end{array}$ & $\begin{array}{l}\text { ANTOINE }{ }^{f} \\
\text { Mérimée }\end{array}$ & $\begin{array}{l}\text { LEBEGUE } \\
\text { Duméril }\end{array}$ & Thomas & $\begin{array}{l}\text { HALLBERG } \\
\text { Duméril }\end{array}$ & $\begin{array}{l}\text { BEAUDOIN }{ }^{\circ} \\
\text { Mazuel }\end{array}$ & & \\
\hline $1887-89$ & BENOIST & $\begin{array}{l}\text { ANTOINE/MERIMEE } \\
\text { Dumbach }\end{array}$ & $\begin{array}{l}\text { LEBEGUE } \\
\text { Duméril }\end{array}$ & Thomas & $\begin{array}{l}\text { HALLBERG } \\
\text { Duméril } \\
\text { ANTOINE } 8\end{array}$ & $\begin{array}{l}\text { BEAUDOIN } \\
\text { Durrbach/Mazuel }\end{array}$ & MERIMEE & \\
\hline $1889-90$ & $\begin{array}{l}\text { BENOIST } \\
\text { Jeanroy }\end{array}$ & $\begin{array}{l}\text { ANTOINE/MERIMEE } \\
\text { Dürrbach }\end{array}$ & $\begin{array}{l}\text { LEBEGUE } \\
\text { Duméril }\end{array}$ & Jeanroy ${ }^{h}$ & $\begin{array}{l}\text { HALLBERG } \\
\text { Duméril }\end{array}$ & $\begin{array}{l}\text { BEAUDOIN } \\
\text { Dürrbach/Mazuel }\end{array}$ & MERIMEE & \\
\hline $1890-91$ & $\begin{array}{l}\text { BENOIST } \\
\text { Jeanroy }\end{array}$ & $\begin{array}{l}\text { ANTOINE/MERIMEE } \\
\text { Dürbach }\end{array}$ & $\begin{array}{l}\text { LEBEGUE } \\
\text { Duméril }\end{array}$ & $\begin{array}{l}\text { THOMAS } \\
\text { Jeanroy }\end{array}$ & $\begin{array}{l}\text { HALLBERG } \\
\text { Duméril }\end{array}$ & $\begin{array}{l}\text { BEAUDOIN } \\
\text { Dürrbach/Mazuel }\end{array}$ & MERIMEE & \\
\hline $1891-92$ & $\begin{array}{l}\text { BENOIST } \\
\text { Jeanroy }\end{array}$ & ANTOINE/MERIMEE & LEBEGUE & $\begin{array}{l}\text { THOMAS } \\
\text { Jeanroy }\end{array}$ & $\begin{array}{l}\text { HALLBERG } \\
\text { Duméril }\end{array}$ & $\begin{array}{l}\text { BEAUDOIN } \\
\text { Navarre/Audoin }\end{array}$ & MERIMEE & \\
\hline $1892-93$ & $\frac{\text { BENOIST }}{\text { Jeanroy }}$ & ANTOINE/MERIMEE & LEBEGUE & $\begin{array}{l}\text { THOMAS } \\
\text { Jeanroy }\end{array}$ & $\begin{array}{l}\text { HALLBERG } \\
\text { Duméril }\end{array}$ & $\begin{array}{l}\text { BEAUDOIN } \\
\text { Navarre/Audoin }\end{array}$ & MERIMEE & \\
\hline $1893-94$ & $\frac{\text { BENOIST }}{\text { JEANROY }}$ & ANTOINE/MERIMEE & $\begin{array}{l}\text { LEBEGUE } \\
\text { Dürbach }\end{array}$ & JEANROY & HALLBERG & $\begin{array}{l}\text { BEAUDOIN } \\
\text { Navarre/Audoin }\end{array}$ & MERIMEE & DUMERIL \\
\hline $1894-95$ & $\frac{\text { BENOIST }}{\text { Guy }}$ & ANTOINE/MERIMEE & DURRBACH & JEANROY & HALLBERG & $\begin{array}{l}\text { BEAUDOIN } \\
\text { Navarre }\end{array}$ & MERIMEE & DUMERIL \\
\hline $1895-96$ & BENOIST & ANTOINE/MERIMEE & DURRBACH & JEANROY & HALLBERG & BEAUDOIN/DU & $\begin{array}{l}\mathrm{ACH} \\
\text { MERIMEE }\end{array}$ & DUMERIL \\
\hline $1896-97$ & $\begin{array}{l}\text { Guy } \\
\text { BENOIST } \\
\text { Guy }\end{array}$ & $\begin{array}{l}\text { ANTOINE/MERIMEE } \\
\text { DURRBACH }\end{array}$ & DURRBACH & JEANROY & HALLBERG & $\begin{array}{l}\text { Navarre } \\
\text { BEAUDOIN } \\
\text { Navarre }\end{array}$ & MERIMEE & DUMERIL \\
\hline
\end{tabular}

\footnotetext{
* : La chaire de "Littérature latine" de Sauvage disparaît pour étre rétablie en 1876 lorsqu'une chaire de "Littérature grecque" - qui deviendra "Antiquités grecques et latines" en 1879 - succàde à celle de "Littérature ancienne"; une chaire distincte de "Littérature grecque" est fondée en 1881.
} 


\section{NOTES SUR TOULOUSE}

a : En 1859/60, "le professeur exposera l'histoire de la littérature française au moyen-âge. Il étudiera, d'abord,les principaux monuments de l'histoire et de l'épopée au XIIle et au XIVe siècles";

en 1865/66, "le professeur étudiera, dans leur apparition successive, les oeuvres caractéristiques de l'esprit français, pendant la durće du moyen-âge. Il analysera tour à tour les épopées chevaleresques et allégoriques, les mćmoires historiques (Villehardouin, Joinville, Froissard); et dans le second semestre, il s'occupera surtout des origines et des progrès du théâtre, pendant le XVe ct le XVIe siècles";

en 1868/69, "le professeur prendra pour sujet de scs ćtudes,l'histoire du thêâtre en France pendant toute la durée du moyen-âge, et particulièrement de ses modifications et de ses progrès pendant le XVIe siècle et jusqu'à la venuc de Comeille";

en 1873/74: "Le professeur fera l'histoirc des lettres françaises au moyen-âge. Il s'occupera d'abord de l'épopée, ct commencera par l'ćtude du Cycle carlovingien,et particulièrement de La Chanson de Roland."

b : Hallberg fait une "Histoire comparée des littćratures méridionales au moyen-âge".

c : Le cours de "Langues et littératures romanes" commence

en 1881/82 avec de la "Phonétique comparćc des langues romanes"; Antoine Thomas annonce,

en $1882 / 83$, "Explication des textes de vieux français inscrits aux programmes des agrégations de grammaire et des lettres. Explication des plus anciens textes de langue d'oc. Phonétique comparée des langues romancs";

en 1883/84: "Grammaire historique de la langue provençale et de tous ses dialectes (...) L'épopée française au moyen-âge (...) Histoire de la versification française" et, comme toutes les années suivantes, l'explication des textes d'ancien-français portés au programme de la licence et de l'agrégation (essenticllement la Chanson de Roland);

en 1884/85: "Etude grammaticale de la languc des troubadours" et "Histoire de l'épopée française au moyen-âge";

en 1885/86: "Explication de La Chanson de Roland (...) Explication de textes provençaux (...) Grammaire élémentaire de la langue des Troubadours";

en 1887/88: "Bertran de Born, sa vic et ses ocuvres (...) Grammaire historique de la langue provençale (...) Explication des poćsies de Pcire Vidal, troubadour toulousain de la fin du XIIe siècle" et, 
en 1888/89: "Grammaire comparćc de l'ancien provençal et de l'ancien français (...) Explication d'anciens textes provençaux".

Thomas conservera sa chaire jusqu'en 1893 mais c'est Jeanroy qui désormais assurera les cours, avant d'être à son tour nommć professcur dans cette même chaire qu'il rebaptise: "Langues et littératures méridionales" au moment où il en prend définitivement possession.

d : A partir de 1881, et jusqu'à 1897 au moins, il y a un enseignement de grammaire auprès de la chaire de littérature, assuré par un maître de conférences, de Girard à Navarre.

e : En 1885/86, Beaudoin assure "Histoire du dévcloppement général des langues indogermaniques et étude particulière de la formation de la langue grecque":

en 1886/87: "Métrique grecque et latine" entre autres;

en 1891/92: "Principes généraux de la phonćtique indo-européenne. Métrique grecque (...)";

en 1896/97: "Phonétique grecque et latine" cntre autres.

f : En 1886/87, Antoine annonce: "Métrique latine" cntre autres

g: Sous le couvert d'un cours rattaché à la chairc de littérature étrangère, Antoine annonce, en 1887/88: "Etude de la grammaire latine dans une grammaire classique allemande".

$\mathrm{h}$ : Comme suppléant de Thomas, Jcanroy intitulc son cours,

en 1889/90: "Poésie lyrique de la France méridionale, aux XIle et XIIle siècles (...) La conjugaison en provençal et en ancien français. Explication de textes", ainsi que l'explication des textes d'ancien français portćs aux programmes de la licence et de l'agrégation, comme toutes les années suivantes;

en 1890/91: "Les grands chroniqueurs du moyen-âge: Villehardouin, Joinville, Commines, Froissart (...) Phonétique du provençal et de l'ancien français (...) Explication de textes provençaux et français du moyen-âge";

en 1891/92: "La société au XIVe siècle d'après Froissart et quelques autres documents (...) Grammaire sommaire de l'ancien français (...) Explication de textes provençaux"; en 1892/93: "Histoire de la littćrature méridionale aux XIIe et XIIIe siècles: la poésie lyrique des Troubadours (...) Grammairc sommaire de l'ancien français et de l'ancien provençal. Morphologie: formation des mots (...) Explication de textes provençaux".

En 1893/94, l'intitulé de la chaire est modifić en "Langue et littérature méridionales" et Jeanroy, devenu professeur, y enseigne:"La poćsie au moyen-âge (...) Explication de textes provençaux"; 
en 1894/95: "Histoire de la littérature française au moyen-âge: l'épopée au nord et au midi" avec l'explication de textes d'ancien français et de provençal et, au second semestre, "Grammaire historique du français:syntaxe" entre autres;

en 1895/96: "L'épopée française au moyen-âge. Le cycle méridional (...) Langue et littérature italiennes" avec l'explication de textes en rapport avec cet enseignement et, au second semestre, de la "Phonétique française".

En 1896/97: "Grammaire de l'ancien français : phonćtique et morphologie (...) Langue et littérature italiennes" avec, au second semestre: "Histoire sommaire de la versification française".

i : En 1891/92, Audoin annonce entre autres: "Grammaire comparée du grec et du latin. Phonétique et formation des mots (...) Syntaxe grecque et latine;

en 1892/93: "Déclinaison grecque et latine; formes ct syntaxe" au premier semestre et, au second: "Sanscrit. Déclinaison grecque et latinc; formes et syntaxe" entre autres;

en 1893/94: "Grammaire et philologie grecque et latine (...) Métrique grecque et latine (...) Grammaire comparé du grec et du latin". 
INDEX

$-91-$ 


\section{INDEX : MODE D'EMPLOI}

comprenant six colonnes :

Pour faciliter la consultation de ce travail, nous avons constitué un index

$\left.1^{\circ}\right)$ NOM

Seuls figurent les noms des enseignants ; on ne trouvera pas, par exemple, les auteurs étudiés. En revanche, nous avons porté dans ces colonnes des enseignants qui, sans figurer dans un tableau, sont mentionnés dans les notes, soit qu'ils y soient signalés comme professeur honoraire ( cf GERUZEZ), soit comme enseignants dans des disciplines extérieures à notre étude ( cf DURKHEIM), soit commc assurant une charge de cours en marge du cursus universitaire ( cf CHANTRE).

\section{$\left.2^{\circ}\right)$ PRENOM}

$\left.3^{\circ}\right)$ ANNEE DE NAISSANCE notre disposition par M. Karady.

Cette indication -comme celle du prénom- est extraite du fichier mis à

$4^{\circ}$ ) FACULTE

a 1887 ;

Deux cas particuliers à signaler :

- Douai a étć regroupć avcc Lille pour tous les enseignements antérieurs

- Paris a ćté divisé en trois :

- "frg" = "FRançais el Grammaire comparée";

- "lag" = "LAtin et Grec" ;

- "slv" = "Sanscrit ct Langucs Vivantes".

$\left.5^{\circ}\right)$ ANNEES

Les années portées dans cctte colonne correspondent à celles figurant dans les tableaux, ce qui induit certaines distorsions avec les situations réelles :

- les affiches ont parfois un an de retard pour inscrire ou effacer les enseignants (l'absence d'une affiche semestriclle pouvant encore accroître les décalages) ;

- des enseignants figurent en même temps dans deux universités (cf CHASLES, THOMAS...) lorsqu'ils interviennent à titre de suppléant dans une faculté alors qu'ils sont en poste dans une autre.

Pour des cnscignants qui ne sont portés qu'en note, on a retenu l'année universitaire correspondant à la date de la note, même si lcur magistère s'est exercé sur d'autres années.

\section{$\left.6^{\circ}\right)$ NOTES}

Les notes sont reportécs sous la forme : A (10) où A correspond au report de l'appel de note figurant dans le tablcau $\mathrm{ct}$ les chiffres entre parenthèses à la page où est explicitée la note. On lira donc: " pour cet enscignant, consulter la note " $\mathrm{A}$ " de la page $10^{\text {". }}$ 


$\begin{array}{llllll}\text { ALBERT } & \text { Paul } & 1827 & \text { POITIERS } & 1860-1866 & \\ \text { ALLAIS } & \text { Gustave } & 1853 & \text { CLERMONT } & 1883-1893 & \\ & & & \text { RENNES } & 1893-1897 & \\ \text { ALLEGRE } & \text { Femand } & 1849 & \text { LYON } & 1884-1892 & \\ & & & \text { LILLE } & 1891-1893 & \\ & & & \text { LYON } & 1893-1897 & \\ \text { ANGELLIER } & \text { Auguste } & 1848 & \text { LILLE/DOUAI } & 1881-1897 & \\ \text { ANOT } & \text { Auguste } & 1799 & \text { POITIERS } & 1859-1863 & \text { A (79) } \\ \text { ANSTETT } & \text { Jean-Philippe } & 1831 & \text { LYON } & 1884-1887 & \\ \text { ANTOINE } & \text { Ferdinand } & 1844 & \text { TOULOUSE } & 1884-1897 & \text { F (88) } \\ \text { ARNOULD } & \text { Edmond } & 1811 & \text { PARIS slv } & 1853-1860 & \text { E (33) } \\ \text { ARNOULD } & \text { Louis } & 1862 & \text { POITIERS } & 1890-1897 & \\ \text { AUBERTIN } & \text { Charles } & 1825 & \text { DIJON } & 1859-1874 & \text { D/ (55) } \\ & & & \text { DIJON } & 1879-1895 & \text { I (55) } \\ \text { AUDOIN } & \text { Edouard } & 1864 & \text { AIX } & 1889-1890 & \text { M (40) } \\ & & & \text { TOULOUSE } & 1891-1894 & \text { I (89) } \\ & & & \text { POITIERS } & 1896-1897 & \\ \text { AUDOLLENT } & \text { Auguste } & 1864 & \text { CLERMONT } & 1893-1897 & \\ \text { AUERBACH } & \text { Bertrand } & 1856 & \text { CAEN } & 1883-1885 & \\ \text { AULARD } & \text { François } & 1849 & \text { DIJON } & 1879-1880 & \text { I (55) } \\ & & & \text { POITIERS } & 1879-1884 & \text { E (79) }\end{array}$




\begin{tabular}{|c|c|c|c|c|c|}
\hline $\begin{array}{l}\text { BAILLY } \\
\text { BARBEAU }\end{array}$ & $\begin{array}{l}\text { Edmond } \\
\text { Charles }\end{array}$ & $\begin{array}{l}1848 \\
1867\end{array}$ & $\begin{array}{l}\text { LILLEE/DOUAI } \\
\text { RENNES }\end{array}$ & $\begin{array}{l}1882-1889 \\
1896-1897\end{array}$ & M (84) \\
\hline BARDINET & & & POITIERS & $1882-1883$ & \\
\hline BARDOT & Georges & 1863 & GRENOBLE & $1892-1898$ & \\
\hline $\begin{array}{l}\text { BARET } \\
\text { BARET }\end{array}$ & $\begin{array}{l}\text { Pierre } \\
\text { Adrien }\end{array}$ & $\begin{array}{l}1814 \\
1843\end{array}$ & $\begin{array}{l}\text { CLERMONT } \\
\text { PARIS slv }\end{array}$ & $\begin{array}{l}1859-1873 \\
1887-1897\end{array}$ & $A(53)$ \\
\hline BARON & Charles & 1861 & CLERMONT & $1887-1897$ & \\
\hline BASCH & Victor & 1863 & $\begin{array}{l}\text { NANCY } \\
\text { RENNES }\end{array}$ & $\begin{array}{l}1885-1887 \\
1887-1897\end{array}$ & $\begin{array}{l}P(75) \\
\operatorname{lnM}(84)\end{array}$ \\
\hline BEAUDON-MONDRY & Pierre & 1852 & $\begin{array}{l}\text { BORDEAUX } \\
\text { TOULOUSE }\end{array}$ & $\begin{array}{l}1880-1885 \\
1885-1897\end{array}$ & $\begin{array}{l}\text { I (47) } \\
\text { E (88) }\end{array}$ \\
\hline BEAUSSIRE & Emile & 1824 & POITIERS & 1859.1867 & \\
\hline BEDIER & Joseph & 1864 & CAEN & $1891-1893$ & \\
\hline BEIJAME & Alexandre & 1842 & PARIS slv & $1881-1897$ & \\
\hline BENARD & Lén & 1847 & POITIERS & $1882-1885$ & $F(79)$ \\
\hline BENLOEW & Louis & 1818 & DIJON & $1853-1877$ & $B / C(55)$ \\
\hline BENOIST & Eugène & & $\begin{array}{l}\text { NANCY } \\
\text { AIX } \\
\text { PARIS lag }\end{array}$ & $\begin{array}{l}1867-1870 \\
1871-1874 \\
1873-1887\end{array}$ & $\begin{array}{l}D(73) \\
C(39) \\
G(27)\end{array}$ \\
\hline ENOIST & Antoine & 1846 & $\begin{array}{l}\text { BORDFAUXX } \\
\text { TOUI.OUSE: }\end{array}$ & $\begin{array}{l}1878-1880 \\
1880-1897\end{array}$ & $H(47)$ \\
\hline BENOIT & Charles & 1815 & NANCY & $1858-1883$ & $A(73) I(64)$ \\
\hline BERGAIGNE & Abel & 1838 & PARIS slv & $1877-1888$ & $\begin{array}{l}\mathrm{I}(33) \mathrm{K} /(35) \\
\mathrm{F}(61)\end{array}$ \\
\hline BERGER & Adolphe & 1810 & PARIS lag & $1854-1869$ & $C(27)$ \\
\hline BERGMANN & Frédétic & 1812 & STRASBOUURG & $1858-1869$ & $\mathrm{~B} / \mathrm{E} / \mathrm{F}(85)$ \\
\hline BERR & Henri & 1863 & LIILIE/DOUAI & $1886-1888$ & \\
\hline BERTHELE & & & MONTPEILIIIER & $1895-1896$ & $\mathrm{~L}(71)$ \\
\hline BERTRAND & Edmond & 1829 & CAINN & $1845-1864$ & \\
\hline & & & GRIENOIBI.E & $1881 \cdot 1898$ & $G(59)$ \\
\hline BESSON & Emile & 1858 & BORDFAUXX & $1891-1894$ & $\mathrm{~T}(49)$ \\
\hline BETOUT & Emest & 1854 & LII.IF:/IOUAI & $\begin{array}{l}1894-1898 \\
1881-1886\end{array}$ & \\
\hline BEVOTTE voir GENDARME & DE $B$. & & & & \\
\hline BIZOS & Gaston & 1848 & AIX & $1879-1890$ & $\begin{array}{l}E(39) L(40) \\
N(41)\end{array}$ \\
\hline & & & DIJON & $1895-1896$ & $P(56)$ \\
\hline BOISSIERE & Gustave & 1837 & AIX & $1885-1895$ & \\
\hline BOISSONNADE & J.-Francois & 1774 & PARIS & $1853-1855$ & \\
\hline BONAFOUS & Norbert & 1809 & $\operatorname{AIX}$ & $1847-1878$ & \\
\hline BONAFOUS & Raymond & 1856 & AIX & $1895-1897$ & $\mathrm{~S}(42) \mathrm{T}(42)$ \\
\hline BONNET & Maximilien & 1841 & MONTPPELLLIIER & $1880-1897$ & \\
\hline BORE & Leon & 1807 & BESANCON & $1858-1860$ & \\
\hline & & & $\begin{array}{l}\text { DIJON } \\
\text { GRENOBLE }\end{array}$ & $\begin{array}{l}1859-1870 \\
1870-1871\end{array}$ & $\mathrm{D}(55)$ \\
\hline BOSSERT & Adolphe & 1832 & LIL.LIE/DOUAI & $1871-1882$ & $\mathrm{C} D(61)$ \\
\hline BOUCHE-LECLERCQ & Auguste & 1842 & MONTIPILLITER & $1877-1890$ & \\
\hline BOUCHER & Leon & 1838 & BIESANCON & $1875-1896$ & \\
\hline BOUCHERIE & Anatole & & MONTPPEIIIIIR & $1879-1883$ & $A / B(69)$ \\
\hline BOUGOT & Auguste & 1842 & DUION & $1877-1893$ & $K(56)$ \\
\hline $\begin{array}{l}\text { BOULIN } \\
\text { BOULLY }\end{array}$ & Stéphane & 1853 & $\begin{array}{l}\text { BOORDEAUX } \\
\text { CI.ERMONT }\end{array}$ & $\begin{array}{l}1885-1891 \\
1881-1882\end{array}$ & $N / P(48)$ \\
\hline $\begin{array}{l}\text { BOURCIEZ } \\
\text { BOURGUET }\end{array}$ & Edouard & 1854 & $\begin{array}{l}\text { BORDE:AUX } \\
\text { I.YON }\end{array}$ & $\begin{array}{l}1883-1897 \\
1896-1897\end{array}$ & K (48) S (49) \\
\hline BREDIF & Léon & 1835 & ToUl.oUSI: & $1873-1879$ & \\
\hline BRENOUS & Joseph & 1858 & $\begin{array}{l}\text { CI.ERMONT } \\
\text { MONIPIIILIIER }\end{array}$ & $\begin{array}{l}1882-1885 \\
1885-1895\end{array}$ & \\
\hline & & & NIX & 1895.1896 & $S(42)$ \\
\hline BRUNOT & Ferdinand & 1860 & I.YON & 1883-1892 & $\mathrm{K}(67)$ \\
\hline BUCHNER & Alexandre & 1827 & $\begin{array}{l}\text { CAINN } \\
\text { CAIS }\end{array}$ & $\begin{array}{l}1892-1897 \\
1868-1897\end{array}$ & $\begin{array}{l}\mathrm{T}(25) \mathrm{O}(30) \\
\mathrm{F}(51)\end{array}$ \\
\hline BURNOUF & Emile & 1821 & NANCY & $1858-1867$ & \\
\hline
\end{tabular}




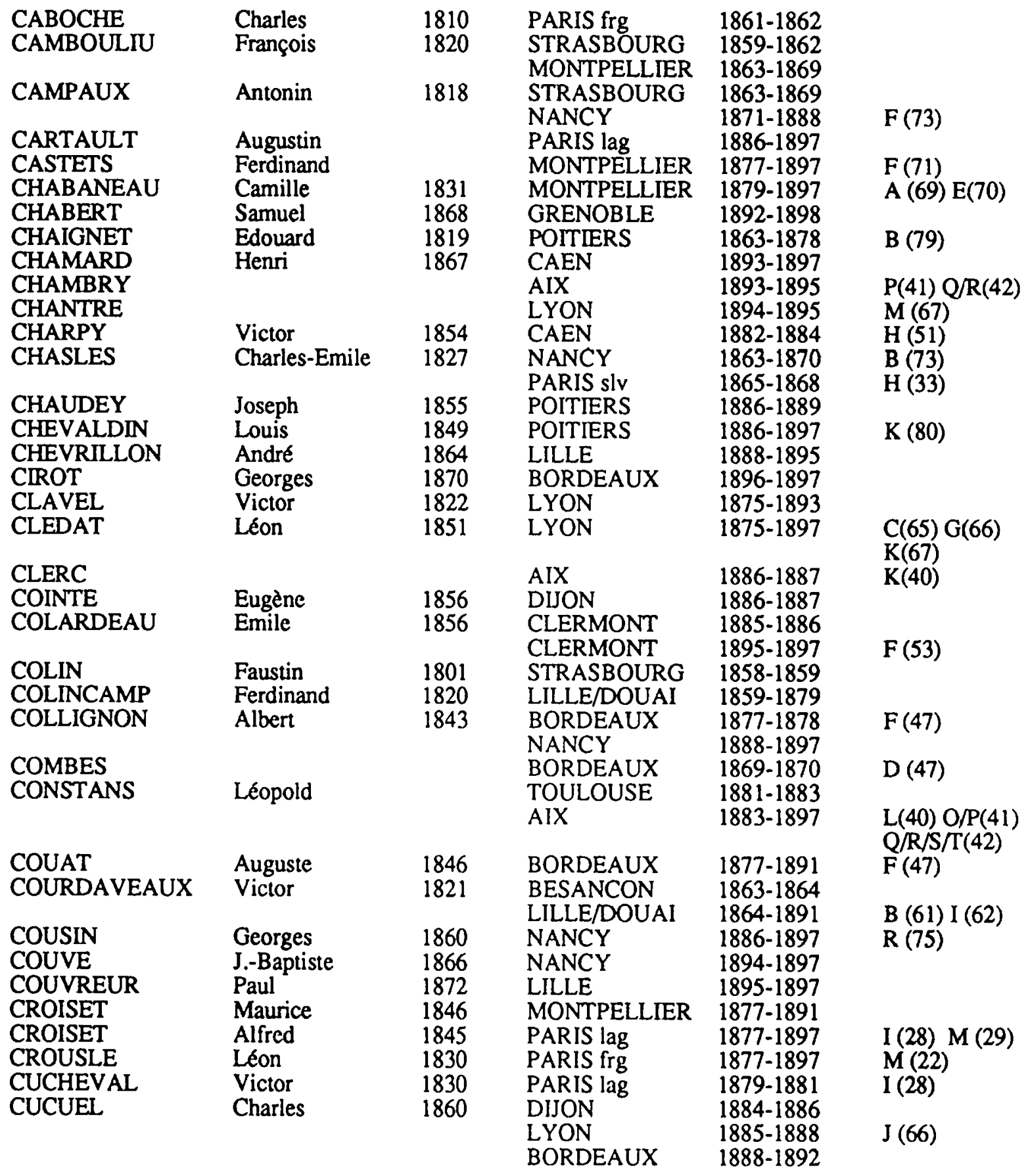




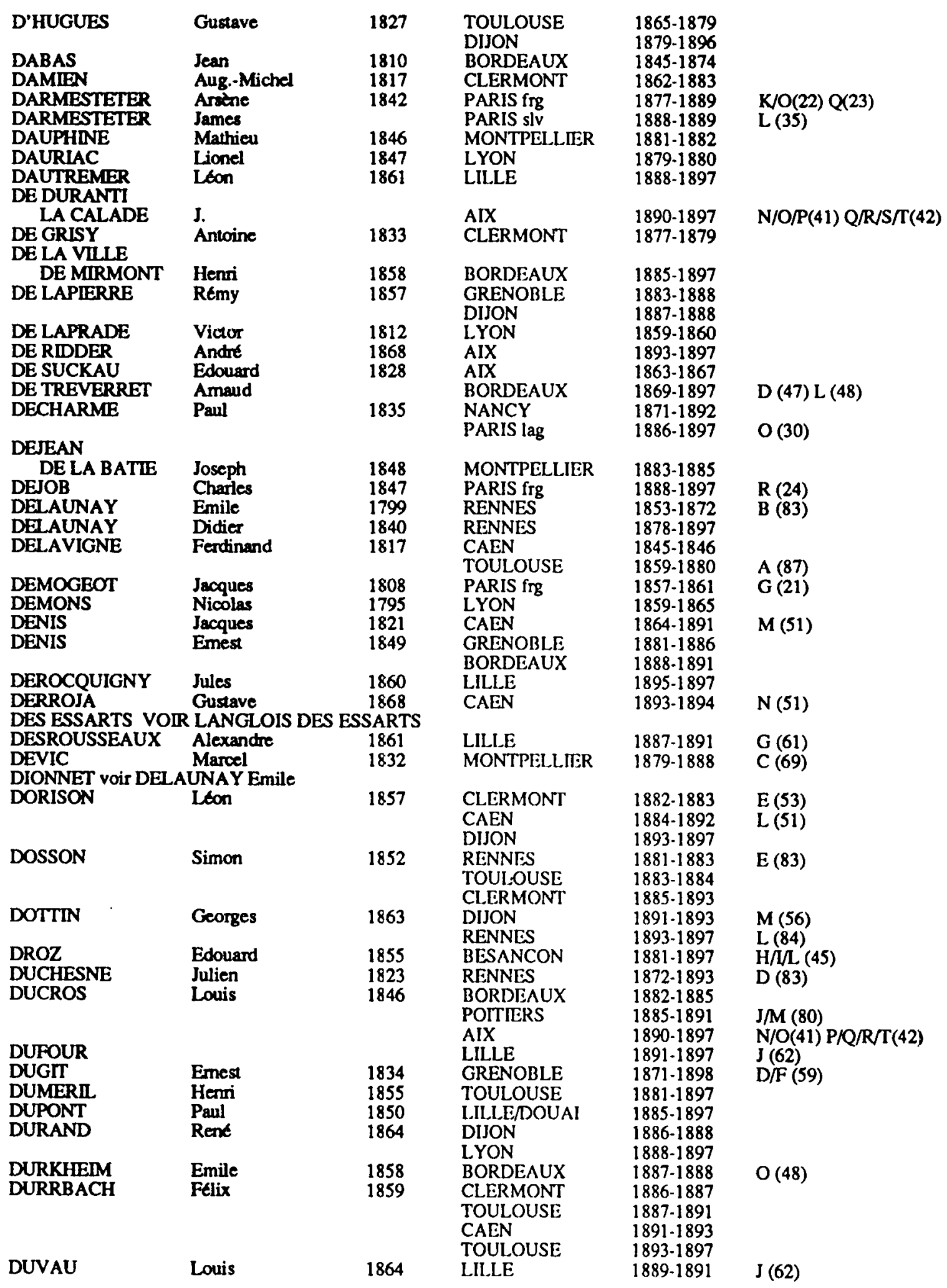




\begin{tabular}{|c|c|c|c|c|c|}
\hline EDET & Georges & 1854 & $\begin{array}{l}\text { MONTPELLIER } \\
\text { PARIS }\end{array}$ & $\begin{array}{l}1882-1885 \\
1896-1897\end{array}$ & \\
\hline $\begin{array}{l}\text { EGGER } \\
\text { EGGER }\end{array}$ & $\begin{array}{l}\text { Emile } \\
\text { Victor }\end{array}$ & $\begin{array}{l}1813 \\
1848\end{array}$ & $\begin{array}{l}\text { PARIS lag } \\
\text { BORDEAUX }\end{array}$ & $\begin{array}{l}1854-1885 \\
1878-1879\end{array}$ & $\begin{array}{l}\mathrm{C} / \mathrm{D} / \mathrm{G}(27) \mathrm{H}(28) \\
\mathrm{G}(47)\end{array}$ \\
\hline ERHARD & Auguste & 1861 & $\begin{array}{l}\text { NANCY } \\
\text { BORDEAUX } \\
\text { GRENOBLE } \\
\text { CLERMONT }\end{array}$ & $\begin{array}{l}1882-1883 \\
1885-1887 \\
1887-1889 \\
1889-1897\end{array}$ & \\
\hline $\begin{array}{l}\text { ERNAULT } \\
\text { ETIENNE } \\
\text { ETIENNE }\end{array}$ & $\begin{array}{l}\text { Emile } \\
\text { Louis } \\
\text { Eugène }\end{array}$ & $\begin{array}{l}1852 \\
1813 \\
1843\end{array}$ & $\begin{array}{l}\text { POITIERS } \\
\text { PARIS frg } \\
\text { NANCY }\end{array}$ & $\begin{array}{l}1884-1896 \\
1869-1873 \\
1883-1897\end{array}$ & $\begin{array}{l}\mathrm{G} / \mathrm{H}(79) \\
\mathrm{N}(75)\end{array}$ \\
\hline
\end{tabular}

F

\begin{tabular}{|c|c|c|c|c|c|}
\hline FABLA & Philippe & 1860 & $\begin{array}{l}\text { MONTPELLIER } \\
\text { AIX }\end{array}$ & $\begin{array}{l}1883-1885 \\
1892-1893 \\
1803-1807\end{array}$ & $\begin{array}{l}\mathrm{H}(71) \\
\mathrm{P}(41)\end{array}$ \\
\hline FAGUET & Emile & 1847 & BORDEAUX & $1881-1885$ & \\
\hline AURE & Henri & 1826 & $\begin{array}{l}\text { PARIS frg } \\
\text { CAEN }\end{array}$ & $\begin{array}{l}1895-1897 \\
1883-1884\end{array}$ & $U(25)$ \\
\hline $\begin{array}{l}\text { FECAMP } \\
\text { FERRAZ }\end{array}$ & Albert & 1851 & MONTPELLIER & $1882-1897$ & $G(71)$ \\
\hline $\begin{array}{l}\text { FERRAZ } \\
\text { FERTE }\end{array}$ & & & $\begin{array}{l}\text { LYON } \\
\text { BESANCON }\end{array}$ & $\begin{array}{l}1863-1864 \\
1888-1892\end{array}$ & $\mathrm{~J}(45)$ \\
\hline FEUGERE & Gaston & 1836 & PARIS frg & $1879-1880$ & \\
\hline FIALON & Eugène & 1824 & GRENOBLE & $1869-1881$ & $\mathrm{C} / \mathrm{E}(59)$ \\
\hline FIRMERY & Joseph-Léon & 1853 & RENNES & 1883-1887 & \\
\hline FONTAINE & & & $\begin{array}{l}\text { LYON } \\
\text { MONTPELLIER } \\
\text { LYON }\end{array}$ & $\begin{array}{l}1887-1897 \\
1879-1880 \\
1881-1884\end{array}$ & $N(67)$ \\
\hline RTOUL & Hippolyte & 181 & AI & 18 & \\
\hline OURNIER & Albert & 1859 & CLERMONT & $1885-18$ & \\
\hline ROMENT & Theodore & 1839 & BORDEAUX & $1877-1885$ & \\
\hline $\begin{array}{l}\text { FUSTEL } \\
\text { DE COULANGES }\end{array}$ & & 1830 & $\begin{array}{l}\text { STRASBOURG } \\
\text { PARIS frg }\end{array}$ & $\begin{array}{l}1864-1865 \\
1879-1880\end{array}$ & $\begin{array}{l}C(85) \\
\mathrm{L}(22)\end{array}$ \\
\hline
\end{tabular}




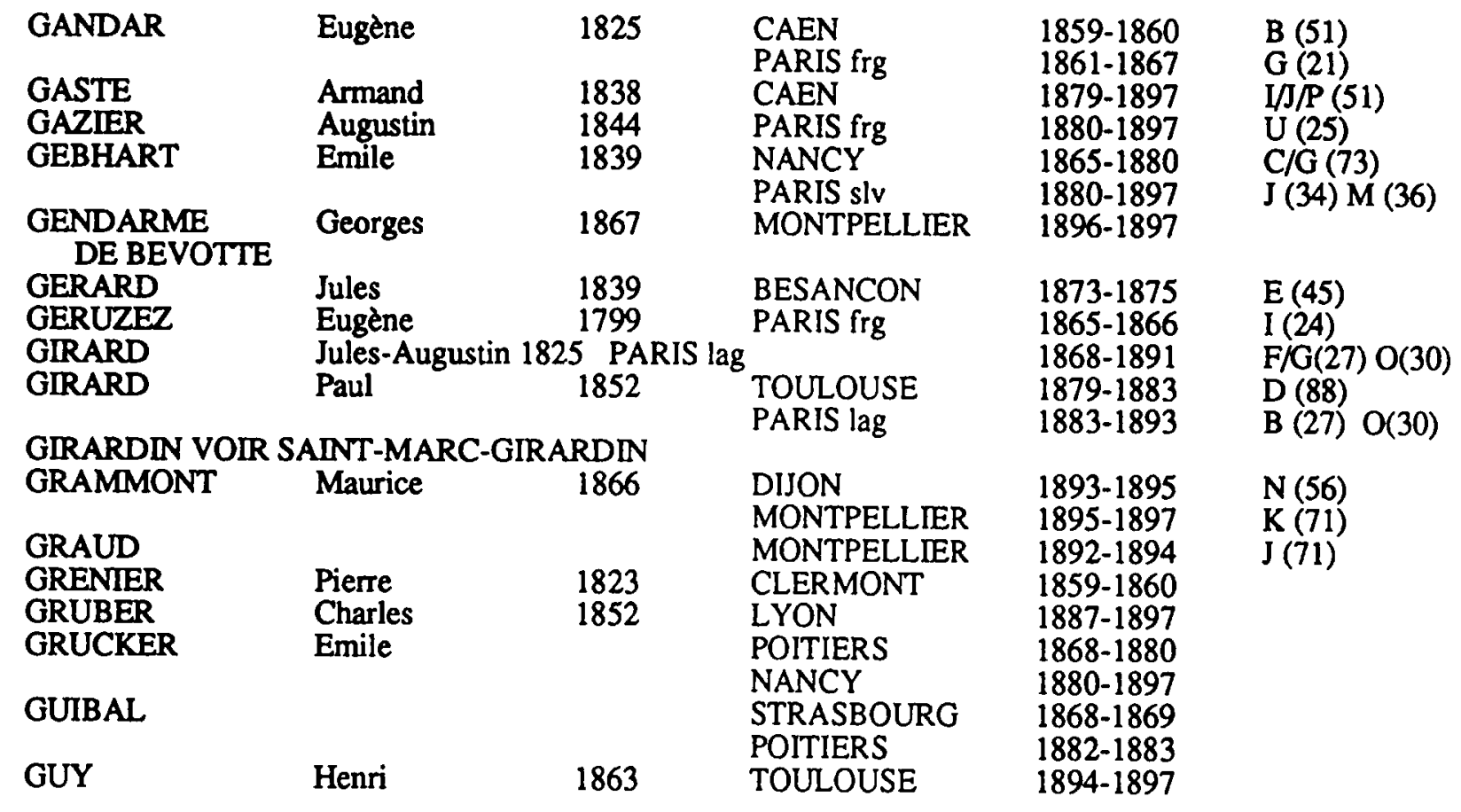


H

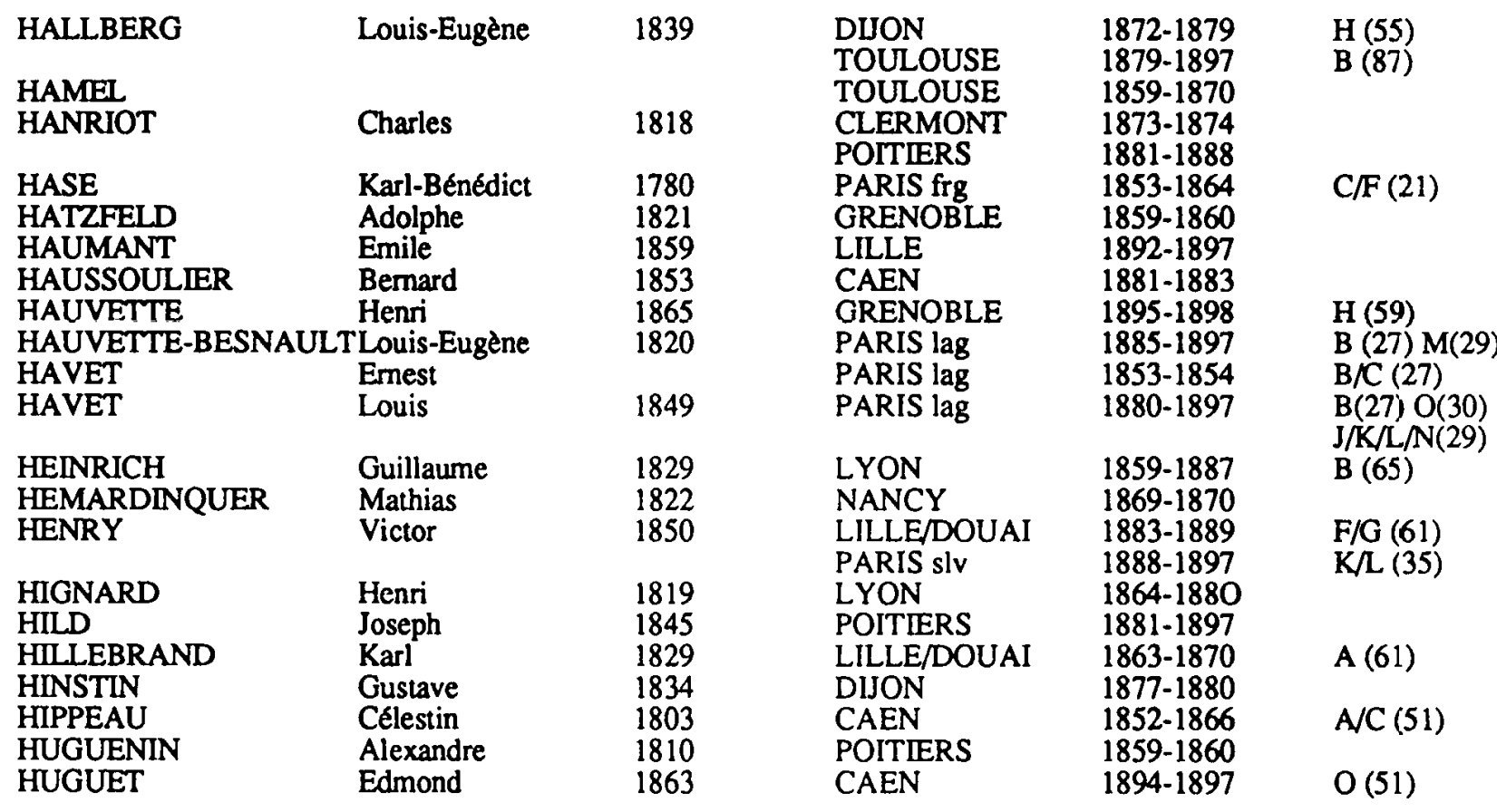

J

\begin{tabular}{|c|c|c|c|c|c|}
\hline $\begin{array}{l}\text { JACQUINET } \\
\text { JEANNEL }\end{array}$ & $\begin{array}{l}\text { Paul } \\
\text { Charles }\end{array}$ & $\begin{array}{l}1815 \\
1840\end{array}$ & $\begin{array}{l}\text { GRENOBLE } \\
\text { GRENOBLE }\end{array}$ & $\begin{array}{l}1883-1884 \\
1868-1869\end{array}$ & \\
\hline JEANROY & Alfred & 1859 & $\begin{array}{l}\text { BESANCON } \\
\text { POITLERS }\end{array}$ & $\begin{array}{l}1871-1872 \\
1883-1885 \\
1888-1889\end{array}$ & $\begin{array}{l}F(55) \\
G(45)\end{array}$ \\
\hline JOLY & Aristide & 1824 & $\begin{array}{l}\text { TOULOUSE } \\
\text { AIX } \\
\text { CAEN }\end{array}$ & $\begin{array}{l}1889-1897 \\
1859-1860 \\
1863-1884\end{array}$ & $\begin{array}{l}\mathrm{C}(87) \mathrm{H}(88) \\
\mathrm{B}(39) \\
\mathrm{D} / \mathrm{E} / \mathrm{G}(51)\end{array}$ \\
\hline JORET & Charles & 1839 & AIX & $1875-1897$ & $\begin{array}{l}\mathrm{D} / \mathrm{F} / \mathrm{I}(39) \\
\mathrm{L} / \mathrm{M}(40) \\
\mathrm{N} / \mathrm{O} / \mathrm{P}(41) \\
\mathrm{Q} / \mathrm{R} / \mathrm{S} / \mathrm{T}(42)\end{array}$ \\
\hline
\end{tabular}

K

KONTZ

KRANTZ

Emile

1849
K (45)

J (74) 


\begin{tabular}{|c|c|c|c|c|c|}
\hline LAFAYE & Georges & 1854 & $\begin{array}{l}\text { AIX } \\
\text { LYON } \\
\text { PARIS lag }\end{array}$ & $\begin{array}{l}1881-1885 \\
1884-1891 \\
1891-1896\end{array}$ & $\mathrm{G} / \mathrm{I}(39)$ \\
\hline LAFITE & Jean & 1799 & STRASBOURG & $1858-1869$ & $\mathrm{~A} / \mathrm{D}(85)$ \\
\hline LAHIILLONNE & Jacques & & GRENOBLE & $1889-1892$ & \\
\hline \multirow[t]{2}{*}{ LALLIER } & Roger & 1845 & TOULOUSE & $1876-1884$ & \\
\hline & & & PARIS lag & $1882-1885$ & K (29) \\
\hline LAMBERT & Charles & 1866 & DUON & $1895-1897$ & $P(56)$ \\
\hline LAME & Femand & 1851 & DIJON & $1884-1897$ & \\
\hline LANGE & Albert & 1842 & PARIS slv & $1882-1897$ & \\
\hline LANGLOIS & Emest & 1857 & LILLE & $1887-1897$ & $H(62)$ \\
\hline \multicolumn{6}{|l|}{ LANGLOIS } \\
\hline DES ESSARTS & Emmanuel & 1839 & DIJON & $1872-1874$ & \\
\hline \multirow[t]{2}{*}{ LANTOINE } & Henri-Eugène & 1845 & BESANCON & $1877-1878$ & $D(03)$ \\
\hline & & & PARIS lag & $1879-1882$ & I (28) \\
\hline LANUSSE & Maximin & 1853 & GRENOBLE & $1892-1893$ & \\
\hline LAPAUME & Jean & 1813 & GRENOBLE & $1863-1868$ & B (59) \\
\hline LARROUMET & Gustave & 1852 & PARIS frg & $1884-1892$ & $R(24)$ \\
\hline LE BRETON & André & 1860 & BORDEAUX & $1893-1897$ & \\
\hline LE CLERC & Victor & 1789 & PARIS lag & $1853-1865$ & $E(27)$ \\
\hline LEBEGUE & Albert & 1845 & TOULOUSE & $1876-1894$ & \\
\hline LECLERC & Eugène & 1832 & CLERMONT & 1884-1897 & $\mathrm{F} / \mathrm{G} / \mathrm{H}(53)$ \\
\hline LECONTE & Albert & 1844 & LYON & $1882-1885$ & \\
\hline LEFEBURE & & & LYON & $1879-1884$ & $E(66)$ \\
\hline LEFRANC & & & BORDEAUX & $1868-1869$ & \\
\hline LEGOUIS & Emile & 1861 & LYON & $1885-1897$ & \\
\hline LEGRAND & & & LYON & $1892-1896$ & \\
\hline LEGRAS & Jules & 1866 & BORDEAUX & 1894-1897 & \\
\hline \multirow[t]{3}{*}{ LEHANNEUR } & Louis & & AIX & $1879-1882$ & G (39) \\
\hline & & & CLERMONT & $1883-1885$ & \\
\hline & & & CAEN & $1884-1897$ & \\
\hline \multirow[t]{2}{*}{ LEMAITRE } & Jules & 1853 & BESANCON & $1882-1883$ & \\
\hline & & & GRENOBLE & $1883-1889$ & \\
\hline \multirow[t]{2}{*}{ LEMERCIER } & Aimé & 1857 & NANCY & $1887-1891$ & $S(75)$ \\
\hline & & & CAEN & 1892-1897 & \\
\hline LENA & Maurice & 1859 & AIX & $1885-1887$ & $J(40)$ \\
\hline LENIENT & Charles & 1826 & PARIS frg & $1868-1896$ & $J(24) U(25)$ \\
\hline LEVI & Sylvain & 1863 & PARIS slv & 1889-1895 & $L(35)$ \\
\hline LEVY-WOGUE & & & BESANCON & $1896-1897$ & $M(45)$ \\
\hline \multirow{2}{*}{ LICHTENBERGER } & Charles-Emest & 1847 & NANCY & $1879-1880$ & $J(74)$ \\
\hline & & & PARIS slv & $1880-1881$ & \\
\hline LICHTENBERGER & Henri & 1864 & NANCY & $1887-1897$ & $\mathrm{~T}(76)$ \\
\hline \multicolumn{6}{|l|}{ LODIN } \\
\hline DE LALAIRE & André & 1797 & DIJON & $1853-1857$ & $A(55)$ \\
\hline LORET & Victor & 1859 & LYON & $1884-1896$ & $\mathrm{E} / \mathrm{H}(66)$ \\
\hline LOTH & Joseph & 1847 & RENNES & $1883-1897$ & $\mathrm{G}(83) \mathrm{H} / \mathrm{K}(84)$ \\
\hline \multirow[t]{2}{*}{ LUCHAIRE } & Achille & 1846 & BORDEAUX & $1877-1879$ & $E / J(47)$ \\
\hline & & & PARIS frg & $1885-1886$ & $P(23)$ \\
\hline
\end{tabular}




\section{M}

\begin{tabular}{|c|c|c|c|c|c|}
\hline \multirow{3}{*}{$\begin{array}{l}\text { MABILLEAU } \\
\text { MACE }\end{array}$} & Léopold & 1853 & TOULOUSE & $1879-1881$ & \\
\hline & Alcide & 1862 & DIJON & $1888-1891$ & \\
\hline & & & RENNES & $1891-1897$ & \\
\hline \multicolumn{6}{|c|}{ MAGNY voir DUPUY DE MAGNY } \\
\hline \multicolumn{3}{|l|}{ MAHIEU } & CLERMONT & $1896-1897$ & $I(53)$ \\
\hline MAIGNIEN & Charles & 1805 & GRENOBLE & $1859-1873$ & $A(59)$ \\
\hline MARCOU & Léopold & 1826 & PARIS frg & $1879-1882$ & \\
\hline \multirow[t]{2}{*}{ MARTHA } & Constant & 1820 & LILLE/DOUAI & $1859-1860$ & \\
\hline & & & PARIS lag & $1865-1895$ & $E(27)$ \\
\hline \multirow[t]{4}{*}{ MARTHA } & Jules & 1853 & MONTPELLIER & $1880-1881$ & $\mathrm{D}(70)$ \\
\hline & & & DIJON & $1881-1882$ & $\mathrm{~J}(55)$ \\
\hline & & & LYON & $1883-1885$ & \\
\hline & & & PARIS lag & $1885-1897$ & \\
\hline MARTIN & Henri-Thomas & 1813 & RENNES & $1853-1880$ & \\
\hline MARTIN & Albert & 1844 & NANCY & $1883-1897$ & $O(75)$ \\
\hline MARTIN & Alexandre & & NANCY & $1885-1886$ & $Q(75)$ \\
\hline MASQUERAY & Paul & & BORDEAUX & 1891-1897 & $\mathbf{R}(48)$ \\
\hline MATHIAS & Gustave & 1861 & GRENOBLE & $1894-1898$ & \\
\hline \multirow[t]{2}{*}{ MAURY } & Ferdinand & 1854 & AIX & $1887-1893$ & $L(40)$ \\
\hline & & & MONTPELLIER & 1894-1897 & \\
\hline MAZUEL & Henri & 1822 & TOULOUSE & 1883-1891 & \\
\hline MELLERIO & Louis & 1859 & CAEN & $1883-1884$ & \\
\hline MERIMEE & Amédée & 1846 & TOULOUSE & $1882-1897$ & \\
\hline MERY & Louis & & AIX & $1847-1870$ & \\
\hline MEYER & Maurice & & POITIERS & $1859-1860$ & \\
\hline \multirow[t]{2}{*}{ MEZIERES } & Alfred & 1826 & NANCY & $1858-1859$ & \\
\hline & & & PARIS slv & $1860-1897$ & F/G (33) \\
\hline MICHEL & Francisque & & BORDEAUX & 1845-1869 & $\mathrm{A} / \mathrm{B}(45)$ \\
\hline MONDOT & Jean-Baptiste & 1804 & MONTPELLIER & $1859-1869$ & \\
\hline MONNIER & Charles & 1820 & POITIERS & $1866-1878$ & $\mathrm{C}(79)$ \\
\hline MONTET & Emile & 1851 & LYON & $1884-1889$ & $F(66)$ \\
\hline MORILLOT & Paul & 1858 & GRENOBLE & 1885-1898 & \\
\hline \multirow[t]{2}{*}{ MOY } & Léon & 1838 & LILLE/DOUAI & $1877-1897$ & $E(61)$ \\
\hline & & & $\mathbf{N}$ & & \\
\hline NAGEOTTE & Eugène & 1837 & BESANCON & $1879-1897$ & \\
\hline NAVARRE & Octave & 1864 & TOULOUSE & $1891-1897$ & $\mathrm{D}(88)$ \\
\hline NICOLAS & Alexandre & 1809 & RENNES & $1853-1883$ & $A(83)$ \\
\hline NICOLAS & Jacques & 1850 & LILLE/DOUAI & $1881-1885$ & \\
\hline NISARD & Désiré & 1806 & PARIS frg & 1853-1867 & \\
\hline NOEL & Henri & 1851 & DIJON & $1884-1886$ & \\
\hline NOEL & Jacques & 1849 & GRENOBLE & $1888-1891$ & \\
\hline
\end{tabular}




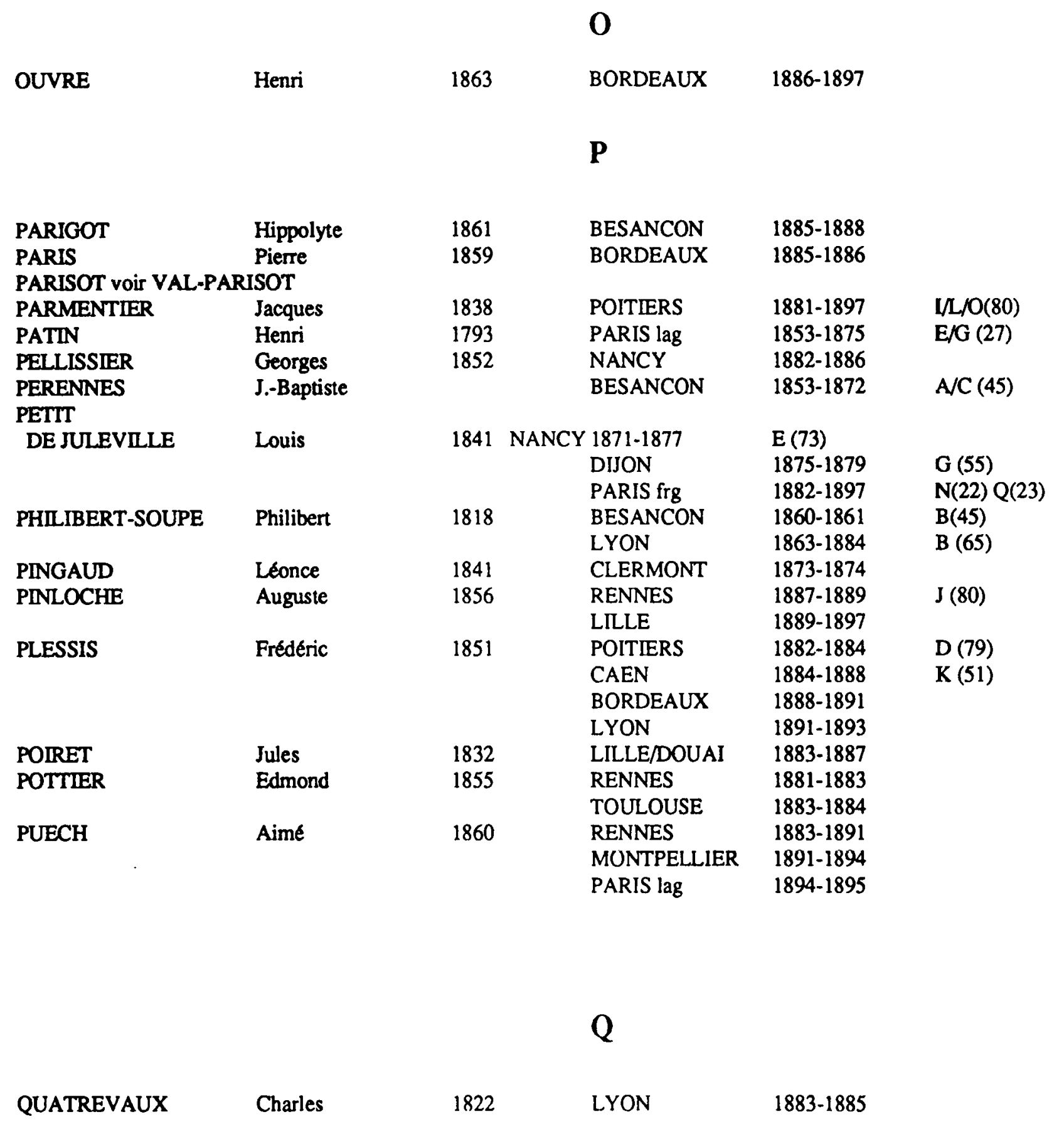




\section{$\mathbf{R}$}

\begin{tabular}{|c|c|c|c|c|c|}
\hline RABAUD & Gaston & 1854 & MONTPELLIER & $1885-1894$ & \\
\hline REBELLIAU & Alfred & 1858 & RENNES & $1890-1893$ & L (84) \\
\hline REGNAUD & Paul & 1838 & LYON & $1879-1897$ & $D / 1(66)$ \\
\hline REVILLOUT & Charles & 1821 & MONTPELLIER & $1863-1891$ & \\
\hline \multirow{2}{*}{ REYNALD } & Hermile & & CAEN & $1866-1867$ & \\
\hline & & & AIX & $1867-1877$ & \\
\hline REYNAUD & Hector & 1849 & MONTPELLIER & $1886-1897$ & \\
\hline REYNIER & Gustave & 1859 & GRENOBLE & $1884-1888$ & \\
\hline RIBOT & Theodule & 1839 & PARIS frg & $1885-1886$ & $P(23)$ \\
\hline \multirow[t]{2}{*}{ RIEMANN } & & 1853 & NANCY & $1877-1881$ & H (73) \\
\hline & & & PARIS lag & $1881-1882$ & $\mathrm{~J}(28) \mathbf{K}(29$ \\
\hline \multirow[t]{2}{*}{ RIGAL } & Eugène & 1856 & AIX & $1883-1891$ & $H(39)$ \\
\hline & & & MONTPELLIER & 1891-1897 & $M / L /$ \\
\hline ROBERT & Louis & 1828 & RENNES & $1881-1885$ & \\
\hline ROBIOU & Félix & 1818 & RENNES & $1878-1888$ & \\
\hline ROGER & Maurice & 1863 & LILLE & $1894-1895$ & \\
\hline ROUX & Philippe & 1808 & BORDEAUX & $1845-1883$ & $\mathrm{C} / \mathrm{D}(47)$ \\
\hline ROUX & Emmanuel & 1819 & GRENOBLE & $1859-1871$ & \\
\hline \multirow[t]{3}{*}{ ROY } & Emile & 1856 & CLERMONT & $1882-1885$ & \\
\hline & & & BESANCON & $1892-1896$ & \\
\hline & & & DIJON & $1895-1897$ & $O(56)$ \\
\hline \multirow[t]{2}{*}{ ROYER } & J.-Baptiste & 1835 & DUON & $1880-1897$ & $\mathrm{~L}(56)$ \\
\hline & & & $\mathbf{S}$ & & \\
\hline \multicolumn{6}{|l|}{ SAINT-MARC } \\
\hline -GIRARDIN & Marc & 1801 & PARIS frg & $1853-1873$ & $E(21)$ \\
\hline \multicolumn{6}{|l|}{ SAINT-RENE } \\
\hline \multirow[t]{2}{*}{-TAILLANDIER } & René & 1817 & MONTPELLIER & $1859-1867$ & \\
\hline & & & PARIS frg & 1863-1879 & $H(21)$ \\
\hline SAUVAGE & & & TOULOUSE & $1859-1860$ & \\
\hline \multirow[t]{2}{*}{ SCHEURER } & Emest & 1837 & CLERMONT & $1879-1889$ & \\
\hline & & & GRENOBLE & $1889-1894$ & \\
\hline SIGUIER & J.-Auguste & 1807 & CLERMONT & $1862-1873$ & $\mathrm{~B} / \mathrm{C}(53)$ \\
\hline SIGUY & & 1801 & MONTPELLIER & $1859-1861$ & \\
\hline \multicolumn{6}{|c|}{ SOUPE VOIR PHILIBERT-SOUPE } \\
\hline \multirow[t]{3}{*}{ SOURIAU } & Maurice & 1856 & CAEN & $1884-1891$ & \\
\hline & & & POITIERS & 1891-1897 & $N(80)$ \\
\hline & & & CAEN & 1895-1897 & \\
\hline \multirow[t]{2}{*}{ STAPFER } & Paul & 1840 & GRENOBLE & $1874-1883$ & \\
\hline & & & BORDEAUX & 1885-1897 & $Q(48)$ \\
\hline STIEVENART & J.-François & 1794 & DUON & $1853-1857$ & \\
\hline STRYIENSKI & Casimir & 1853 & GRENOBLE & 1886-1892 & \\
\hline
\end{tabular}


TAILLANDIER VOIR SAINT-RENE T.

$\begin{array}{lll}\text { TEXTE } & \text { Joseph } & \\ \text { THIAUCOURT } & \text { Camille } & 1854 \\ \text { THIRION } & \text { Emest } & 1856 \\ \text { THOMAS } & \text { Emile } & \\ \text { THOMAS } & \text { Antoine } & 1857 \\ & & \\ \text { THUROT } & \text { Charles } & 1823 \\ \text { TIVIER } & \text { Antoine } & 1824\end{array}$

TRAVERS

Julien

$\begin{array}{lll}\text { LYON } & 1892-1897 & \mathrm{~K}(67) \\ \text { NANCY } & 1882-1897 & \mathrm{~L}(74) \\ \text { RENNES } & 1883-1889 & \\ \text { LILLE/DOUAI } & 1879-1897 & \\ \text { TOULOUSE } & 1881-1893 & \mathrm{C}(87) \mathrm{H}(88) \\ \text { PARIS frg } & 1888-1897 & \mathrm{~S}(24) \\ \text { CLERMONT } & 1859-1860 & \\ \text { DIJON } & 1871-1872 & \mathrm{E}(55) \\ \text { BESANCON } & 1873-1888 & \mathrm{D}(45) \\ \text { CAEN } & 1845-1853 & \end{array}$

V

VAL-PARISOT

Valentin

1800

LILLE/DOUAI $\quad 1859-1860$

VIANEY

Léon

Joseph

1855

1864

BESANCON 1882-1897

MONTPELLIER 1894-1897

F/J (45)

W

WALTZ

WEIL

WIDAL

Henri

1840

1818

Auguste

1822

$\begin{array}{ll}\text { BORDEAUX } & 1885-1897 \\ \text { BESANCON } & 1853-1877 \\ \text { LILLE } & 1859-1864 \\ \text { BESANCON } & 1864-1875\end{array}$

$\mathbf{Z}$

ZYROMSKI

Ernest

1862

BORDEAUX

1892-1897 